\title{
Animal Sanctuary \\ The Designer's Guidebook for the Mental Welfare \\ of Rescued Animals
}

\author{
By \\ Dorothy Lee
}

A thesis submitted to the Faculty of Graduate Studies in partial fulfillment of the requirements for the degree of Master of Architecture

\author{
Carleton University \\ Ottawa, Ontario
}

(C) 2018

Dorothy Lee 


\section{Abstract}

The by-laws protecting animal rights and existing animal shelters, place medical welfare at the forefront of the design of the shelter, meanwhile mental welfare is almost completely neglected. No matter how large a cage, animals can succumb to mental illnesses and depression when faced with monotonous living quarters and no social interaction.

How can animal enclosures, such as dog kennels, cages, etc., be re-designed specifically for the rescued animals' mental welfare? How can the architecture be designed not from the point of view of humans, but from the sensorial perception system of the animal, while also keeping in mind the concern for contamination?

This thesis will be addressing the basic components to de-stress a newly abandoned animal and propose a spatial design that best accommodates an animal's specific sensorial abilities. By creating design modifications to standard enclosures, a designer's guidebook is produced for those creating an environment suitable for rescued animals. 


\section{Acknowledgment}

I would like to thank my family and friends for the inspiration and enoucragement. Thank you to my thesis advisor, Federica Goffi, for helping me shape my thesis and supporting my exploration. 


\section{Table of Contents}

ii ABSTRACT

iii ACKNOWLEDGEMENTS

iv TABLE OF CONTENTS

$v \quad$ LIST OF FIGURES

1 INSTRODUCTION

\section{EXISTING WELFARE BASICS}

4 WHY SHOULD WE CARE?

9 PRECEDENTS STUDIES

15 WELFARE STANDARDS

NEW DESIGN GUIDELINES

19 FREEDOM FROM FEAR AND DISTRESS

26 FREEDOM TO EXPRESS NORMAL BEHAVIOUR

43 BENEFITS OF HUMAN-ANIMAL INTERACTION

CONCLUSION: DESIGN OF THE GUIDEBOOK BECAUSE WE CARE

47 SUMMARY: BECAUSE WE CARE

50 DESIGNER'S GUIDEBOOK FOR SHELTER DOGS PAGE

79 DESIGNER'S GUIDEBOOK FOR SHELTER CATS PAGES

99 CONCLUSION

101 BIBLIOGRAPHY

103 LEXICON 


\section{List of Figures}

All images are by author unless otherwise stated. 2018 C DL

Figure 1 Dogs socializing at New York City's Madison Square Dog Park

Figure 2 Does the house rabbit have consciousness?

Figure $3 \quad$ Stray cat in Italy

Figure 4 Photos of spaces for dogs from Montreal's SPCA: (right) Chains of dog Kennels, (center) Large dog in typical dog kennel, (left) Yard for Dogs

Figure $5 \quad$ Montreal SPCA's Cat cages with personal litter boxes compartment

Figure 6 Photos of Humane Society on the page 21: (top row, left) individual dog room, (top row, center) interior cat nursery, (top row, right) cat rooms, (middle row, left) exterior cat nursery, (middle row, right) dog yard, (bottom image) cat in the exterior cat nursery

Figure 7 Photos of Cedar Rapids Animal Care in lowa. (top) front elevation, (middle) corridor with display of cat and dog cages, (bottom) cat nurseries (Source: http://www. jacksonryan.com/our-work/animal-welfare/cedar-rapids-animal-care)

Figure 8 Photos of Galveston County Animal Resource Center in Texas. (top) front lobby, (middle) corridor with display of cat cages and catteries, (bottom) dog yard (Source: http://www. jacksonryan.com/our-work/animal-welfare/galveston-county-animal-resource-center)

Figure 9 Lounging lion at San Francisco Zoo

Figure $10 \quad$ Branbell Committee's Five Freedoms

Figure 11 The Blue-Ribbon Emotions for all human and animals

Figure 12 Dog emotions on entering a new animal shelter

Figure 13 Diagrammatic perspective of a dog kennels as preliminary understanding of animals needs to de-stress and eliminate fear.

Figure 14 Diagrammatic plan of dog kennels and dog park as preliminary understanding of animals needs to de-stress and eliminate fear.

Figure 15 Cat emotions on entering a new animal shelter

Figure 16 Diagrammatic perspective of a cat nursery as preliminary understanding of animals needs to de-stress and eliminate fear.

Figure 17 Diagrammatic plan of cat nurseries and social areas as preliminary understanding of animals needs to de-stress and eliminate fear.

Figure $18 \quad$ Illustration of the difference in animals senses 
Figure 19 Photo of a cat's eye by Serge S. (Source: https://www.flickr.com/photos/ sergioarmani/2424234530/sizes/z/in/photostream/)

Figure 20 Diagram comparing human and animal field of perception

Figure $21 \quad$ Rendering of a human's scope of vision

Figure 22 Rendering of a cat and dog's scope of vision

Figure $23 \quad$ Installation to visualize a dog's vision with a dog nose.

Figure 24 (top) human vision, (bottom) Dog vision - dichromatic vision

Figure 25 Photograph of a dog's nose by Sarah Bourque. (Source: https://500px.com/ photo/39423174/sniff-by-sarah-bourque)

Figure 26 Comparison between human vision and dog's scent

Figure 27 Visualization of dog's spatial recognition through scent. (top) present objects, (middle) objects from the past, (bottom) objects from the future.

Figure $28 \quad$ Diagram of cat's scent marking while wandering

Figure 29 Diagram of cat's scent marking at a specific location (top) present objects on site, (middle) trail of scent left by cats, (bottom) territorial markings

Figure 30 Photograph of dog ears by Ashley Randall. (Source: https://dog-milk.com/dogphotography-by-ashley-randall/dog_pet_photography_ashley_randall_03/)

Figure $31 \quad$ Diagram of sounds around site

Figure 32 Diagram comparing hearing ranges (top) distance a human can hear- $20 \mathrm{~m}$, (middle) distance a cat can hear - 100 m, (bottom) distance a dog can hear - $200 \mathrm{~m}$

Figure 33 Diagram comparing frequencies heard by different humans, dogs and cats

Figure $34 \quad$ Typical room for dogs in animal shelters

Figure $35 \quad$ Exploring a connection between human and animals

Figure $36 \quad$ The unfolding of the dog guidebook

Figure $37 \quad$ The unfolding of the cat guidebook

Figure $38 \quad$ Photos of the dog and cat guidebooks

Figure 39 Photos of the dog bed design from the "Designer's Guidebooks for Shelter Dogs' Enrichment."

Figure 40 Photos of the cat rubbing furniture detail from the "Designer's Guidebooks for Shelter Cats' Enrichment." 


\section{Introduction}

At the forefront of anti-animal-cruelty, giving voices and protection to the unheard animal community, are animal shelters, refuges and rescues. These organizations temporarily house abandoned, stray, or abused animals. In 2016, it was estimated that 2 million homeless dogs live in Canada - a number that is consistently increasing. Since Canada's CFIA (Canadian Food Inspection Agency) requirements are not as strict as other counties, weekly and monthly vehicles ship rescued animals to Canada from outside the country, despite the already existing numbers of homeless domestic animals. Due to this overpopulation, at least 600,000 dogs are yearly euthanized. 500,000 of these dogs are euthanized in Quebec alone. ${ }^{1}$ At Montreal's SPCA, a team is formed to inspect and investigate complaints and reports against animal abuse. In 2016, 194 animals were seized with several criminal and penal charges to their guardians. ${ }^{2}$ In 2017, SPCA announced an increase of abandoned animals over the summer. The new Breed Specific Legislation (BSL) combined with the moving season has brought the numbers from 600 abandoned animals to 1,600 animals per month. ${ }^{3}$

The need for animal shelters exists. Often these animals have lost their ability to trust humans either from the abandonment(s), or abuse. Knowing the mental issues found in the animal, volunteers at shelters would provide medical and counselling for the animals. Regulations have been set by the cities to help promote the medical and mental welfare of the animals. However, as seen in the existing precedents (page 9), the design of the buildings and the regulations are focused on physical health. Material selections are limited to non-porous materials to avoid cross-contaminations and to facilitate the use of easily cleaned surfaces. Drains, ventilations and spatial organizations are all designed to

${ }^{1}$ Rodhin, "Some MUST READ statistics." Accessed 16 Oct. 2017.

2 "The Montreal SPCA's Investigations." Accessed 16 Oct. 2017.

${ }^{3}$ Fraser, "A Devastating Combination." Accessed 16 Oct. 2017. 
avoid cross-contamination. While stress, comfort and enrichment of the animal's life is left to the shelter's own interpretation, despite mental health being an obviously critical aspect to any animal's well-being. However, this thesis will push the design concept to incorporate the mental welfare of the animal while at the same time attempting to ameliorate the spaces of care towards the overall improvement of both physical and mental health, which are ultimately bound together.

How can animal enclosures, such as the dog kennels, cage and other such spaces, be re-designed specifically for the rescued animals' mental welfare? What are the design elements that need to be considered? How can the architecture be designed not from the point of view of humans but from the sensorial perception system of the animal, while also keeping in mind the concern of contamination? These questions will be tackled in three design phases. The design will focus on the spaces inhabited by the animals, for example the kennels, as the start. The first phase will focus on designs that de-stress the animal. This takes form in a variaty of ways such as allowing control of their own environment, socializing with their own kind, and the reduction of noise such as barking, or traffic. The second phase will look into designing according to the animal's enhanced senses. For example, dogs can only see within a dichromatic color spectrum, which means between bluish purple and yellowish green, not red. ${ }^{4}$ How should the room be designed according to this limited spectrum? Lastly, a new social program will be introduced for human-animal interaction. The social interaction would aid in the animal's ability to trust in humans again and support their rehabilitation, towards a possible adoption, and provide enrichment. Additionally, it will bring about benefits to the workers and visitors. Allowing for social interaction with the different groups of visitors will increase public awareness while giving opportunities for individuals to support the shelters in maintaining the animal's welfare.

Through three design phases, a designer's guidebook is produced to instruct in the 
design for an environment suitable for a rescued animal's mental welfare. The majority of animal shelters existing presently primarily addresses the human senses and the medical welfare of the animals. However, this is secondary to the thesis. The primary focus of the thesis is to curate a design towards the animal's mental welfare. By creating a guidebook, it will cover the components necessary to maintain an overall healthy welfare of the animal. The guidebook will break apart the convention of the typical design of the animal shelter to better express a design based on the animal's experience. By removing the specificity of the site, the guidebook can be applicable for animal shelters, foster homes and an emergency makeshift enclosure.

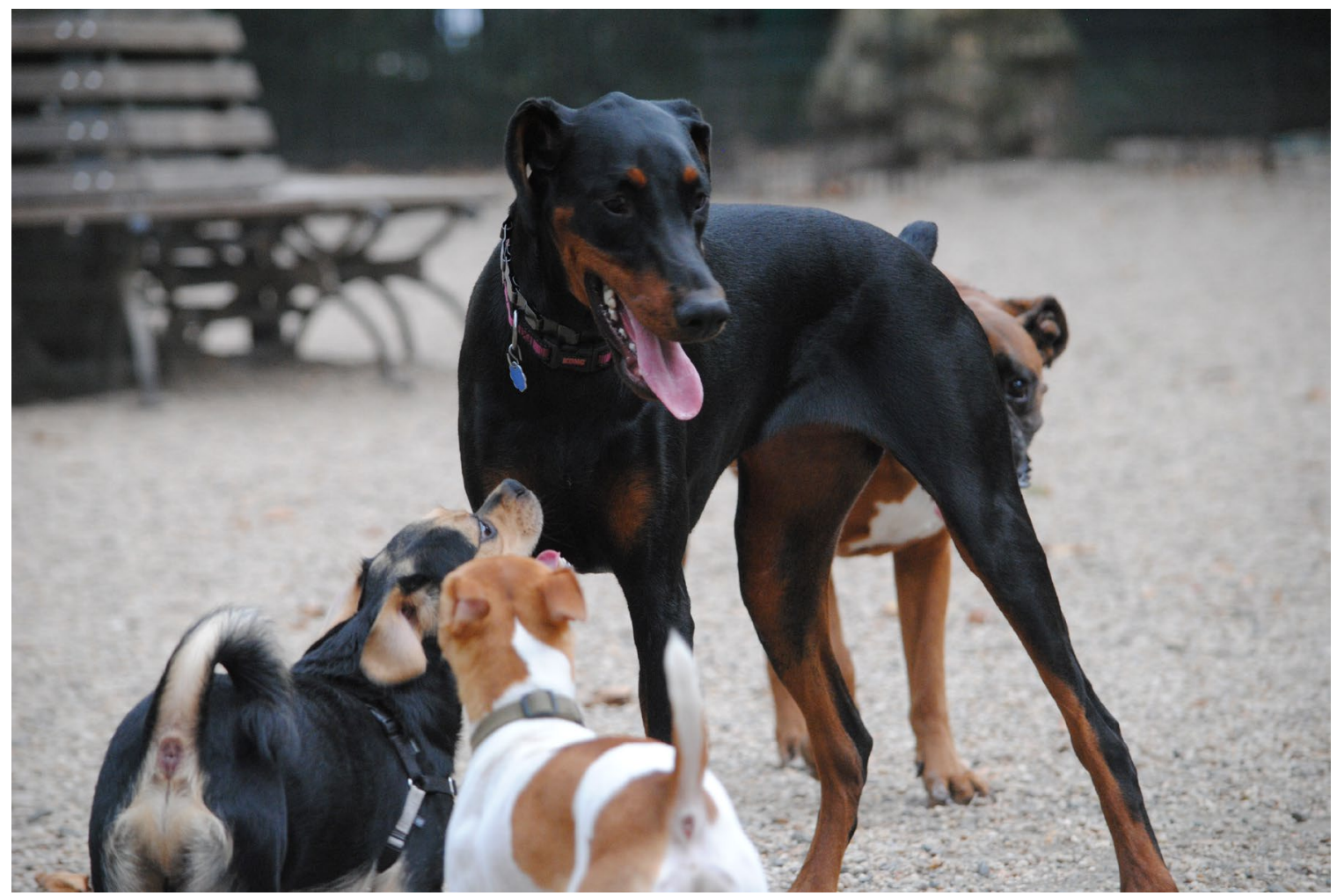

Figure 1: Dogs socializing at New York City's Madison Square Dog Park 


\section{Why Should We Care?}

Before discussing any design proposition, the first fundamental question to be addressed is why animal welfare is important. Whether an animal can experience pain is not contested and to some experts, this gives animals a right to avoid suffering. ${ }^{5}$ However, is this enough for animals to gain moral rights at the same level as humans? Would it not suffice to simply remove pain, or should we be compelled to consider whether they deserve a quality of life? The following chapter will be discussing the philosophy of animal rights based on Kristin Andrew's "The Animal Mind."

Generally, people can agree that human rights are attributed to all humans despite their ethnicity, religion, personality, or physical traits. ${ }^{6}$ It has also been argued that humans have dominion over animals due to our intelligence. This means that humans can be treated far better than animals. However, this becomes flawed when a grown animal is arguably smarter than an infant. If intelligence is not the standard for moral rights, then what is? ${ }^{7}$

Moral philosophers such as Peter Singer and Tom Regan ${ }^{8}$ and movements such as the Nonhuman Rights Project in the United states have been working to achieve legal rights for animals. Nonhuman rights, or animal rights is the idea that all animals, human or not, has a capacity to possess at least one legal right. ${ }^{9}$ According to Tom Regan, all animals who are conscious and who value their lives as important to themselves deserve the same respect and treatment as a human being. This includes being considered more than just a means to an end. ${ }^{8}$

${ }^{5}$ Andrews 2015: 167

${ }^{6}$ Andrews 2015: 168

${ }^{7}$ Andrews 2015: 61-62

${ }^{8}$ Flynn 2008: 355

${ }^{9}$ Wise, "Thats One Small Step for a Judge" Accessed Jan 5, 2018 
To determine if animals qualify to have animal rights, the question becomes whether animals can experience life like humans. In other words, are animals conscious? To this day, animal consciousness has yet to be proven. Without proper understanding of human consciousness, scientist found it impossible to conclusively decide if animals are conscious at all. ${ }^{10}$ The consciousness in question that scientists are focused on is that of phenomenal consciousness. There are at least four types of consciousness:

- Consciousness

- Political Consciousness

- Self-Consciousness and thoughts

- Phenomenal Conciousness
Being awake

Political status

Ability to reflect on experiences
Beyond being affected by an experience but experiencing an event as a being ${ }^{11}$

Animal consciousness is debated and hard to analyse because of the animals' lack of speech. Without speech, it is hard to determine if there is thought. Comparing human and animal brains, the structural system is different, notably in regards to the cortical structures and neocortex. For the human, the neocortex is a part of the brain that process emotions and pain. In some animals, the neocortex is absent and therefore, there is a possibility that animal consciousness does not exist. ${ }^{12}$ Philosophers such as Descartes argue that animals do not possess phenomenal conciousness and therefore are like robot who simply react to stimulus. ${ }^{13}$ Similarly, one can shift while sleeping, or pull off a blanket - conscious of comfort - without being phenomenally conscious of it.

\footnotetext{
${ }^{10}$ Andrews 2015: 50

${ }^{11}$ Andrews 2015: 52

${ }^{12}$ Divrosky, "Promient Scientists sign declaration." Accessed 19 Oct. 2017

${ }^{13}$ Andrews 2015: 54
} 
As evidence of animal consciousness, learning is a flexible trait that reveals a modification in the animal's behaviour without prior programming by nature. In doing so, the animal demonstrates an ability to go beyond the stimulus-response condition. ${ }^{14}$ For example, psychologist Robert Hampton conducted research on monkeys and their ability to assess their own knowledge. The monkeys are given a task, if the monkey passed, he/ she got a treat. If the monkey failed, no treat was given. If the monkey chose not to do the task, he/she would get a smaller portion of the treat. The researcher found that the monkeys would maximize their reward when the task was easy and indeed decided not to do the task when it got too difficult. The monkeys were able to not only learn how to do the tasks, but also self evaluate their own knowledge. ${ }^{15}$ The animal's ability to relate to other minds is another argument proving consciousness. ${ }^{16} \mathrm{~A}$ dog is hypersensitive to social cues. They respond to these reactions with sympathy, joy and other bodily expressions. They have a social relationship with humans. ${ }^{17}$ Even with numerous successful research projects and experiments, none were able to conclusively prove that animals have consciousness. Scientists have yet to understand how consciousness works for not just animals but humans as well. Without knowing the criteria, it is hard to determine what constitutes individual consciousness. If one has dreams but not learning, are they still conscious? If they had all criteria relating to consciousness except one, do they then become regarded as not conscious?
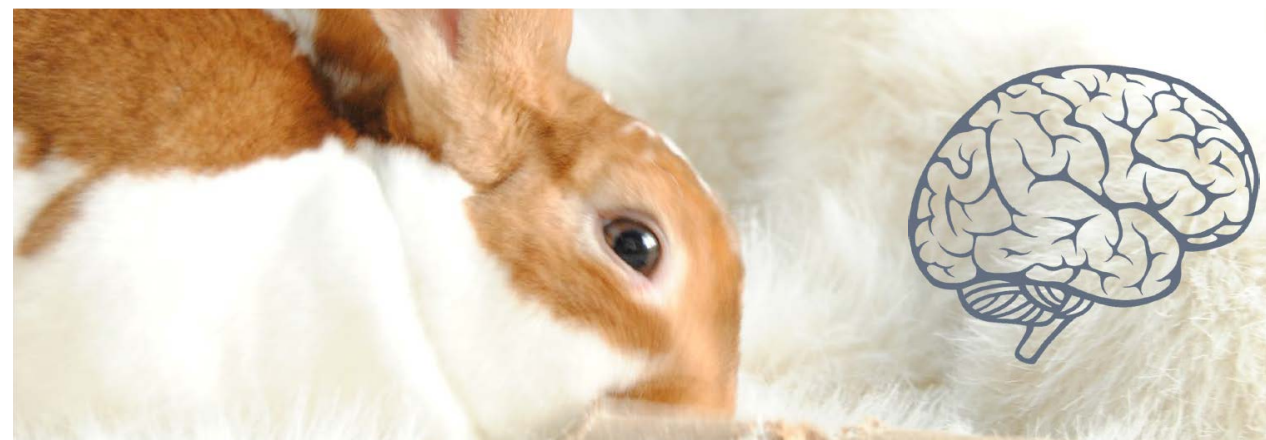

Figure 2: House rabbit has consciousness?

\footnotetext{
${ }^{14}$ Andrews 2015: 56

${ }^{15}$ Andrews 2015: 73-74

${ }^{16}$ Andrews 2015: 170

${ }^{17}$ Chandler, 2010: 363
} 
Science is unable to prove that animal consciousness exists, nor has it proven that animals do not have consciousness. However, much of the evidence does point toward the possession of consciousness in animals. Scientists infer that if the animals were not conscious, the research would not have gone nearly as well as it did. ${ }^{18}$ For this reason, notable scientists have gathered to sign The Cambridge Declaration of Consciousness in a Non-human Animals on July 7, 2012 at the Francis Crick Memorial Conference in the presence of Steven Hawking.

The Cambridge Declaration of Consciousness in Non-human Animals:

"Convergent evidence indicates that non-human animals have the neuroanatomical, neurochemical, and neurophysiological substrates of conscious states along with the capacity to exhibit intentional behaviors Consequently, the weight of evidence indicates that humans are not unique in possessing the neurological substrates that generate consciousness. Non-human animals, including all mammals and birds, and many other creatures, including octopuses, also possess these neurological substrates."

\footnotetext{
${ }^{18}$ Andrews 2015: 51
} 
Despite the animal's lack of a neocortex (a part of the brain that process pain and emotions in humans), scientists have concluded that animals can process emotions and pain from other parts of the brain. This declaration has no legal standing, but it can be used as evidence that science must treat animals as if they are conscious - as conscious as humans. This declaration also gives reason for regulations to be put into place such as MAPAQ (Ministère de l'Agriculture, des Pêcheries et de I'Alimentation du Quebec) and fine or jail anyone who abuse or injure any animal. With MAPAQ regulations in place, the SPCA has legal rights to confiscate and report any abused animals to the authority. For this reason, we no longer can ignore the animal's right to a quality of life and believe our actions have no consequences.

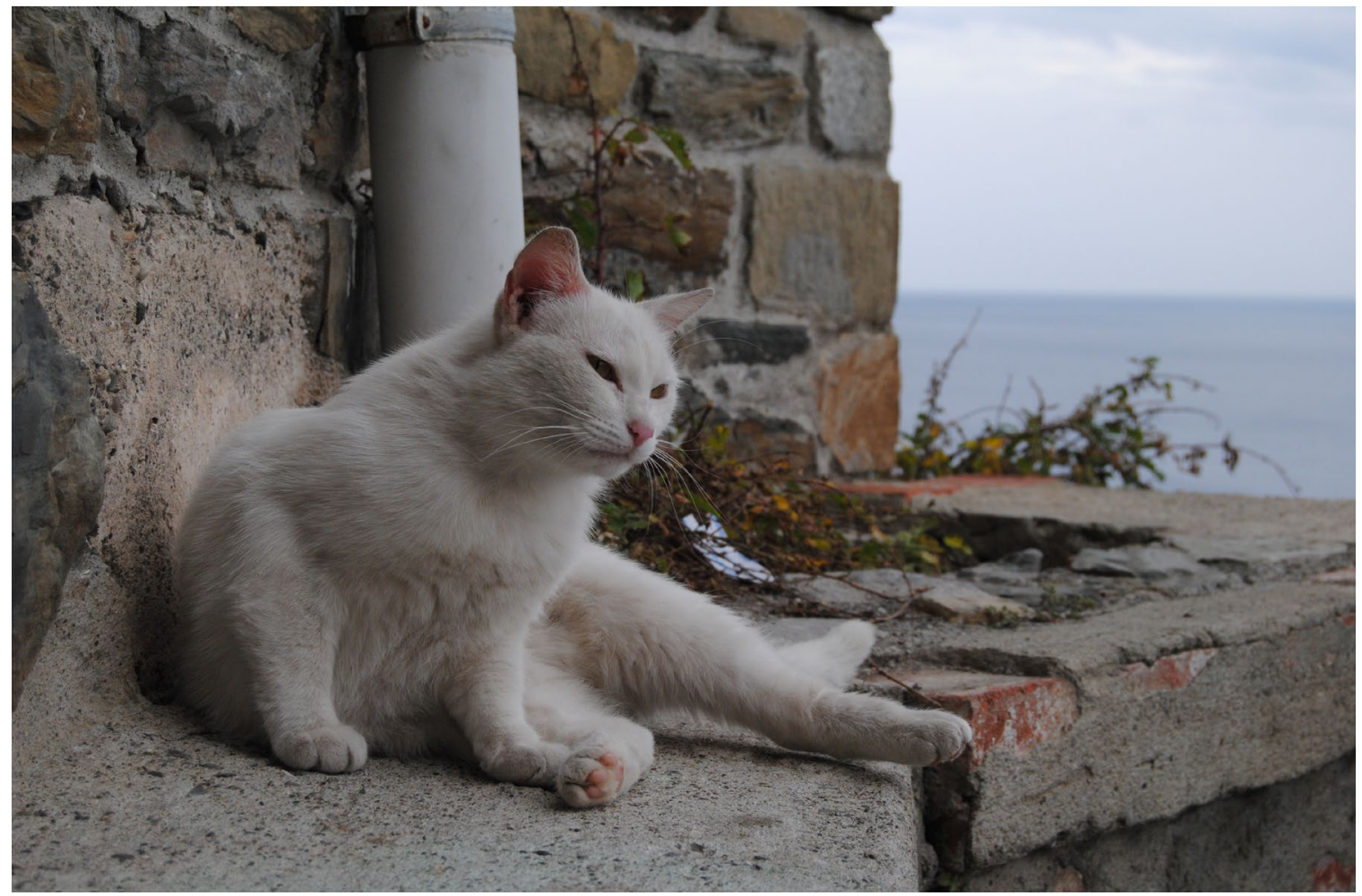

Figure 3: Stray cat in Italy 


\section{Precedent Studies: Montreal's SPCA}

The Society for the Prevention of Cruelty to Animals (SPCA) in Montreal has taken the lead in providing for abandoned animals, located next to the Namur Metro. The site is constantly busy with visitors and volunteers. With the utilization of the well established Petfinder website, most pets find a home quickly and their stay is shortened. SPCA is especially appreciated for their rigorous process in checking for the animal's health and mental welfare before sending them off to a new home. The adopters must also go through a process, ensuring their education on the animal before adopting. However, despite their efforts, the environment does little to promote their vision on how the animal should live. The environment is cold, dim and joyless. Entering the room with dog kennels, the visitor is greeted by loud barking, which not only stress the animals, but the visitors themselves; discouraging potential adopters.

The SPCA is well designed for physical welfare such as veterinary care and precautions against cross contamination. However, spaces are not well designed to de-stress the animals (Fig. 4 and Fig. 5).

PRO

- Vet and animal counselors

- Dog yard and path for exercise

- Non-porous materials to avoid cross-contamination

- Adaptable kennels for variable dog sizes

- Drains in each dog kennel for easy cleaning

- One litter box per cat

- Good location for a consistent amount of visitors

\section{CON}

- No play area for cats

- Lack of social interaction among their own kind (dog-dog or cat-cat)

- Loud barking: increasing stress for both cats and dogs

- Environment feels cold

- Lack of sunlight

- Sometimes two cats in one small cage

- No green space for dogs 

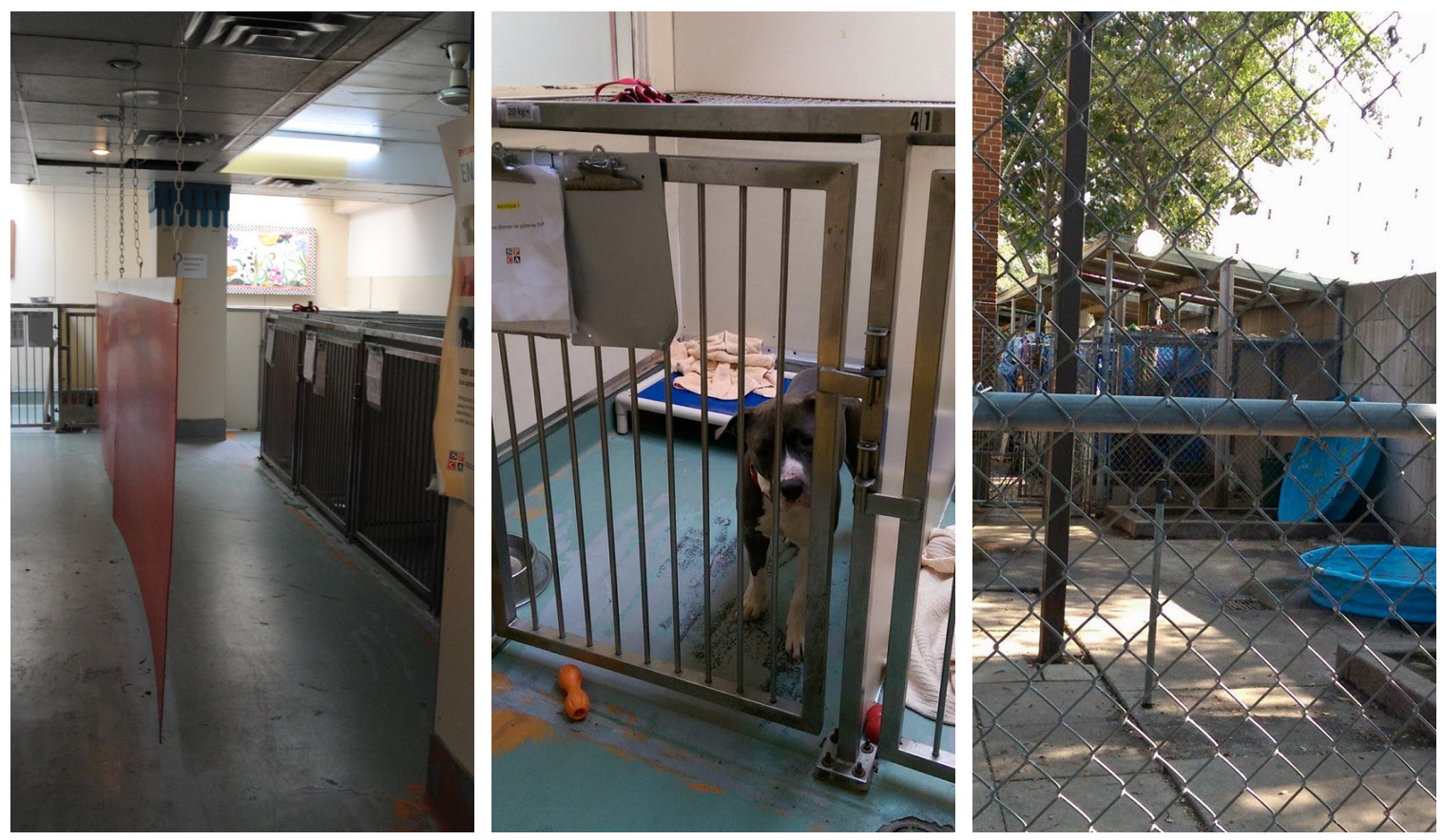

Figure 4: (right) chains of dog Kennels, (center) large dog in typical dog kennel, (left) yard for Dogs

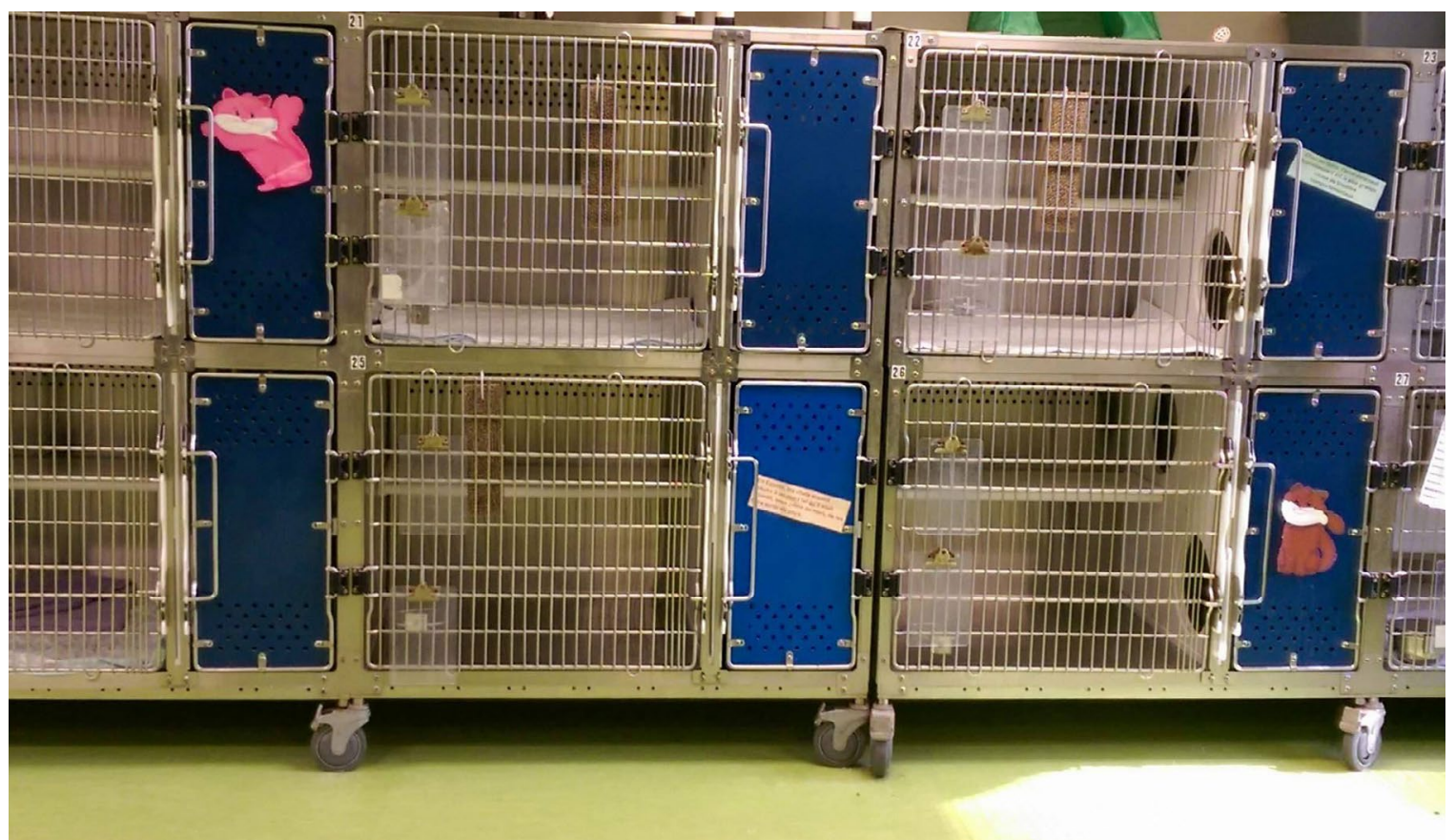

Figure 5: Cat cages with personal litter boxes compartment. 


\section{Ottawa's Humane Society}

In contrast to the first precendent study, Montreal's SPCA, Ottawa's Humane Society is located in a remote area that makes it difficult for visitors (especially by bus, or walking) to reach the facility. For this reason, very little visitors are present in this animal shelter. Large windows are placed in front of each dog kennel to allow for visual stimulation but with little visitors, the visuals are absent. However, the individual rooms do provide for sound proofing. For this reason, the dogs appear much calmer with little to no barking in the building.

The design of the facility does focus mainly on physical health, however, some mental enrichment is given to cats. Cats are given nurseries to socialize and exercise. Both cats and dogs are given outdoor spaces. However, dogs still succumb to monotonous living within their kennels (Fig. 6).

A nice touch to the facility are two additions to the design of the shelter: an educational center and a veternary clinic.

\section{PRO}

- Vet and animal counselors

- Large dog yard for exercise

- Non-porous materials to avoid cross-contamination

- Individual rooms for each dog (no barking)

- Drains in each dog kennel for easy cleaning

- Shared Cat Nurseries

- Exterior play area for cats

\section{CON}

- Lack of social human-animal interaction

- Lack of social interaction among their dogs

- Monotonous living

- Minimum enrichment for dogs

- Lack of direct sunlight (especially for cats)

- Anti-social cats are placed into dog rooms 

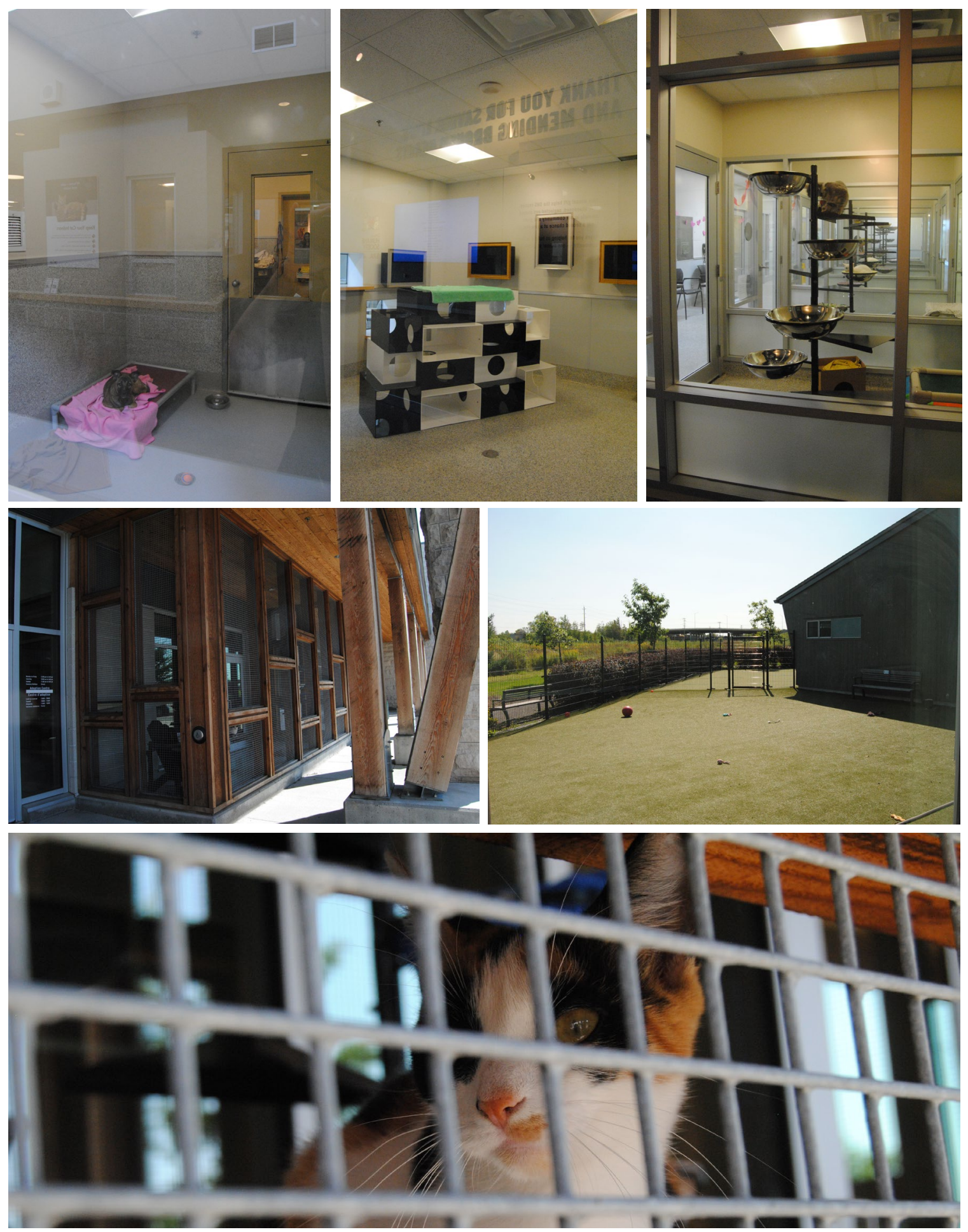

Figure 6: Photos of Humane Society on the next page: (top row, left) individual dog room, (top row, center) interior cat nursery, (top row, right) cat rooms, (middle row, left) exterior cat nursery, (middle row, right) dog yard, (bottom image) cat in the exterior cat nursery. 


\section{Jackson \& Ryan Architects}

The Jackson \& Ryan Architects are known for their expertise in animal shelters. Like most facilities, the design ensures cleanliness to prevent cross-contamination and a well equiped veterinary room. All health related amenities are provided. The highlight of the design is one that welcomes new visitors by colorful schemes and iconic images. As much as it is needed for the facility to draw in families and individuals to adopt animals, the focus on how animals perceive space seems to be overlooked amongst the design goals. How can the facility provide for both physical and mental welfare as well as be welcoming to human and non-human animals?

Although Jackson \& Ryan Architects is known for their animal shelter designs, the lack of design within the cages for mental welfare is consistently present. In some designs, the dog kennels are left open, creating stress by the number of dogs barking. Despite having an education center in some designs, most knnels are left without any social spaces for human-dog interactions (Fig. 7 and Fig. 8).

PRO

- Vet and animal counselors

- Large dog yard for exercise

- Non-porous materials to avoid cross-contamination

- Individual and shared rooms for cats

\section{CON}

- Lack of social interaction among their dogs

- Monotonous living

- Minimum enrichment for dogs 

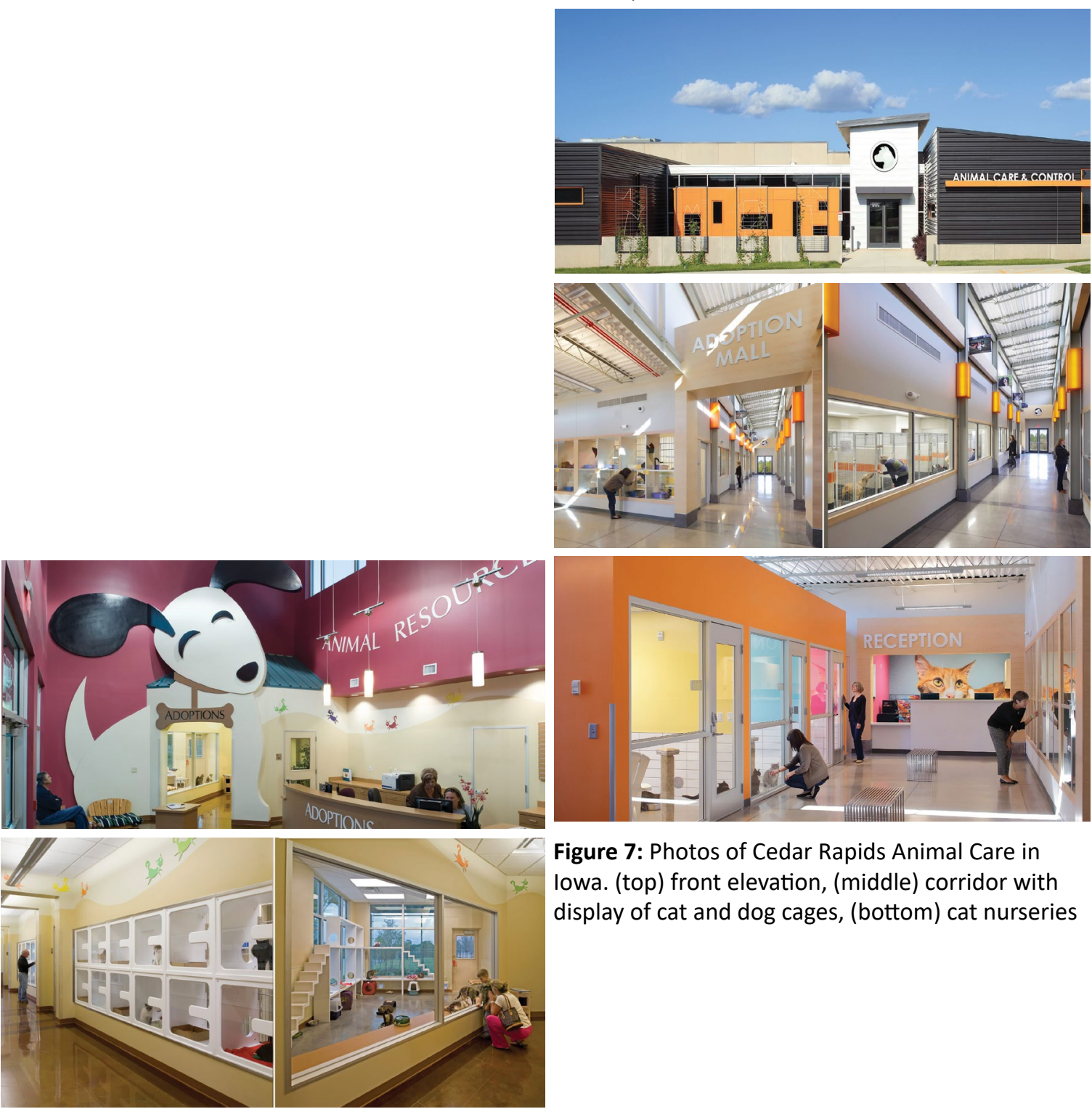

Figure 7: Photos of Cedar Rapids Animal Care in lowa. (top) front elevation, (middle) corridor with display of cat and dog cages, (bottom) cat nurseries

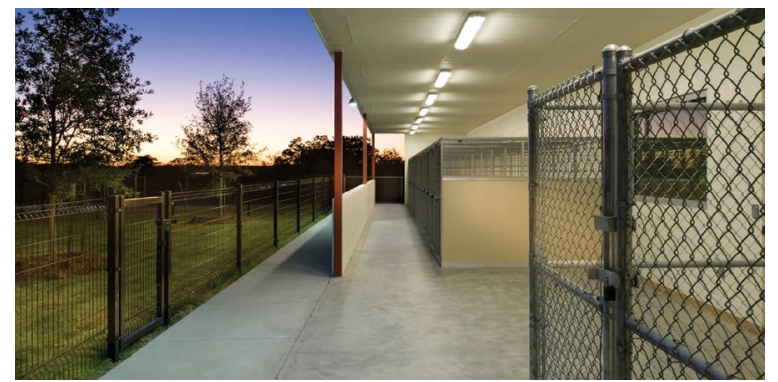

Figure 8: Photos of Galveston County Animal Resource Center in Texas. (top) front lobby, (middle) corridor with display of cat cages and catteries, (bottom) dog yard 


\section{Welfare Standards}

"The result is that some zoos have spent a lot of money building fancy enclosures that appear natural to people, but are just as boring and painful for the animals as a barren concrete cage. I remember one tiger exhibit that looked really pretty with lots of rocks molded from concrete. There was absolutely nothing for the tiger to do. The enclosure was visually stimulating for people, but it was a barren environment for the tiger."

Grandin, Temple, and Catherine Johnson. Animals Make Us Human: Creating the Best Life for Animals. First Mariner Books, 2010, pp. 265 


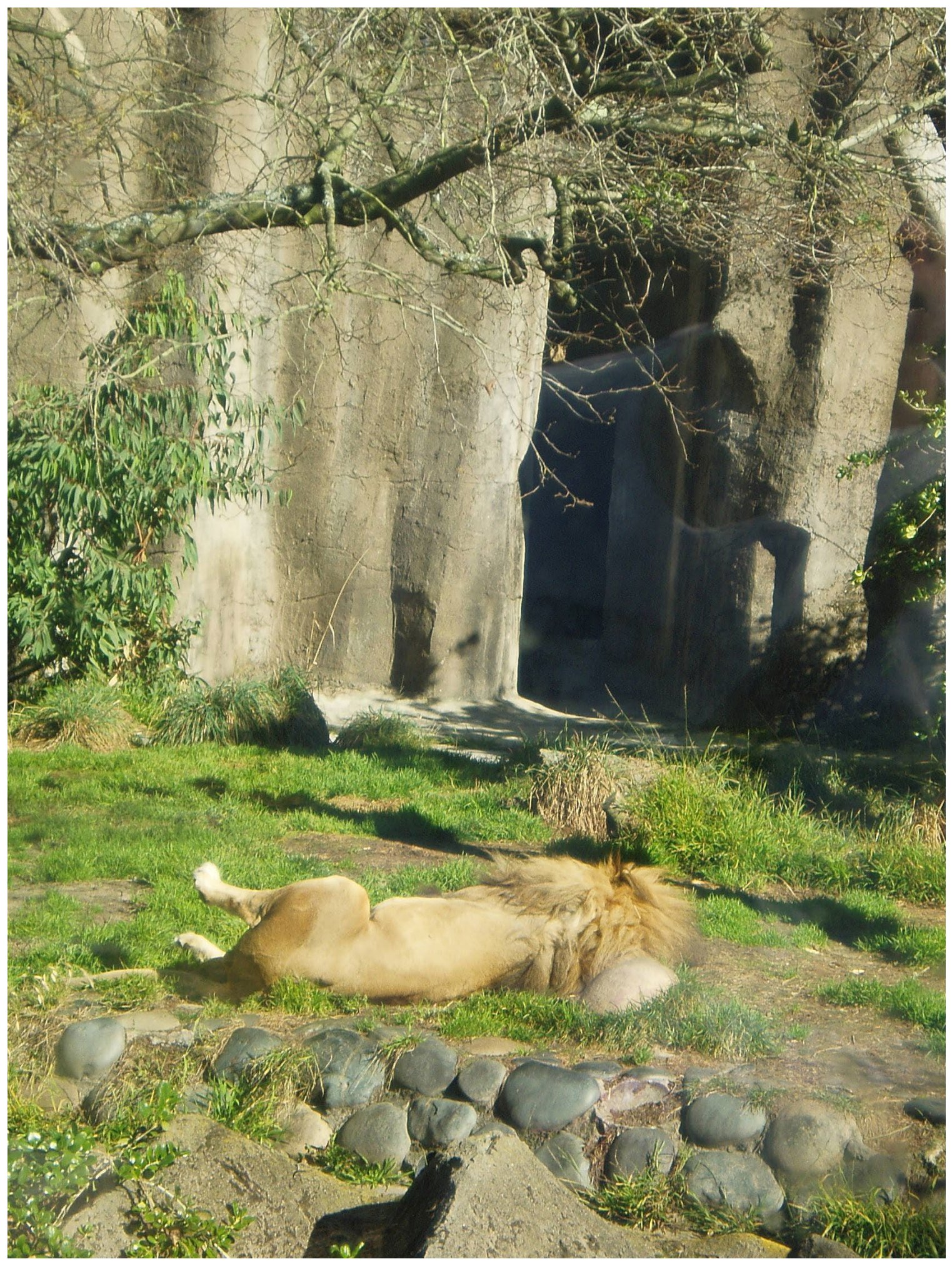

Figure 9: Lounging lion at San Francisco Zoo. Is there enough enrichement for a healthy lifestyle? 


\section{Brambell Committee's Five Freedoms}

The Brambell Committee's Five Freedoms breaks down welfare into three components corresponding to the physical welfare and the last two for mental welfare (Fig. 9). In comparison to Quebec's bylaws by MAPAQ, the regulations clearly defines the animal's physical needs. As for mental welfare, the regulations are left either in the extremes such as death, or unspecific such as "biological needs."

This is problematic since each animal is different in terms of what can stress them. Is noise reduction in dog kennels enough to alleviate stress? Is the lack of predators enough to remove any abnormal behaviours from developing? This is not the case. Most dogs left in an apartment alone tend to chew through furniture. This is a sign of being unable to cope with stress due to the lack of socialization. ${ }^{19}$ Pacing is yet another symptom. ${ }^{20}$ Another problem with the bylaw is the term "biological needs." An understanding of animal behaviour and how they experience space is required to fully understand what their biological needs entails, or what normal behaviour means. This is specific depending on species and the personality of the animal.

The focus of this thesis is then placed on the two freedoms relating to mental welfare by understanding what triggers their emotions and how animals behave.

${ }^{19}$ Grandin 2010: 42

${ }^{20}$ Grandin 2010: 5 
Figure 10: Branbell Committee's Five Freedoms

PHYSICAL WELFARE

FREEDOM FROM

HUNGER AND THIRST

FREEDOM FROM

DISCOMFORT

FREEDOM FROM PAIN, INJURY AND DISTRESS
- Dietary plan (shelter volunteers)

- Adequate quality of food and water ${ }^{21}$

- Sanitation and sufficient lighting ${ }^{21}$

- Protection from excessive heat or cold ${ }^{21}$

- Enclosures for animals must allow it to lie down or extend fully ${ }^{22}$

- Veterinarian Care $^{21}$

- Enclosures must be of non-porous, non-toxic materials ${ }^{21}$

- Isolation of sick animals 22

\section{MENTAL WELFARE}

FREEDOM FROM FEAR

AND DISTRESS

FREEDOM TO EXPRESS

NORMAL BEHAVIOUR
Is the lack of predators enough to dismiss the notion of fear?

What is normal behaviour? For a dog? For a cat?

\section{ANIMAL WELFARE AND SAFETY ACT}

6. A person may not, by an act of omission, cause an animal to be in distress. for the purpose of this Act, an animal is in distress if

(1) it is subjected to conditions that, unless immediately alleviated, will cause the animal death or serious harm;

(2) it is subjected to conditions that cause the animal to suffer acute pain; or

(3) it is exposed to conditions that cause the animal extreme anxiety or suffering

8. The owner or custodian of a cat, a dog, an equine or any other animal determined by regulation must provide the animal with the stimulation, socialization and environtmal enrichment that are consistent with its biological needs.

${ }^{21}$ Animal Welfare and Safety Act

${ }^{22}$ Regulation Respecting the Safety and Welfare of Cats and Dogs 


\section{Freedom From Fear and Distress}

Even as the animal has developed behavioural problems, the solution is not to remove the behaviour, but to alleviate negative emotions. By controlling the animal's emotions, you control their behaviour. For example, when a gerbil is kept in captivity, it would constantly and persistently dig. The solution is not to give it a sand pit, but to return the feeling of safety to the gerbil. To a gerbil, safety is found in tunnels. When scientists placed a group of gerbils in a habitat with tunnels that cannot be dug into further and another group in a habitat with no tunnels, the first group was found to have no urge to dig. ${ }^{23}$

The Blue-Ribbon Emotions describes the base emotions found in all animals (including humans). When dealing with abandoned animals, the goal should be to increase the seeking emotion whereas rage, fear and panic should be reduced or removed. The seeking emotion is the brain's pleasure center. When monkeys were given controls to trigger the seeking emotion, they tend to self-simulate in the experiments due to the pleasure they felt from it. ${ }^{24}$

Figure 11: THE BLUE-RIBBON EMOTIONS

\section{BASE EMOTIONS}

\begin{tabular}{lll|} 
& SEEKING & - Master platform for other emotions, comes in three main forms: \\
& & Anticipation, curiosity, goals/motivation \\
$\downarrow$ & RAGE & - Violent outbust to escape captivity \\
$\downarrow$ & FEAR & - Life threatening events \\
$\downarrow$ & PANIC & $\begin{array}{l}\text { - Social separation } \\
\text { eg. Loss of a mother, lost of a lover }\end{array}$
\end{tabular}

${ }^{23}$ Grandin 2010: 5

${ }^{24}$ Grandin 2010: 6-9 


\section{Dog Kennels}

As creatures genetically modified to work with people, socialization is key to a dog's well-being. ${ }^{25}$ However, with volunteers who are overwhelmingly busy, pairing dogs as companions can help alleviate the lack of socialization. ${ }^{26} \mathrm{~A}$ side window can be an option for two companion dogs to see one another as moral support. It is found that a dog with behaviour problems can learn to be a good pet once it has learnt to behave from an older dog. ${ }^{27}$

At least one window from the kennel should allow visibility to the dog park or public area as a means of visual enrichment, see figure 14 . The dog park should possess some agility equipment for training and play as mental enrichment. These enrichment can help promote the seeking emotion and allow the animal to feel pleasure, therefore, reducing fear. ${ }^{28}$

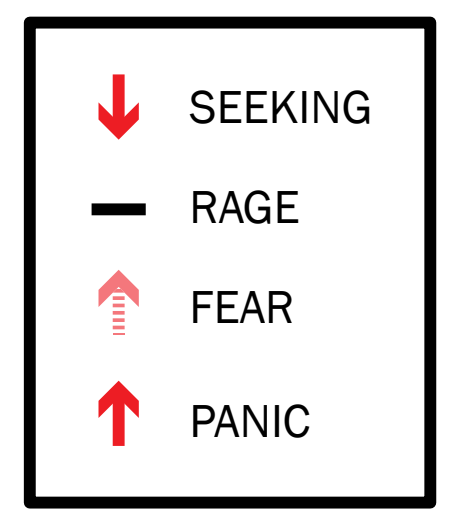

A dog's sense of security is found in its owner ${ }^{29}$ and with abandonment, this sense is lost and panic is enforced. To return to normal conditions, the kennels should promote the seeking emotion with novelty, visual stimulation and enrichment. At the same time, reducing the panic emotion by allowing the dog to feel in control of their environment. ${ }^{30}$

Figure 12: Dog emotions on entering a new animal shelter

${ }^{25}$ Grandin 2010: 26

${ }^{26}$ Stafford 2007: 189

27 Grandin 2010: 44

${ }^{28}$ Grandin 2010: 66

29 "Cat Watch 2014: The New Horizon Experiment" Accessed 7 Dec. 2017

${ }^{30}$ Grandin 2010: 64 
Figure 13: DIAGRAMMATIC PERSPECTIVE

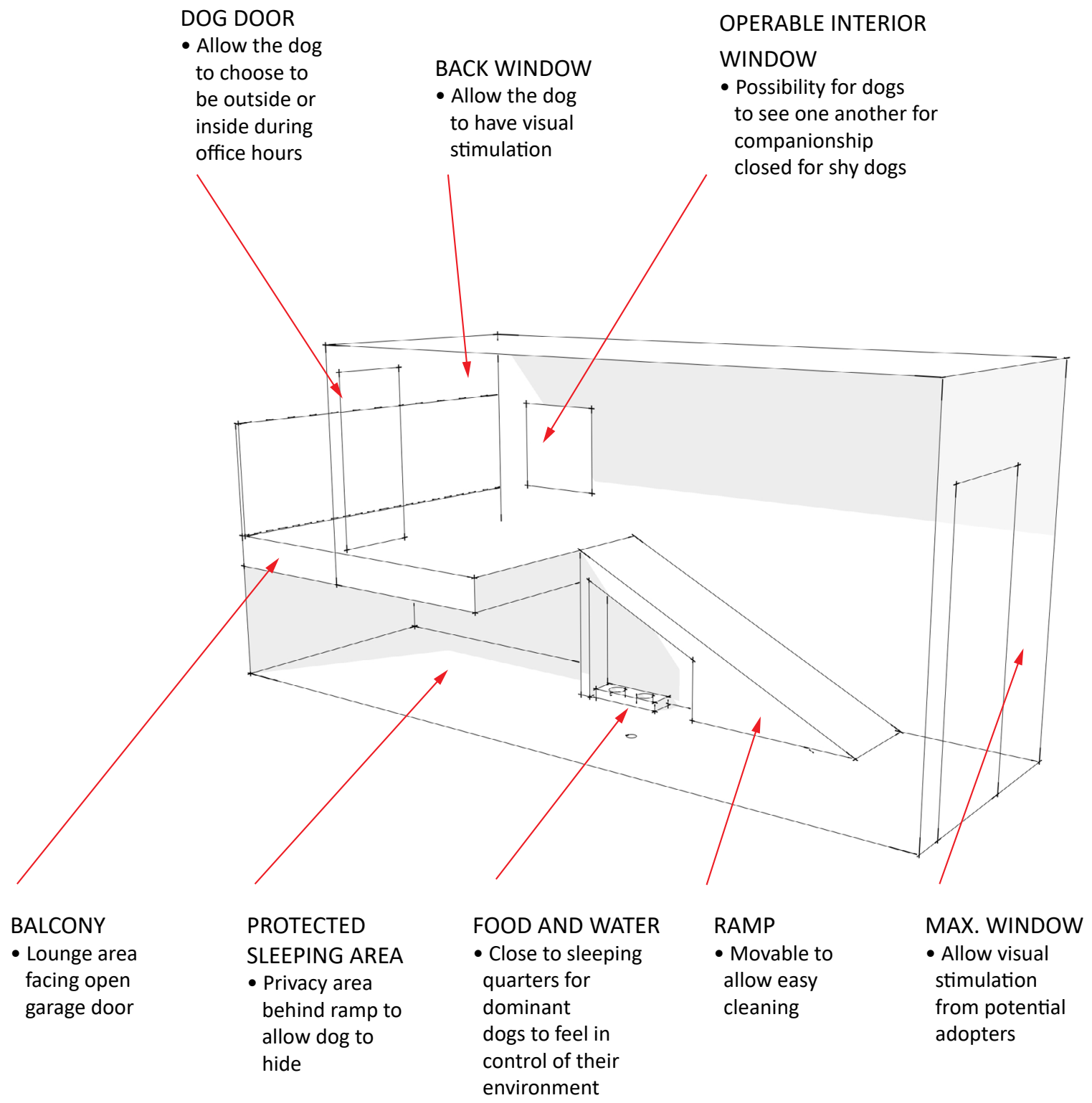


Figure 14: DIAGRAMMATIC PLAN
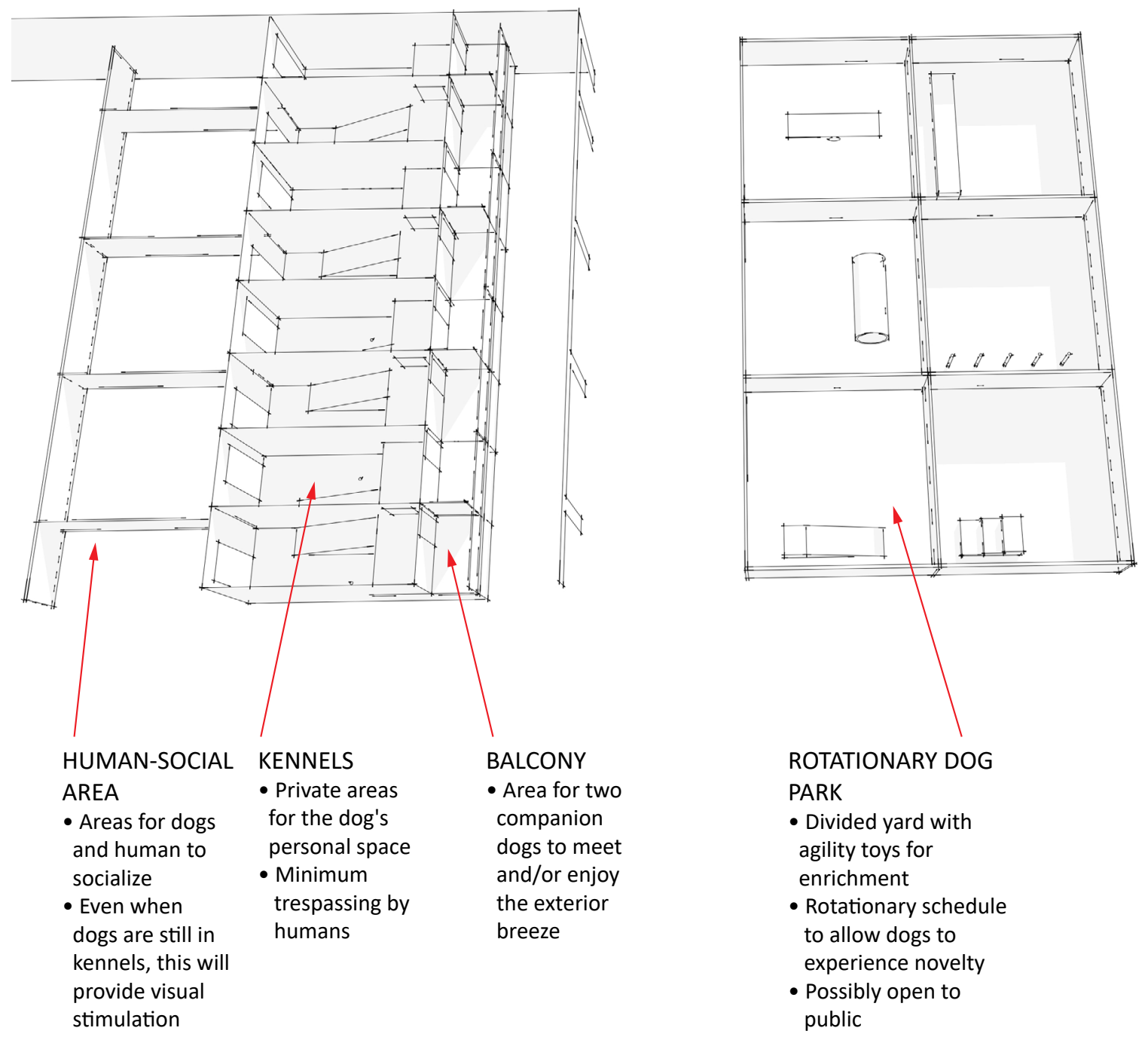


\section{Cat Nursery}

To help relieve a cat's fear, allowing cats to live in groups of 4-12 is beneficial for their well-being. ${ }^{31}$ They learn from one another and utilize play to exercise. ${ }^{32}$ However, it is wise not to place three cats into one nursery since one can become jealous. This would create fights that escalate quickly if without supervision. To avoid this situation, each cat would first be placed in a cat kennel in which the cat can claim as his own personal territory. ${ }^{31}$ Once four or more cats are suitable to live in one room, the cats would be allowed to enter the cat nursery as their living quarters.

Each cat room must have access to sunlight. The heat from the seat is a relaxant to a cat and is crucial for his/her well-being. ${ }^{33}$

When a cat has been living without knowing other cats before entering a shelter, they become stressed from the new encounter. ${ }^{34}$ These shy cats should be place in individual cat kennels near human-cat interractions social areas as a replacement to their normal need for cat-cat socialization.

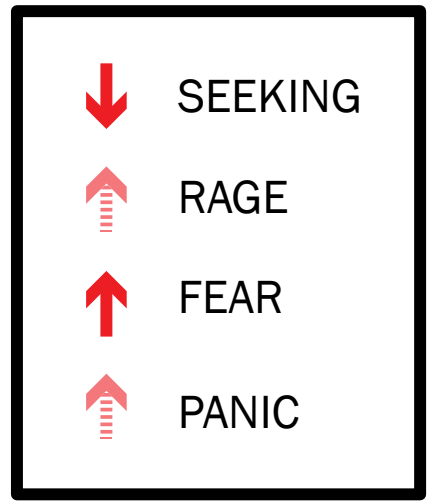

A cat's sense of security is found in the surroundings. Placed in a new environment, cats become paranoid, unfamiliar with the potential threats within the room. They become fearful and can easily spike to rage, or panic. To adjust to the new environment, cats need to take time to re-establish their surroundings. ${ }^{25}$

Figure 15: Cat emotions on

entering a new animal shelter

${ }^{31}$ Fraser 2012: 56

${ }^{32}$ Grandin 2010: 97

${ }^{33}$ Fraser 2012: 39

${ }^{34}$ Fraser 2012: 106

35 "Cat Watch 2014: The New Horizon Experiment" Accessed 7 Dec. 2017 
Figure 16: DIAGRAMMATIC PERSPECTIVE

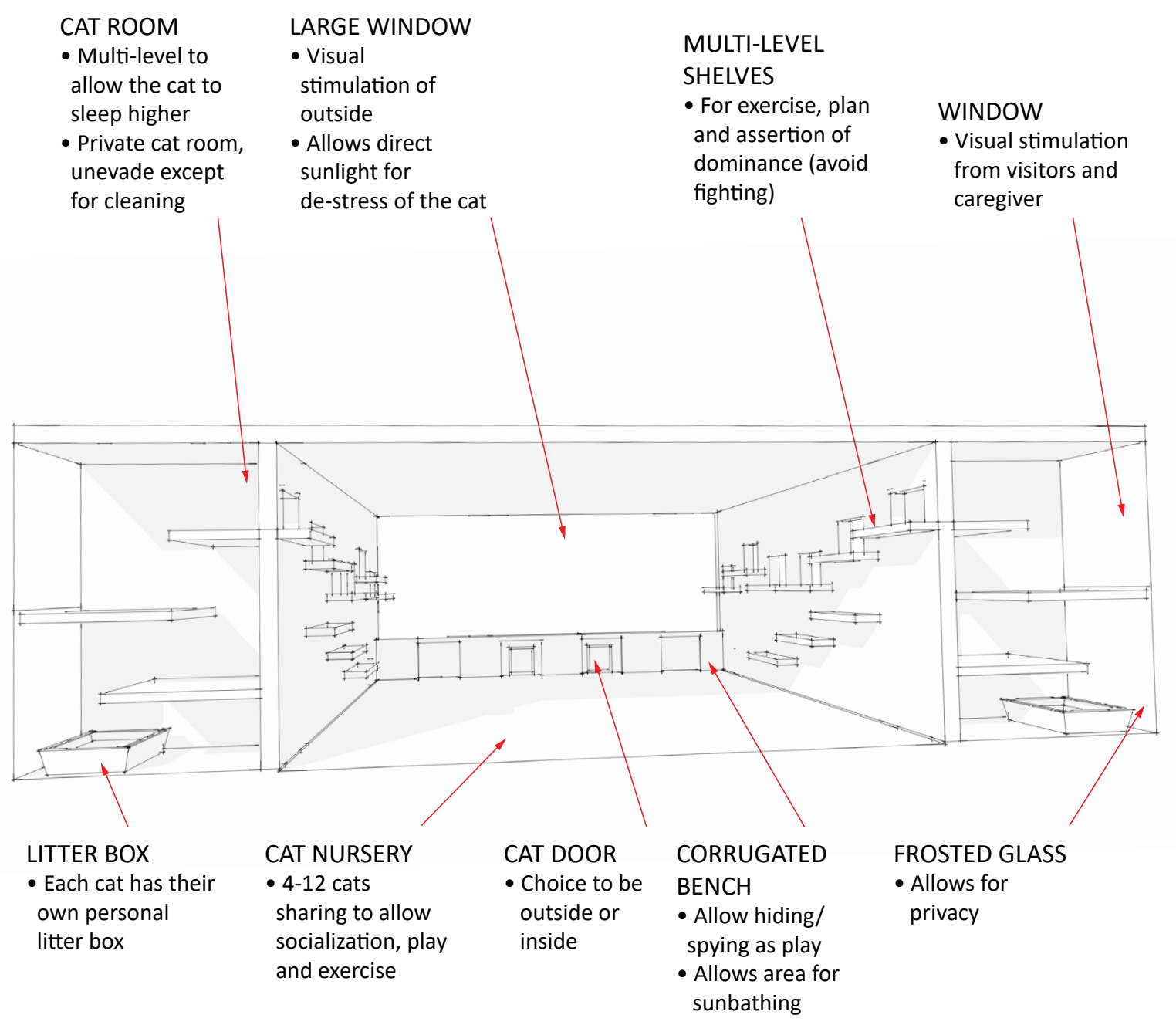


Figure 17: DIAGRAMMATIC PLAN

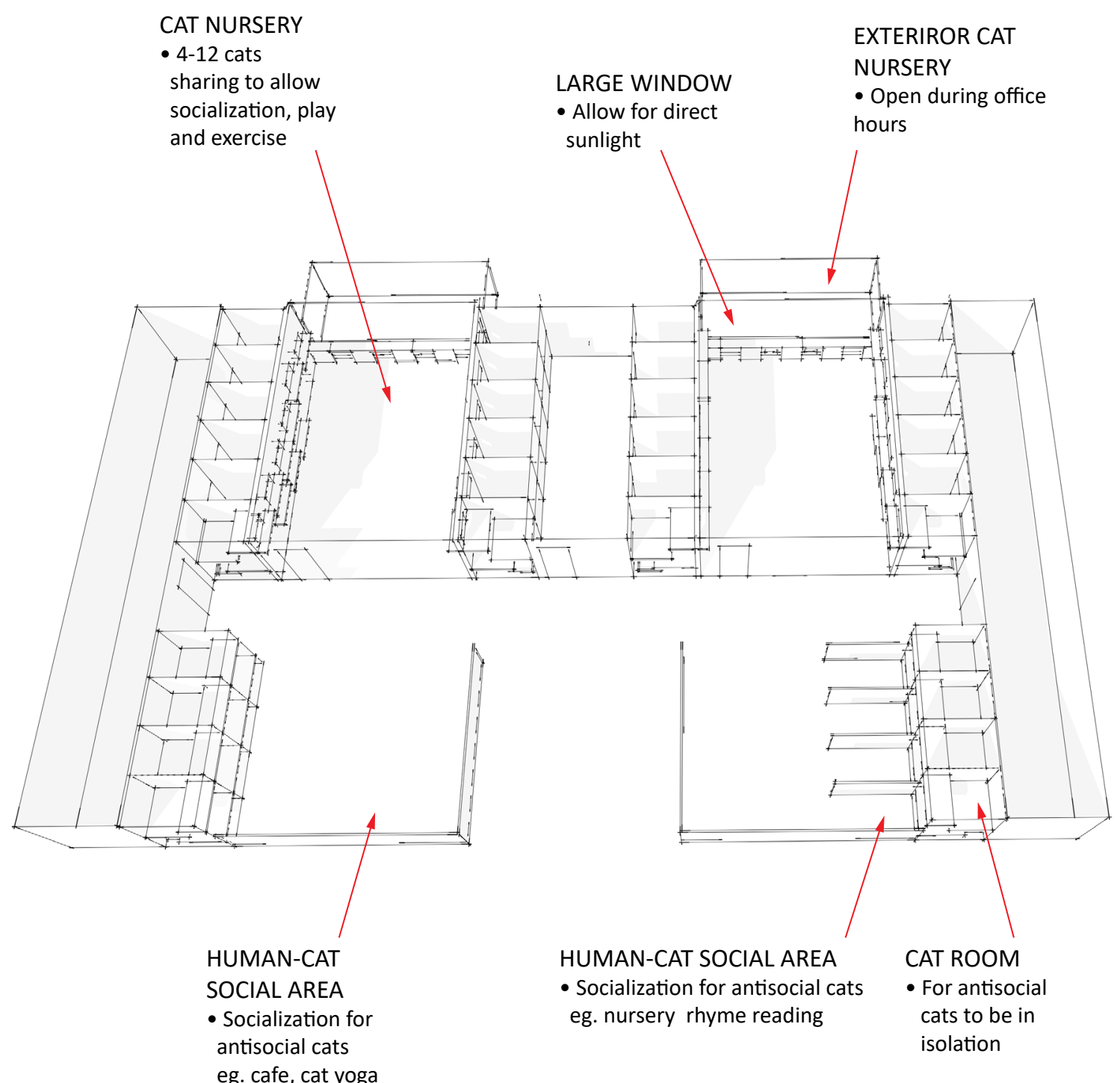




\section{Freedom to Express Normal Behaviour}

For an animal to be able to behave normally, the environment in which they find themselves must be as stimulating as that of their natural environment. This does not mean the environment should look natural, but it should be as enriching as one. Just as a spider does not need to be a fly to be able to design a web made perfectly to fit a fly's characteristic, it is possible to design for an animal by understanding how they experience space. For cats and dogs, the three foremost influencial senses of the five are: sight, hearing and smell.

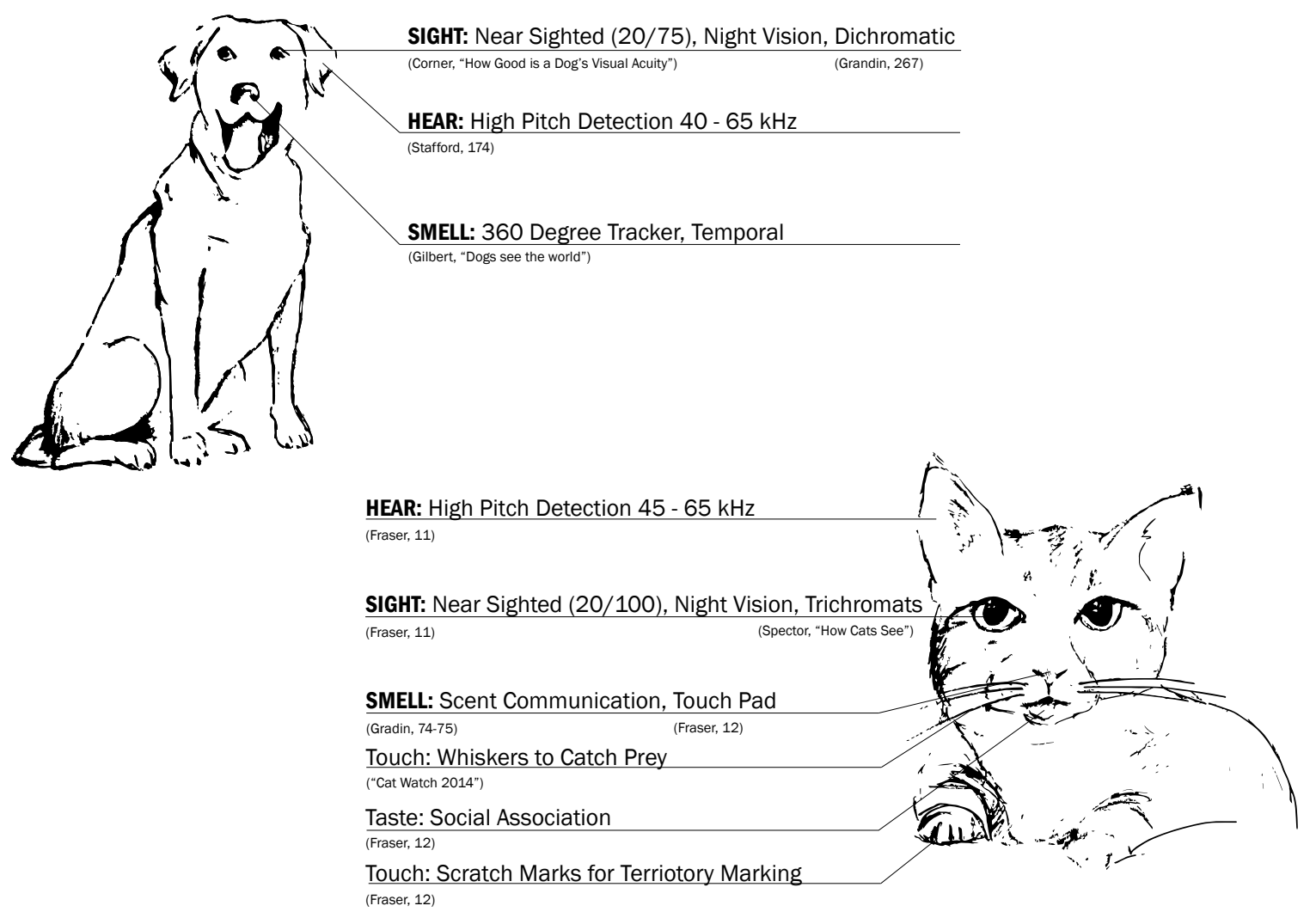

Figure 18: Illustration of the difference in animals senses 
"Let us consider a spider's web from this perspective. The spider knows nothing about the fly, nor can it measure its client as a tailor does before sewing his suit. And yet it determines the length of the stitches in its web according to the dimensions of the fly's body, and it adjusts the resistance of the threads in exact proportion to the force of impact of the fly's body in flight... Indeed, the most surprising fact is that the threads of the web are exactly proportioned to the visual capacity of the eye of the fly, who cannot see them and therefore flies toward death unawares. The two perceptual worlds of the fly and the spider are absolutely uncommunicating, and yet so perfectly in tune that we might say that the original score of the fly, which we can also call its original image or archetype, acts on that of the spider in such a way that the web the spider weaves can be described as "fly-like.""

Agamben, Giorgo. The Open: Man and Animal. Stanford University Press, 1942, pp. 42 


\section{Part 1: Sight}

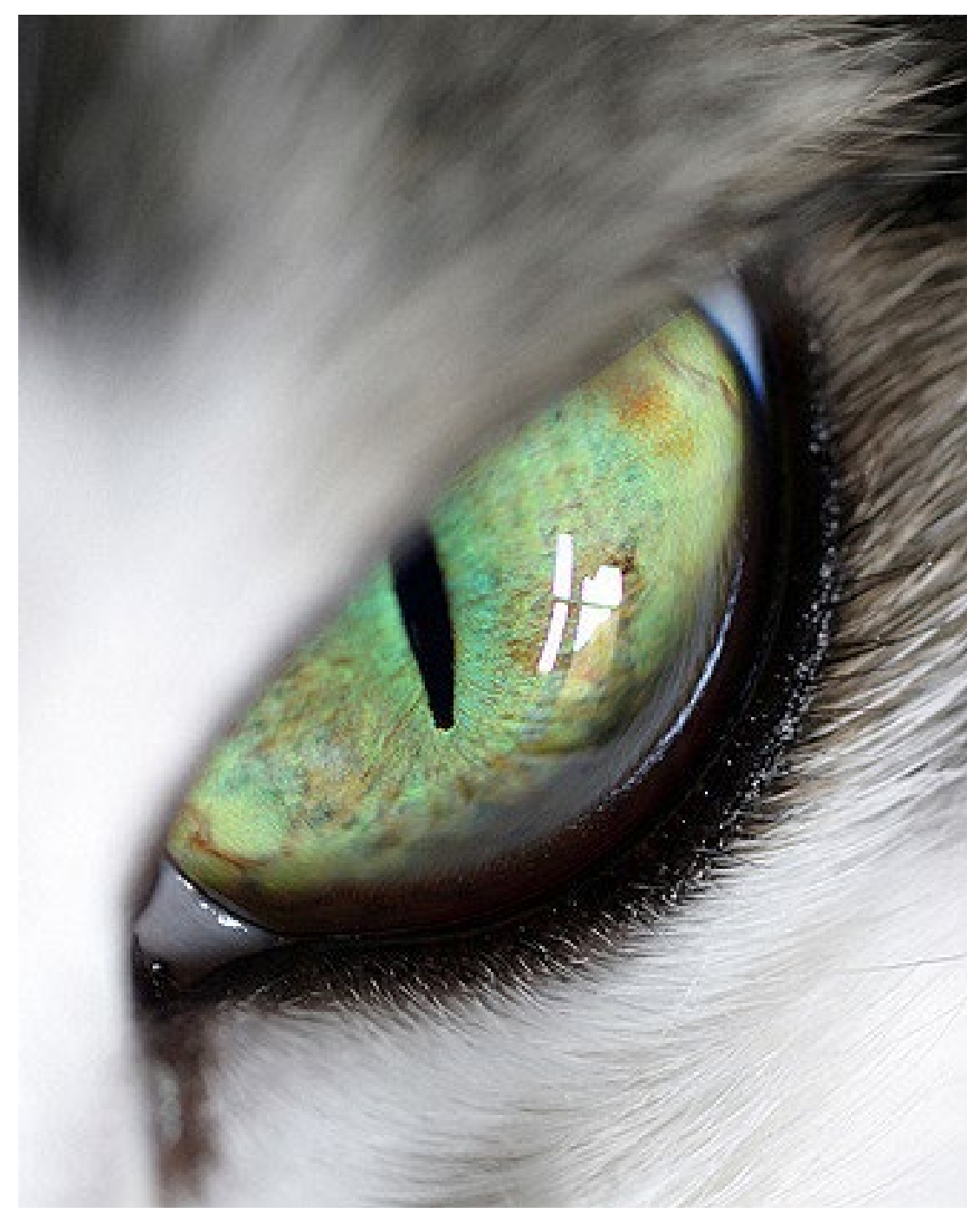

Figure 19: Photo of a cat's eye by Serge S. 
Although both humans and animals share a dependance on sight, what an animal sees is quite different:

\section{- Area of Binocular, or 3D vision:}

Due to the position of the eyes at the front of the human face, our binocular vision is much wider than compared to a dog, or cat. As for a dog and cat's vision, the field in which they see depth is much smaller since their eyes are placed at the side of their heads. ${ }^{36}$ By reducing the binocular vision to half of humans, the animal is able to more accurately judge distance when it is focused on a prey (Fig. 20). ${ }^{37}$

\section{- Peripheral Vision:}

With eyes at the side of their heads, an animal's peripheral vision is larger by approximately 60 degrees when compared with that of a human. For the same reason, the animal's peripheral vision is much clearer than that of a human (Fig. 19, Fig. 20 and Fig. 21) (37 $^{37}$
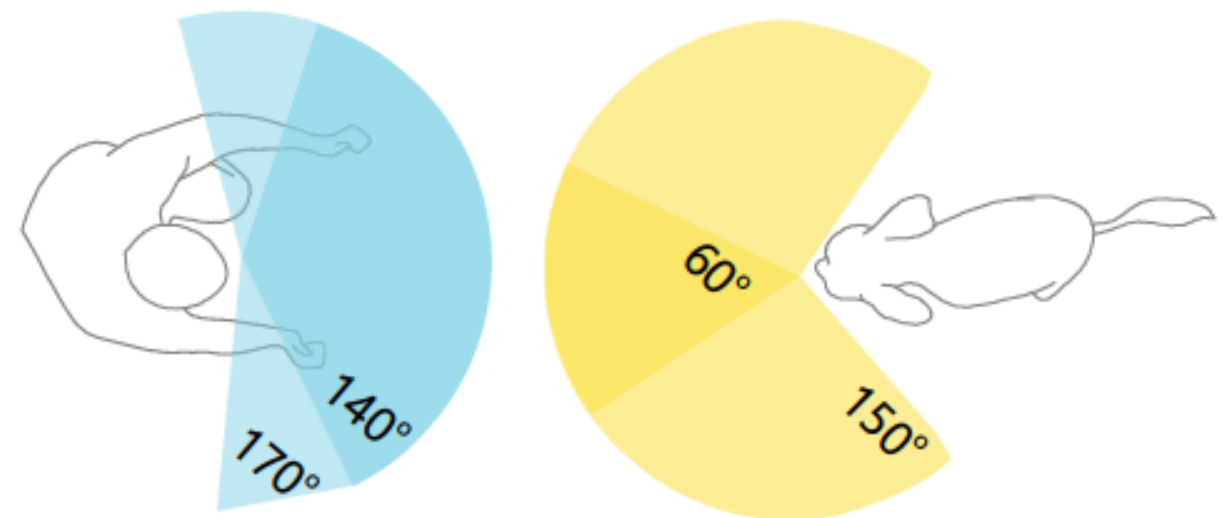

Figure 20: Diagram comparing human and animal field of perception

36 "What do Cats and Dogs See?" Accessed 4 Nov. 2017 

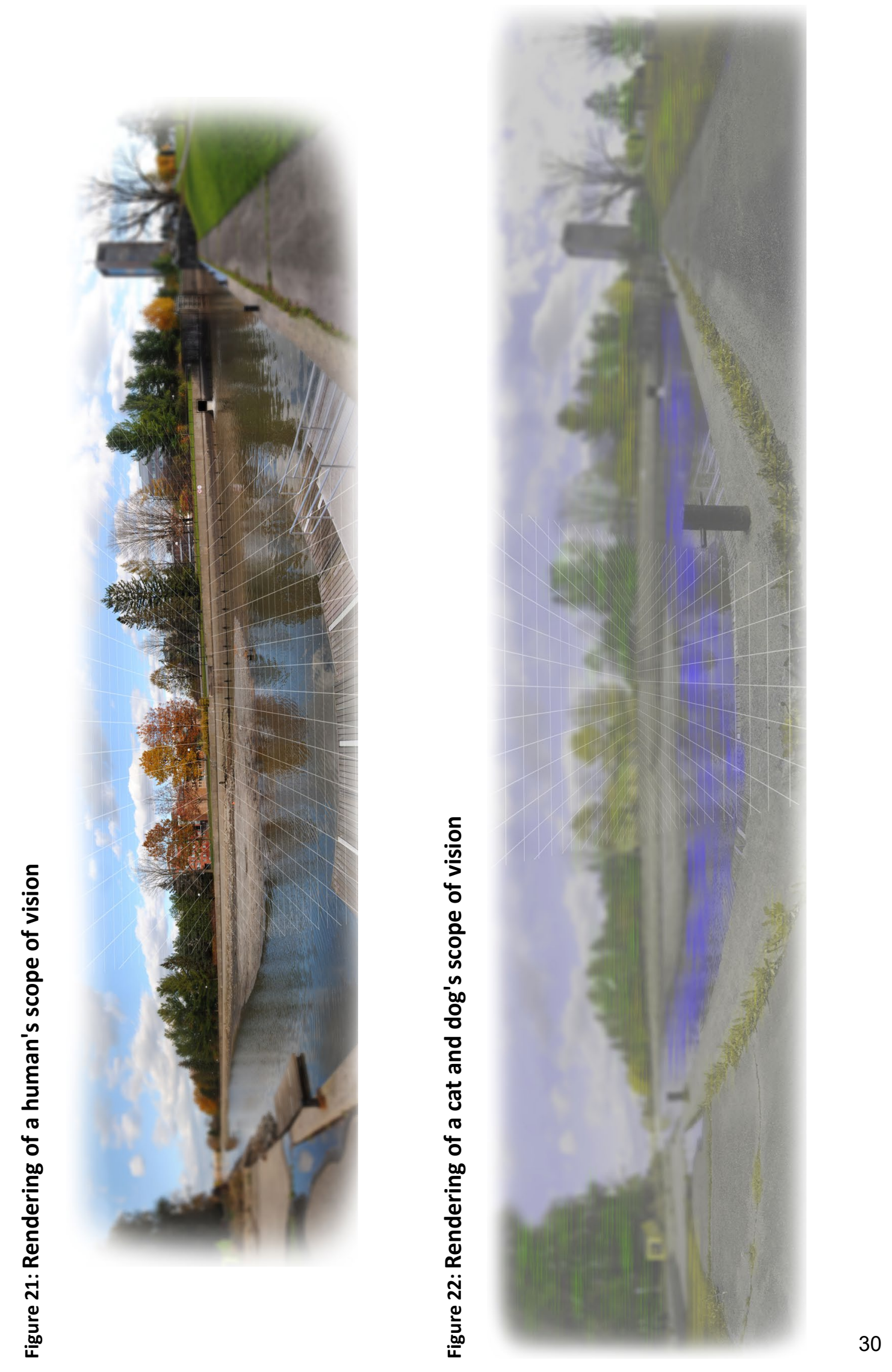


\section{- Visual Acuity:}

A human's visual acuity is found at proximity and mostly directly in front of their face. A dog's acuity is $20-40 \%$ of that of a human and therefore are short sighted (about 20/75 instead of the normal $20 / 20$ vision $^{3}$ ). However, their acuity is also found along their peripheral vision and not simply in the binocular area (Fig. 21 and Fig. 22). ${ }^{38}$

\section{- Motion Sensitivity:}

Although both cats and dogs have low visual acuity, they have high motion sensitivity and therefore are attracted to a prey's movement more easily. ${ }^{38}$

\section{- Blind spot:}

Given their long snouts, their nose becomes their blindspot. To be able to catch their prey, the whiskers becomes especially useful. Instead of seeing their prey, they feel with their whiskers the presence of a creature, or an item. ${ }^{39}$ An installation was built as part of the thesis (Fig. 23) for people to place their nose inside a constructed dog's snout and imagine themselves viewing into the landscape through the narrowing lense.
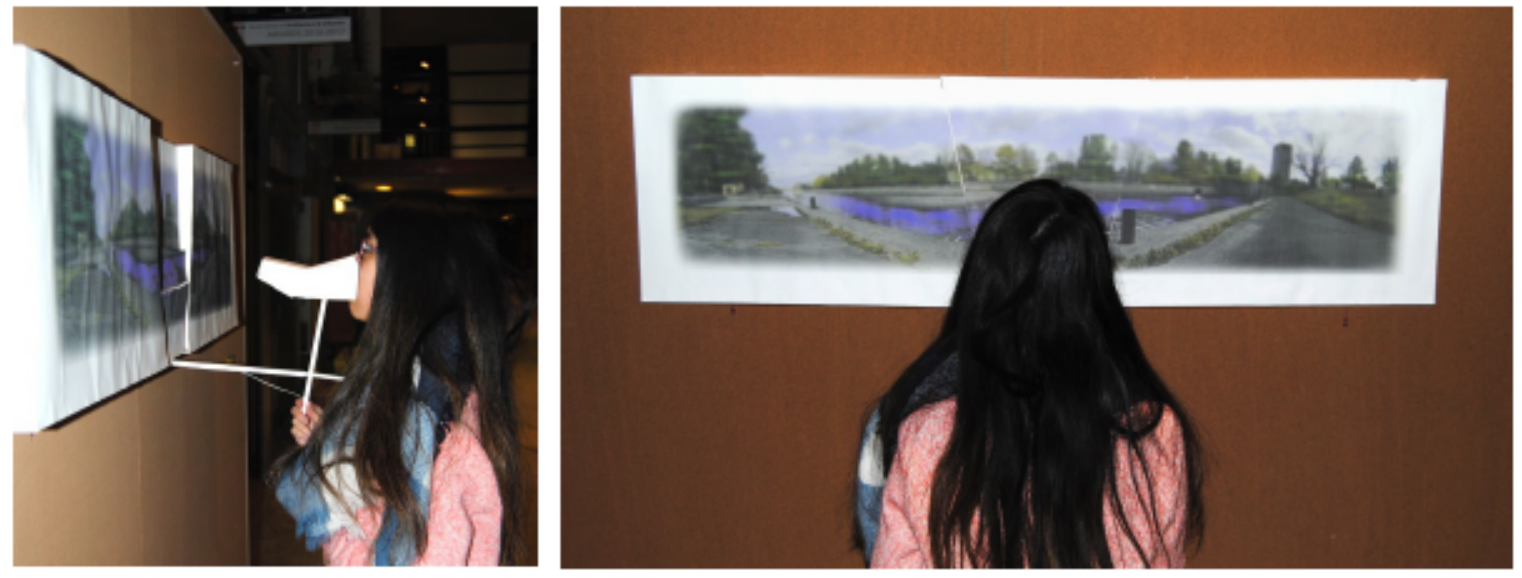

Figure 23: Installation to visualize a dog's vision with a dog nose.

38 "Dog Vision: What Colors can Dogs See" Accessed 31 Dec. 2017

39 "Cat Watch 2014: The New Horizon Experiment" Accessed 7 Dec. 2017 


\section{- Color Blindness:}

Both Cats and Dogs can see color, however their color spectrum differs from our own. Dogs have dichromatic vision, which means they can only see blueish purple - yellowish green. No reds. ${ }^{40}$ Cats on the other hand have trichromatic vision (like humans) but their perception of reds are more greenish. ${ }^{4}$

While designing a space for animals, it may look rather welcoming from a human's perspective to have multi-colored rooms but this may not be the case from an animal's perspective.

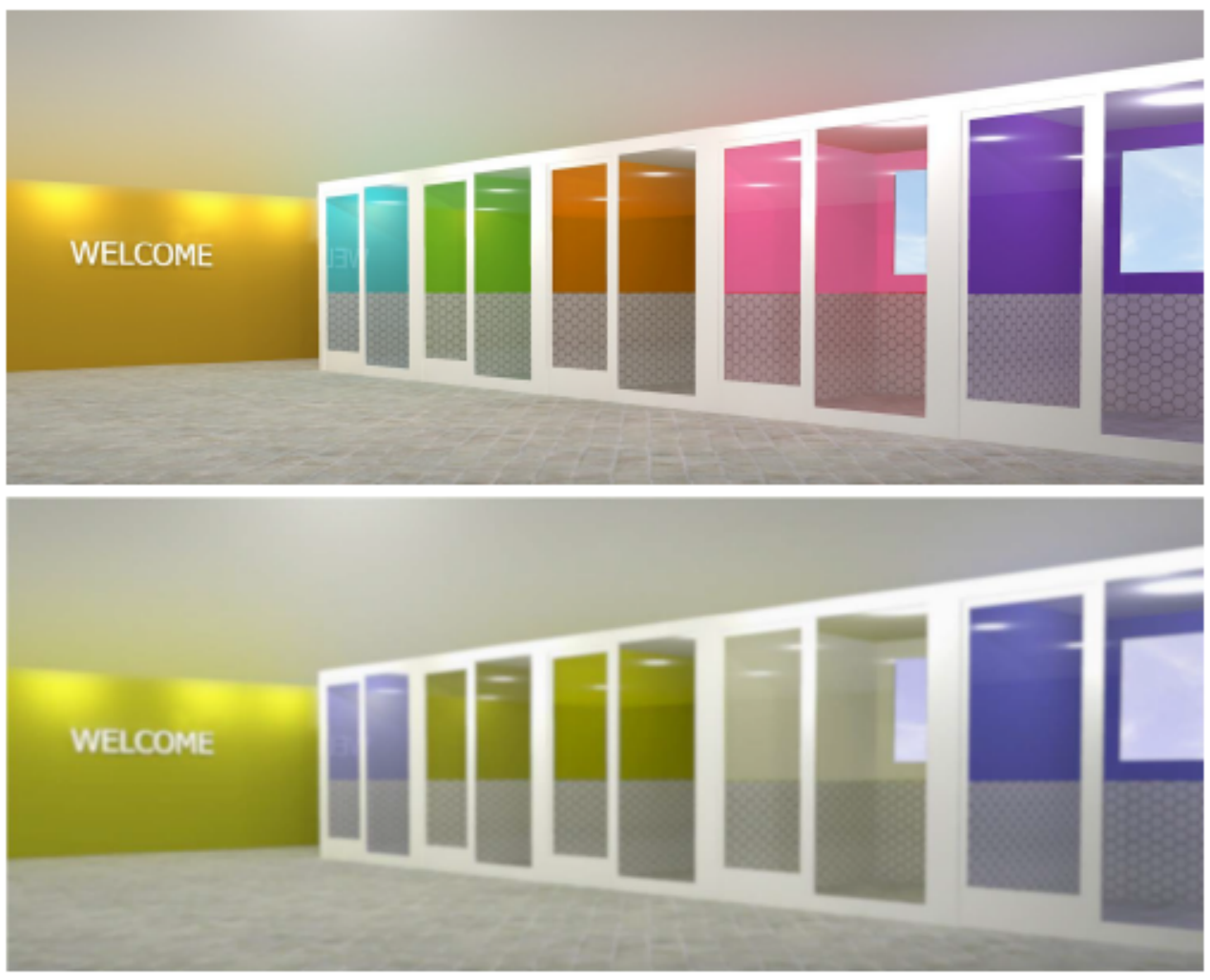

Figure 24: (top) human vision, (bottom) Dog vision - dichromatic vision 


\section{Part 2: Scent}

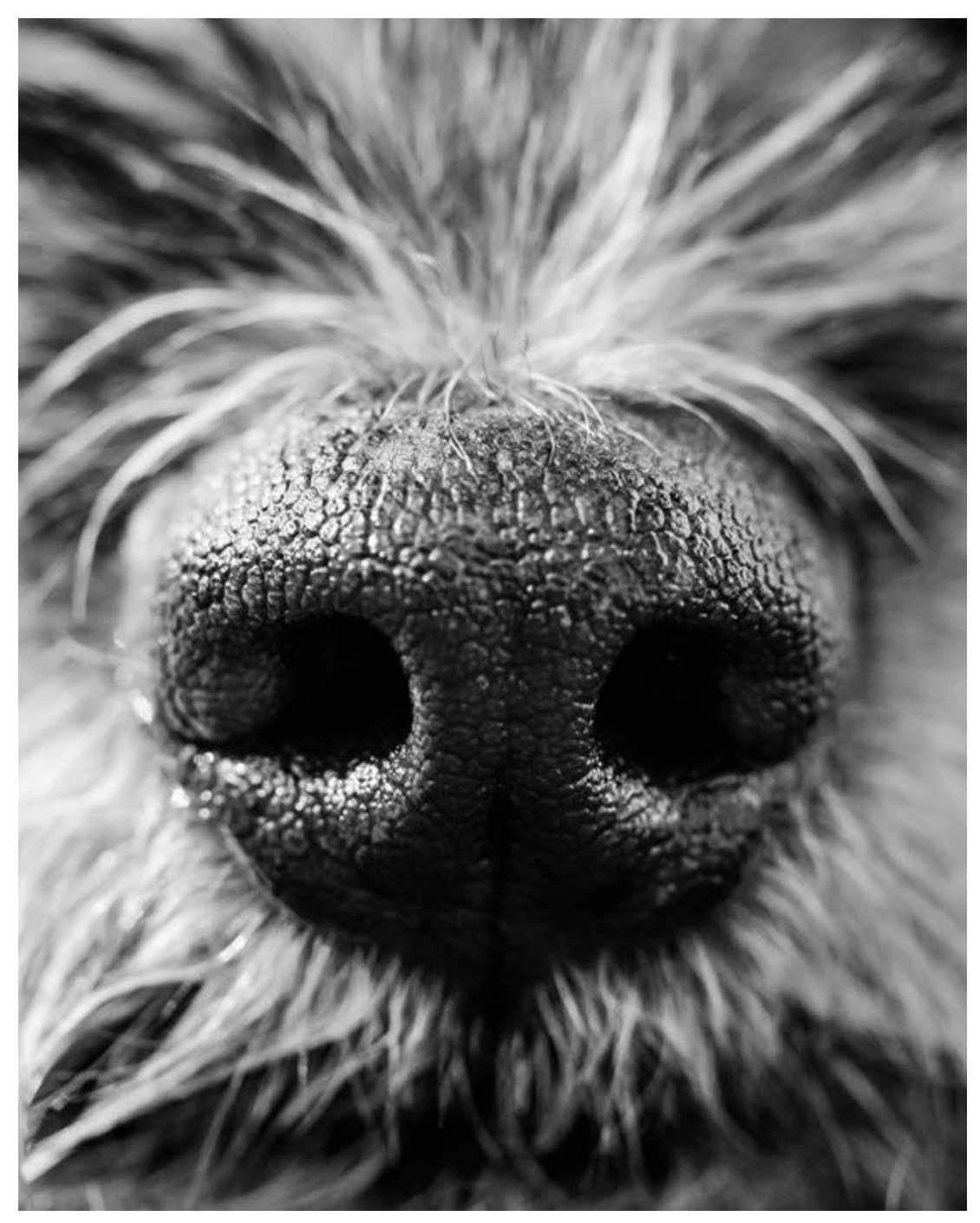

Figure 25: Photograph of a dog's nose by Sarah Bourque 


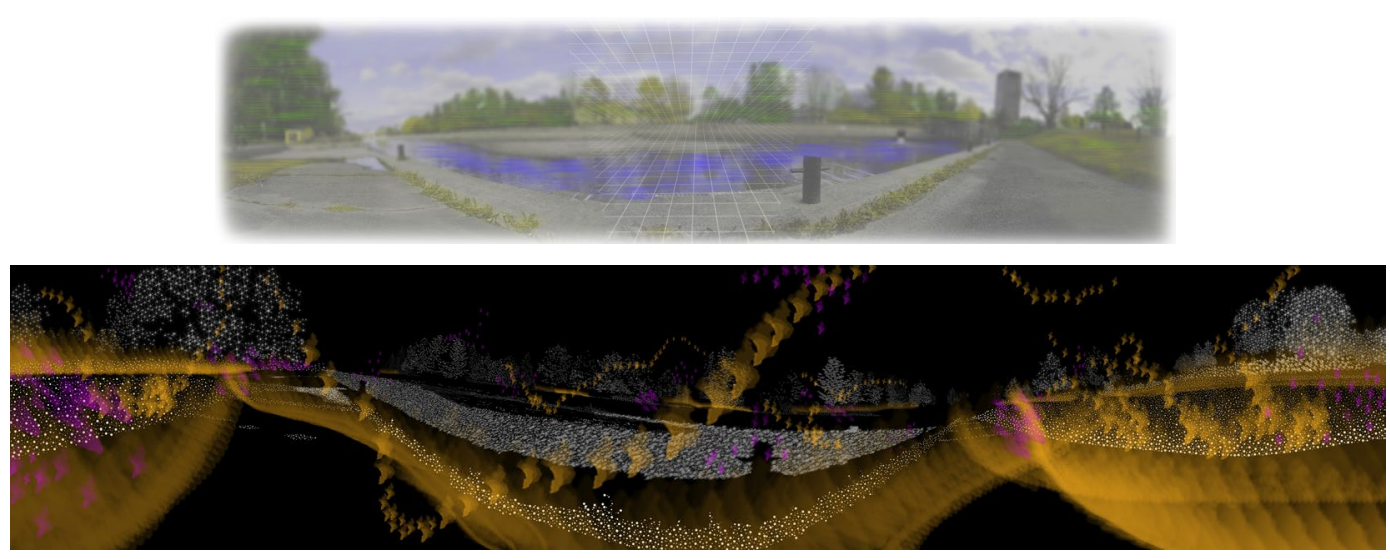

Figure 26: Comparison between human vision and dog's scent

Instead of understanding the surroundings through sight, like humans, animals rely on scent to understand depth. ${ }^{42}$ With one sniff, the animal can know the contents of the object and its direction since they can receive two different odor profiles from each nostril. A dog and cat's nose is capable of differentiating objects based on the smell, similar to how we taste a range of palettes in one bite. ${ }^{43} \mathrm{It}$ is estimated that a dog and cat's smell is at least 100 times better than that of human beings. ${ }^{44}$

Their sense of smell is also temporal. ${ }^{43}$ Placed in a landscape besides Ottawa's Canal and understanding the space solely from the nose, the bottom image in Figure 26 attempts to reveal how a dog might perceive the space. In such an open landscape, the animal's brain is receiving millions of stimuli, each element giving off its own scent profile and information on its location. In figure 26 and 27, the white markings visualizes the different scents existing on site. Each marking symbolizes a specific element within the space. The yellow marking illustrates animals, or humans that have passed through the space beforehand. The purple shows the possibility of other birds and people passing through the space in the future. Animals are able to predict the future thanks to the wind that carries a creature's scent. ${ }^{43}$

\footnotetext{
${ }^{42}$ Gilbert, "Dogs see the World Differently" Accessed 4 Nov. 2017

${ }^{43}$ Horowitz, "How do Dogs "See" with their noses?" Accessed 4 Nov. 2017

44 "Cat Watch 2014: The New Horizon Experiment" Accessed 7 Dec. 2017
} 

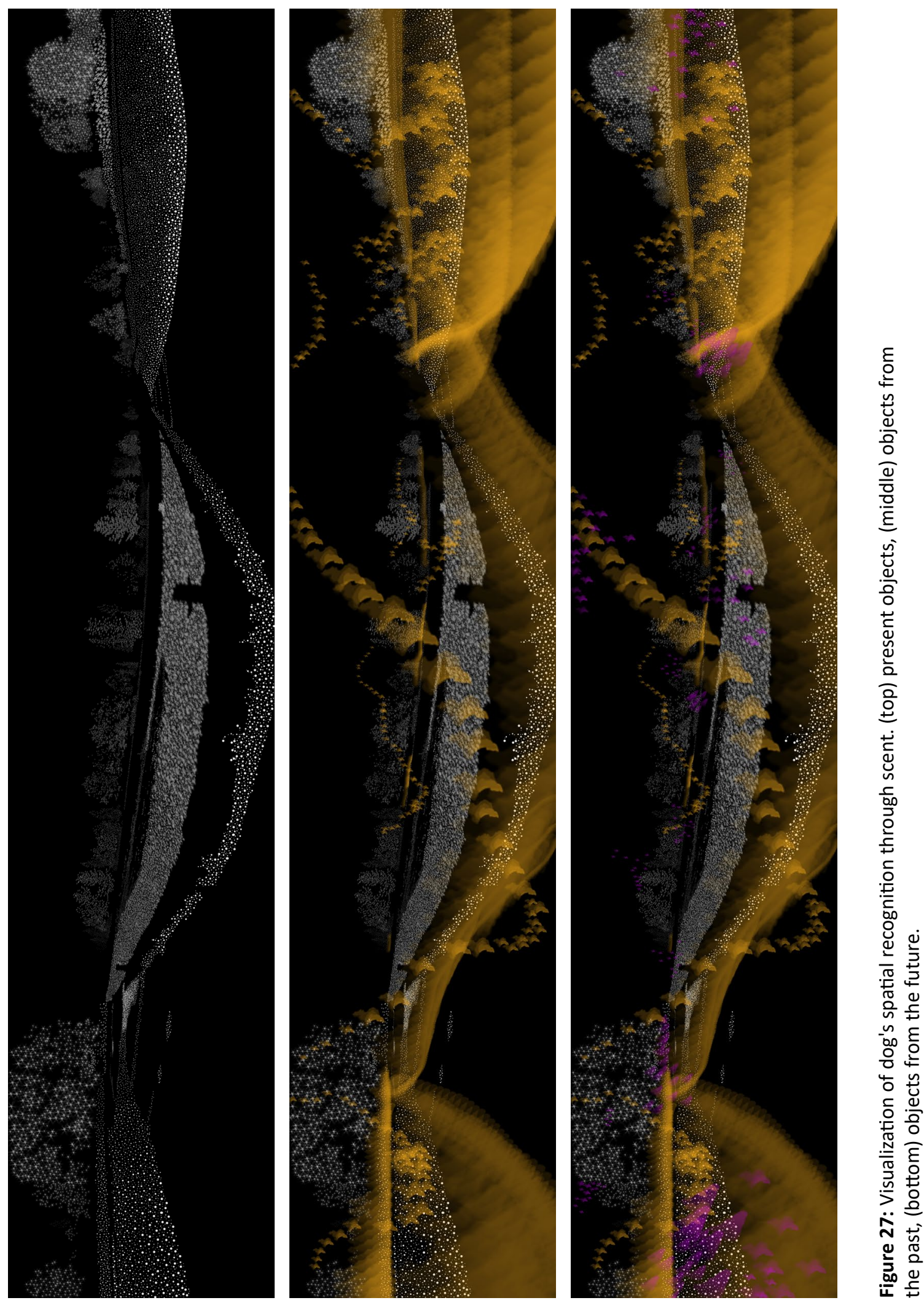


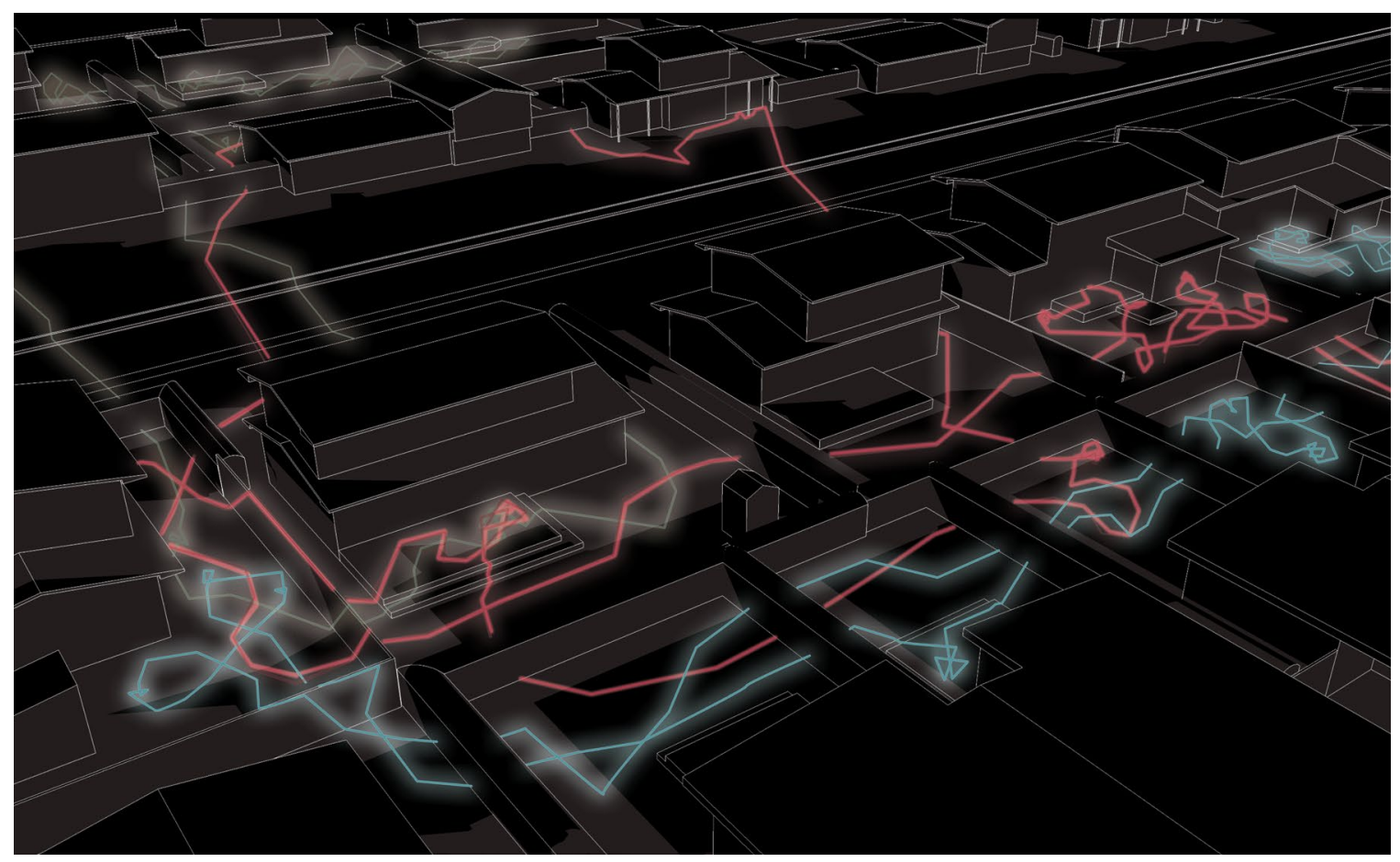

Figure 28: Diagram of cat's scent marking while wandering

Cats utilize scents one step further. Dogs are able to rely on body language and facial recognition. Cats however, do not communicate as much through body language. They communicate through scents. ${ }^{45}$ Cats have an extra organ called the Jacobson Organ located at the top of their mouthes that helps them differentiate scents that are undistinguishable by humans. As wanderers, cats utilize scents to arrange meeting points for mating. ${ }^{46}$ They show their appreciation, or their distaste in other cats. ${ }^{47}$

\footnotetext{
${ }^{45}$ Grandin 2010: 74

46 "Cat Watch 2014: The New Horizon Experiment" Accessed 7 Dec. 2017

${ }^{47}$ Fraser 2012: 12
} 
Cats deposit scents to communicate and set up territory. For this reason, a consistant habitat is crucial to a cat. Similarly, we set up fences to mark our property as a form of communication that our privacy should be respected. Once these delineation is removed, or invaded, we lose our sense of secuirty. This is the same for cats. In a new environment, a cat would leave traces of scent for other cats to know that this spot has been claimed.$^{48}$ Other forms of marking consist of scratching and urinating. ${ }^{49}$

In Figure 29, a cat would perceive the backyard similarly to a dog; being able to distinguish and locate different objects through scent. However, the cat is also able to smell traces of body odors left behind by neighboring cats (middle image of Fig. 29). The cat must then set up territorial markings to announce his new home and favorite resting spots in the area (bottom image of Fig. 29). Unable to do so would frustrate the cat and lead to an unhealthy life style.

In the same manner, for a cat to enter an animal shelter for the first time, it can be stressful. The cat must redefine its territory, because of the lack of awareness of the surroundings and the dangers. Without the cat's established "fences," claimed by traces of his/her scent, the cat is vulnerable without a safe spot within the room. ${ }^{50}$ When meeting with other cats, friendship is out of tolerance. ${ }^{51}$ With time, a dominant cat would be selected and the dominant cat's ranking will be marked by occupying the highest shelf in space, or furniture. Meanwhile the other cats are left to select their resting spots elsewhere. ${ }^{52}$

\footnotetext{
${ }^{48}$ Grandin 2010: 82

${ }^{49}$ Fraser 2012: 12

50 "Cat Watch 2014: The New Horizon Experiment" Accessed 7 Dec. 2017

${ }^{51}$ Fraser 2012: 106

${ }^{52}$ Grandin 2010: 89
} 

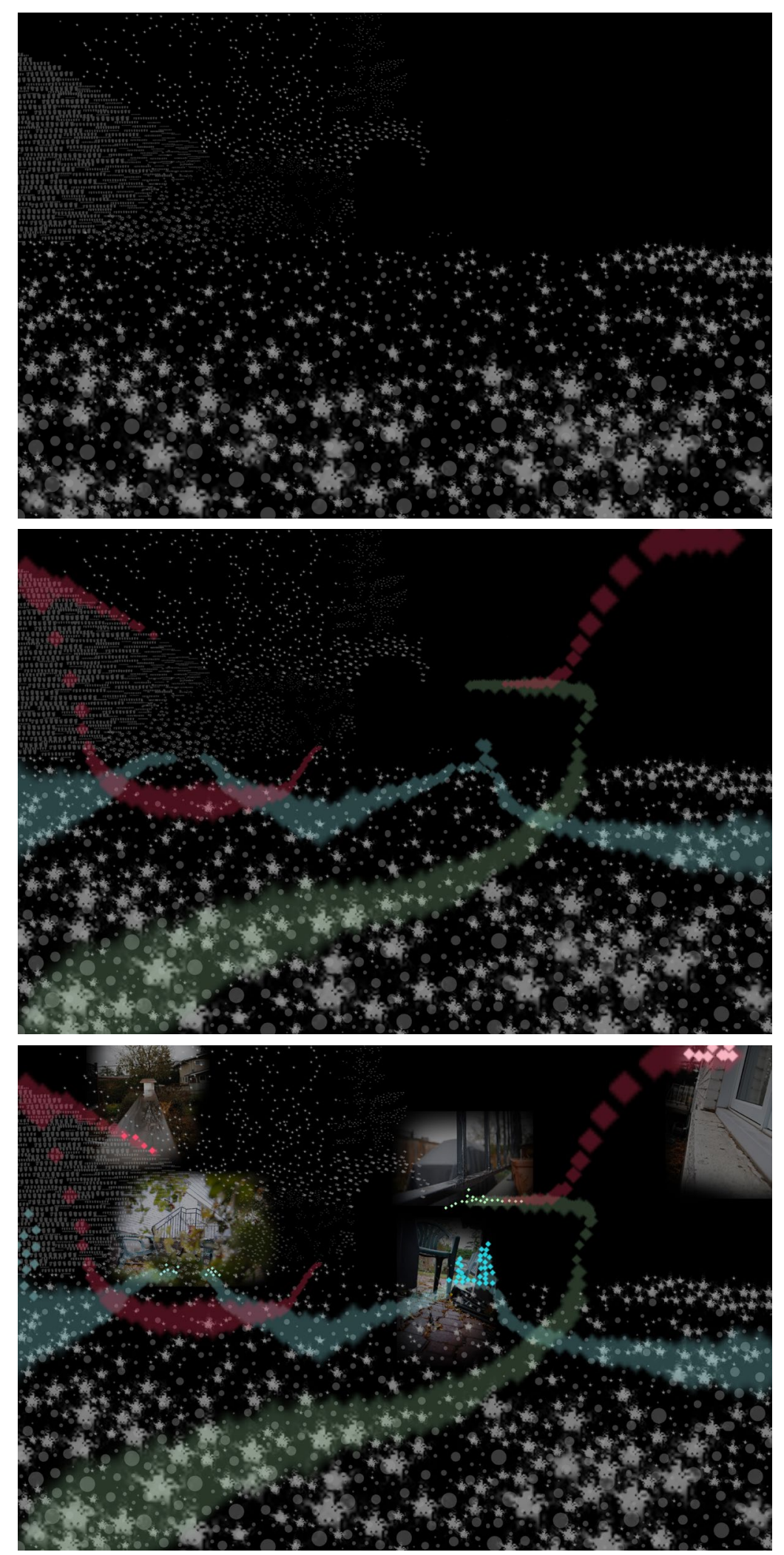

Figure 29: Diagram of cat's scent marking at a specific location (top) present objects on site, (middle) trail of scent left by cats, (bottom) territorial markings 


\section{Part 3: Sound}

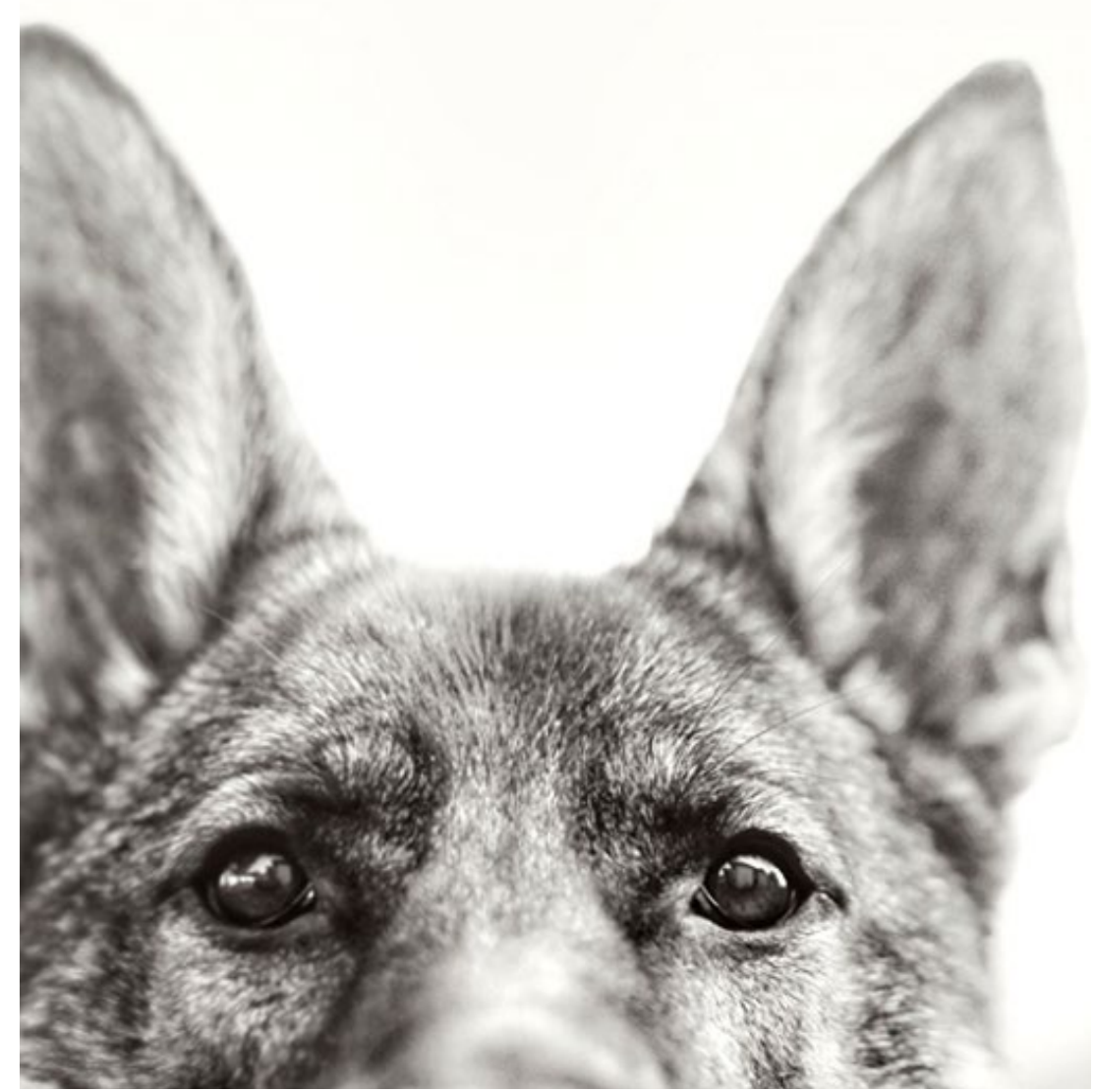

Figure 30: Photograph of dog ears by Ashley Randall 


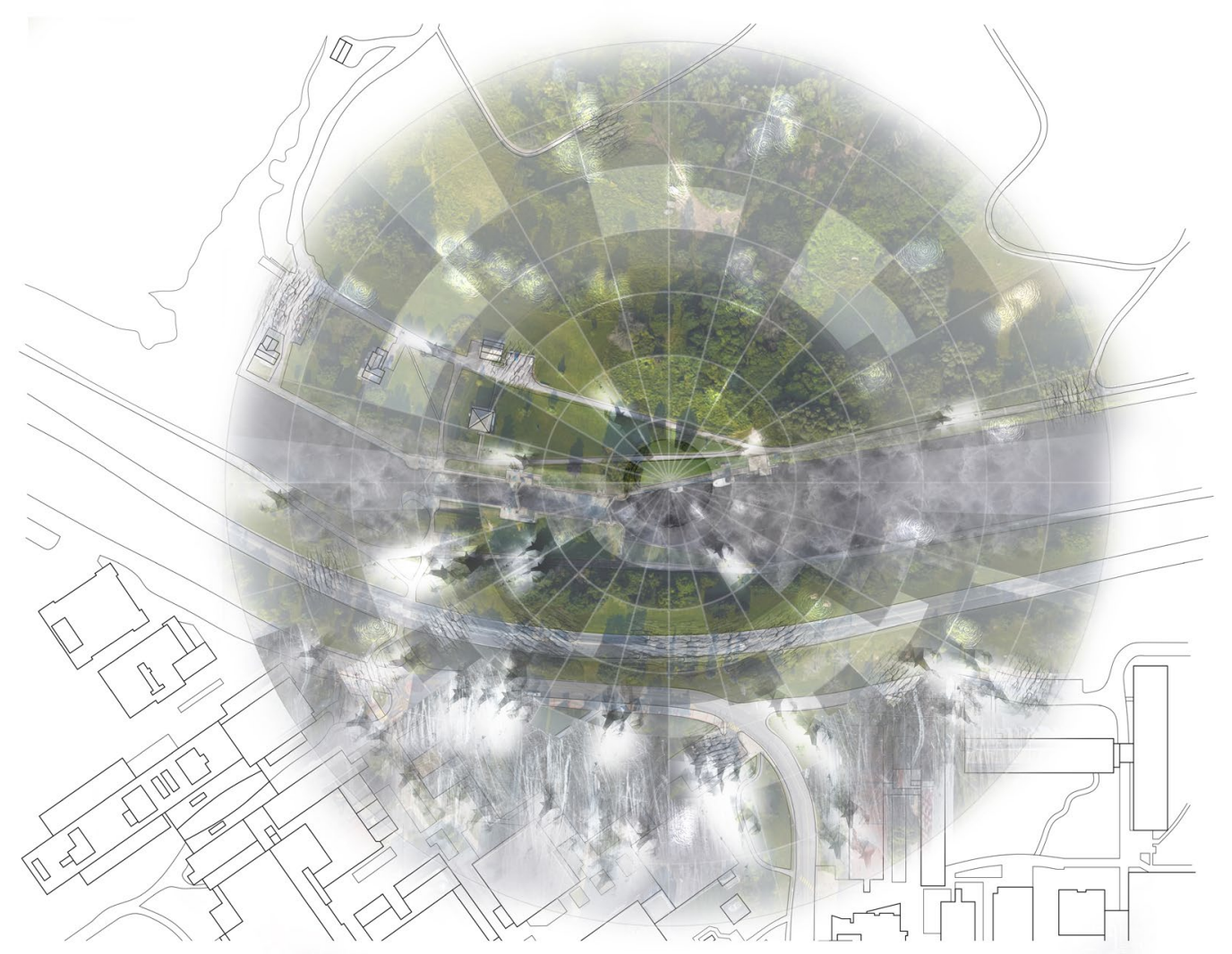

Figure 31: Diagram of sounds around site

Dogs and cats have a far greater hearing range than human beings. The cat can hear 5 times farther ${ }^{53}$ and a dog can hear 10 times farther. ${ }^{54}$ Unlike humans who can only hear what is in front of them, they are able to shift their ears to better and more accurately locate the sound..$^{53}$

Dogs and cats can hear higher frequencies than humans. However, simply because they can hear higher frequencies, it does not mean it is pleasant to the ears. Especially for cats, high frequencies and sudden sounds are both uncomfortable and stressing. ${ }^{55}$

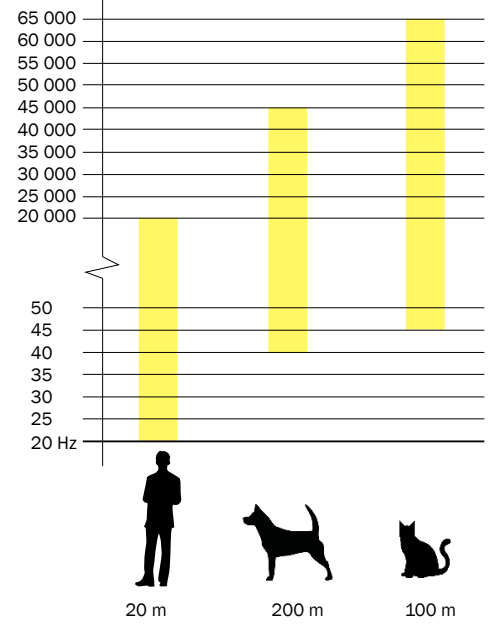

Figure 32: Diagram comparing frequencies heard by different humans, dogs and cats

\footnotetext{
${ }^{53}$ Flagg, "About Hearing Cats" Accessed 1 Jan 2018

54 "How does a Dog... Hear?" Accessed 7 Dec. 2017

${ }^{55}$ Fraser 2012: 59
} 

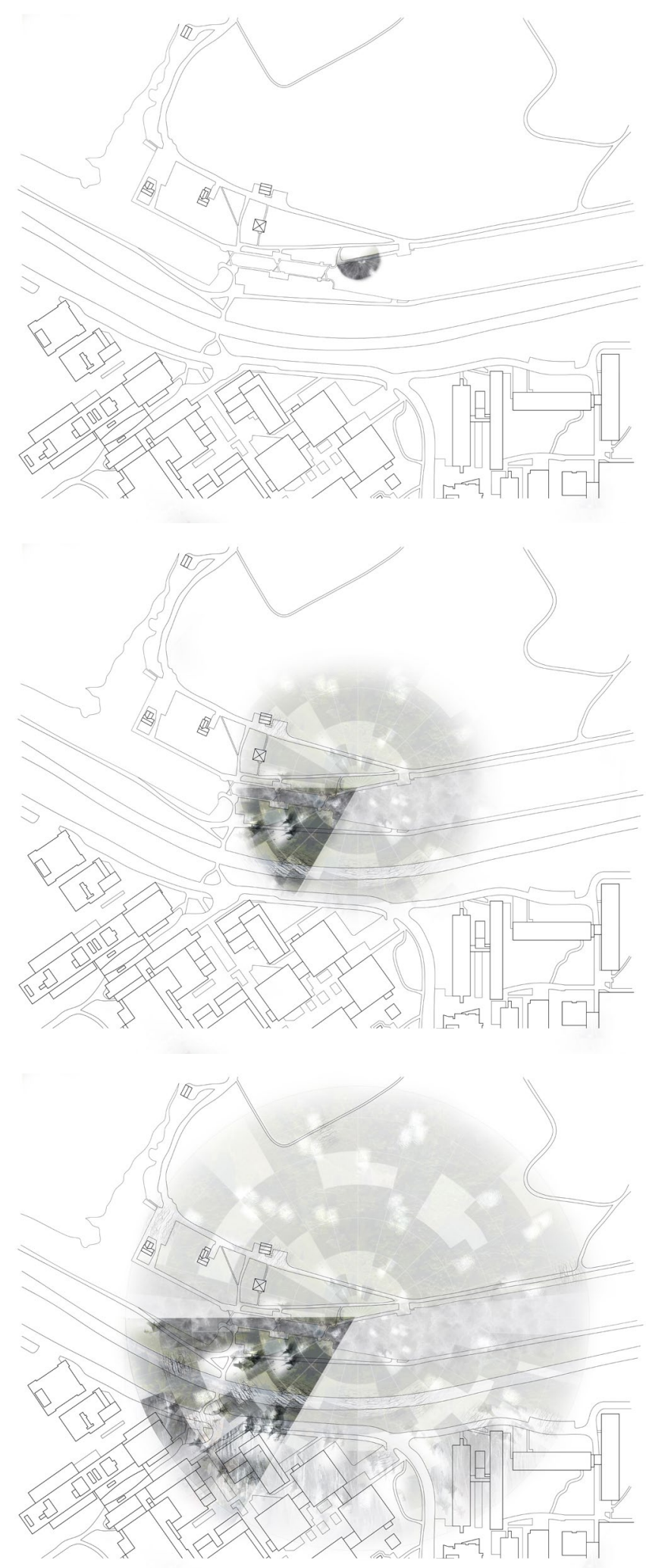

Figure 33: Diagram comparing hearing ranges (top) distance a human can hear- $20 \mathrm{~m}$, (middle) distance a cat can hear - $100 \mathrm{~m}$, (bottom) distance a dog can hear - $200 \mathrm{~m}$ 


\section{What can the dog hear?}

Itself. Cleaning products.
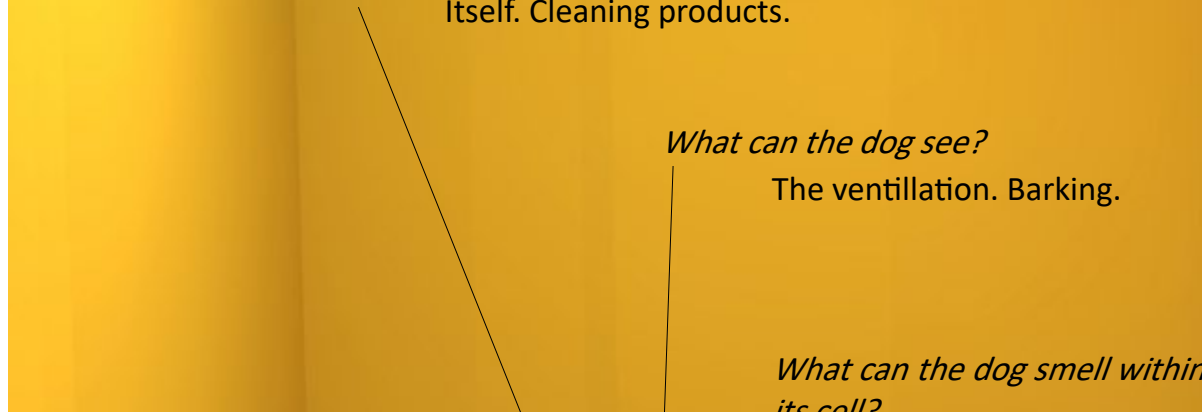
its cell?

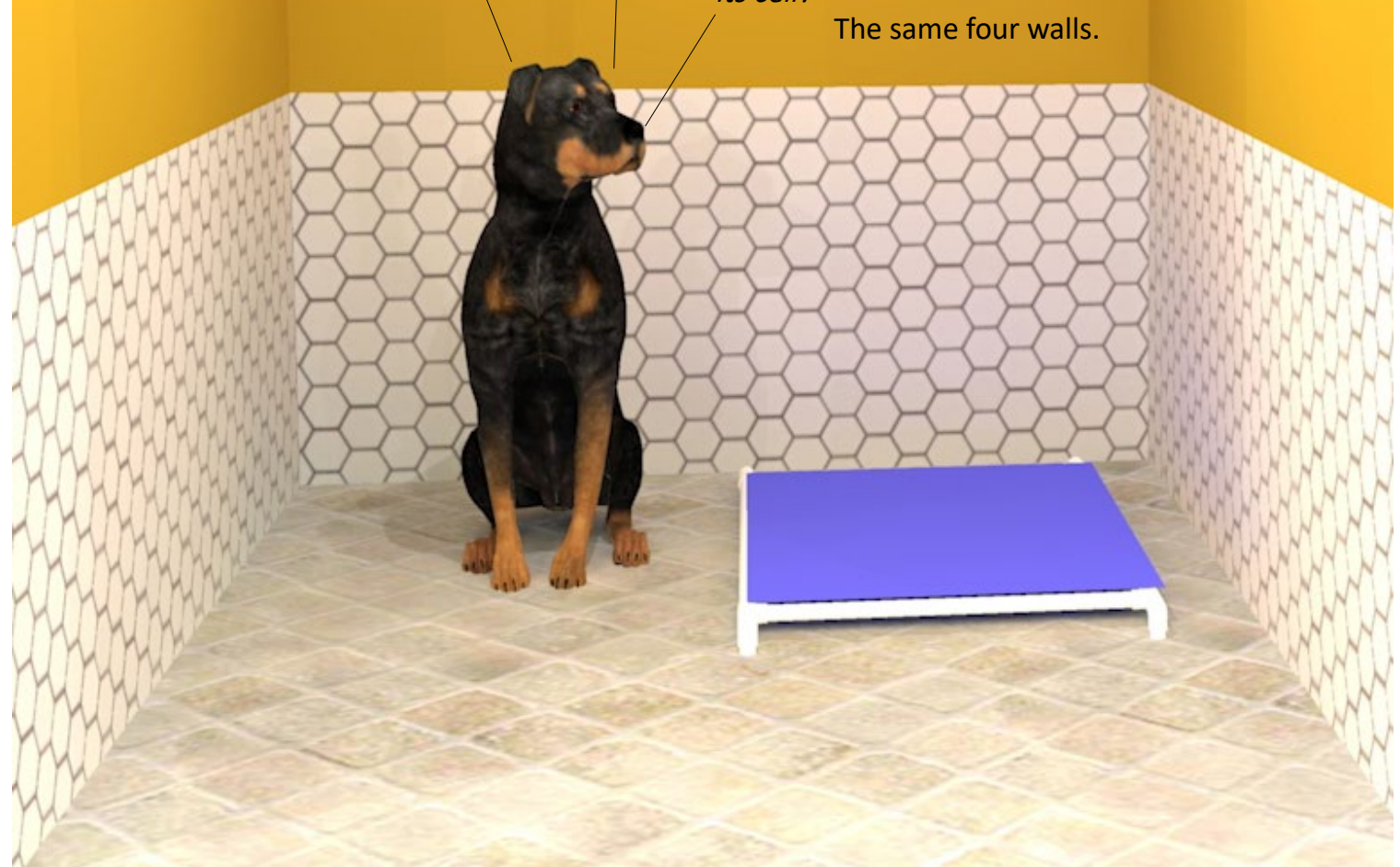

Figure 34: Typical room for dogs in animal shelters

Despite the fact that animals experience space differently and rely on their senses for a feeling of security and understanding, shelters typically offer a room that isolates not only their vision but ALL of their other senses. 


\section{Benefits of Human-Animal Interaction}

Although the focus of this thesis is to design a temporary home specifically for animals, the need to bridge an understanding between animals and humans is still necessary. Especially for dogs, who are genetically predisposed to work closely with their human partner. ${ }^{56} \mathrm{~A}$ dog requires human-dog socialization for a healthy lifestyle. However, the animal is not the only one to receive benefits from the interaction:

1. Horses and dogs have found to be useful in therapy sessions. The sensitivity to body movement and expression allows the therapist to interpret the emotions of the patient. For example, a counselor in a session with a student, guided her dog Rusty to lie next to the student. While the student discussed what was on her mind, the dog repeatedly stood up and walked in a tight circle before laying back down. When the counselor asked what she thought the dog is doing, she replied that the dog was "unsettled." The counselor further asked why she thought Rusty was unsettled, she replied that she felt unsettle herself. At the time, she was suffering from anxiety due to some difficult family issues that she wanted to avoid talking about. ${ }^{57}$

2. The presence of animals, especially puppies and kitties, gives off a calming and safe environment. People find themselves relaxing and de-stressing around them. ${ }^{58} \mathrm{Many}$ universities, such as McGill University have decided to allow puppies on campus during exam hours to de-stress students. ${ }^{59}$ Carleton University also created an ESP Therapy Dog session for students to express themselves more comfortably in the presence of a dog. ${ }^{60}$

\footnotetext{
${ }^{56}$ Grandin 2010: 26,

${ }^{57}$ Chandler 2010: 368-369

${ }^{58}$ Flynn 2008: 276

59 "Destress with puppies at the Schulich and HSSL Libraries!" Accessed 23 March 2018

60 "ESP Therapy Dog" Accessed 23 March 2018
} 
3. Animals also aid in helping children learn socialization and discipline. For example, during a therapy session, a young child who has been having trouble socializing with his peers, played catch with the dog. When the dog retrieved the ball, the boy grabbed onto his collar and teased him by moving the ball back and forth closely from the dog's nose. After that, the boy threw the ball and the dog retrieved it but returned it further away from the boy, whereas he would normally retrieve the ball to the boy's hand. The counselor was able to use this opportunity to teach the boy about respect and using his power to tease and how bullying can offend others. ${ }^{61}$ Even to those children who are shy, dogs and cats can help these children express themselves. Unlike humans, domestic animals are more forgiving and less judgemental. This gives the children a safe haven to let their personalities show. ${ }^{62}$

4. Animals reduce the sense of loneliness. We see this as more homeless people adopt pets. ${ }^{6}$ Dogs and cats are especially useful in elderly homes.

5. Most importantly in animal shelters, the animals provide a rewarding experience. The volunteers give up their free time to help these animals out of love and compassion. For dedicated staff members, this desire to be among animals and to help them first hand is even more important. Designers should hold on to this and create a design that reaps the motivation of these workers. Allow the shelter to be a place of joy and encouragement, which is often masked by paperwork.

Looking to the site of the animal shelter is important. Creating programs accordingly to what is around will help the shelter be recognized. More visitors mean more awareness of the needs. Adopters and existing owners can also become more aware of the home they

${ }^{61}$ Chandler 2010: 360-361

${ }^{62}$ Chandler 2010: 359

63 "Flynn 2008: 277 
are creating themselves for their pets. Education on the understanding of their pet goes a long way. This not only brings income and help, but the animals receive the socialization it requires. Look for existing programs around the site to foster a program within the animal shelter for human-animal interactions:

1. Schools - Café, therapy, de-stressing event during exams, volunteering, animal yoga, education center

2. Elderly Homes - Café, reading to the animals

3. Parks - Dog park, education center, fundraiser, café, animal care services, obedience class

4. Disabilities School - Therapy, education center, reading to the animals

5. Veterinary Clinic - Education center, animal services, bring your own dog café, dog park, obedience class

6. Restaurant Landscape - Café + Desserts, dog park

7. Homesless with Pets - Homeless shelter, soup kitchen for people and pets

When pairing an animal to a program, it is important to recognize the animal's personality. For example, dogs prefer to be around a calm and collected individual. Dogs descended from wolfs and to be able to domesticate the wolves, they were genetically modified to prevent the animal to mature beyond adolescence. ${ }^{64}$ For this reason, dogs require a parent who can clearly instruct and teach them the house rules. Pairing dogs with elderly and the career group is ideal. ${ }^{65}$ However, this is not to say that dogs cannot work with children but dogs need to be observed before being thrown into a crowd of children. ${ }^{66}$ Some dogs are more aggressive than others especially after the abandonment of their owner, their security blanket. ${ }^{67}$ For this reason, the staff members have the responsibility to observe and understand which dogs are suitable for which program.

${ }^{64}$ Grandin 2010: 36

${ }^{65}$ Grandin 2010: 57

${ }^{66}$ Chandler 2010: 371

67 "Cat Watch 2014: The New Horizon Experiment" Accessed 7 Dec. 2017 


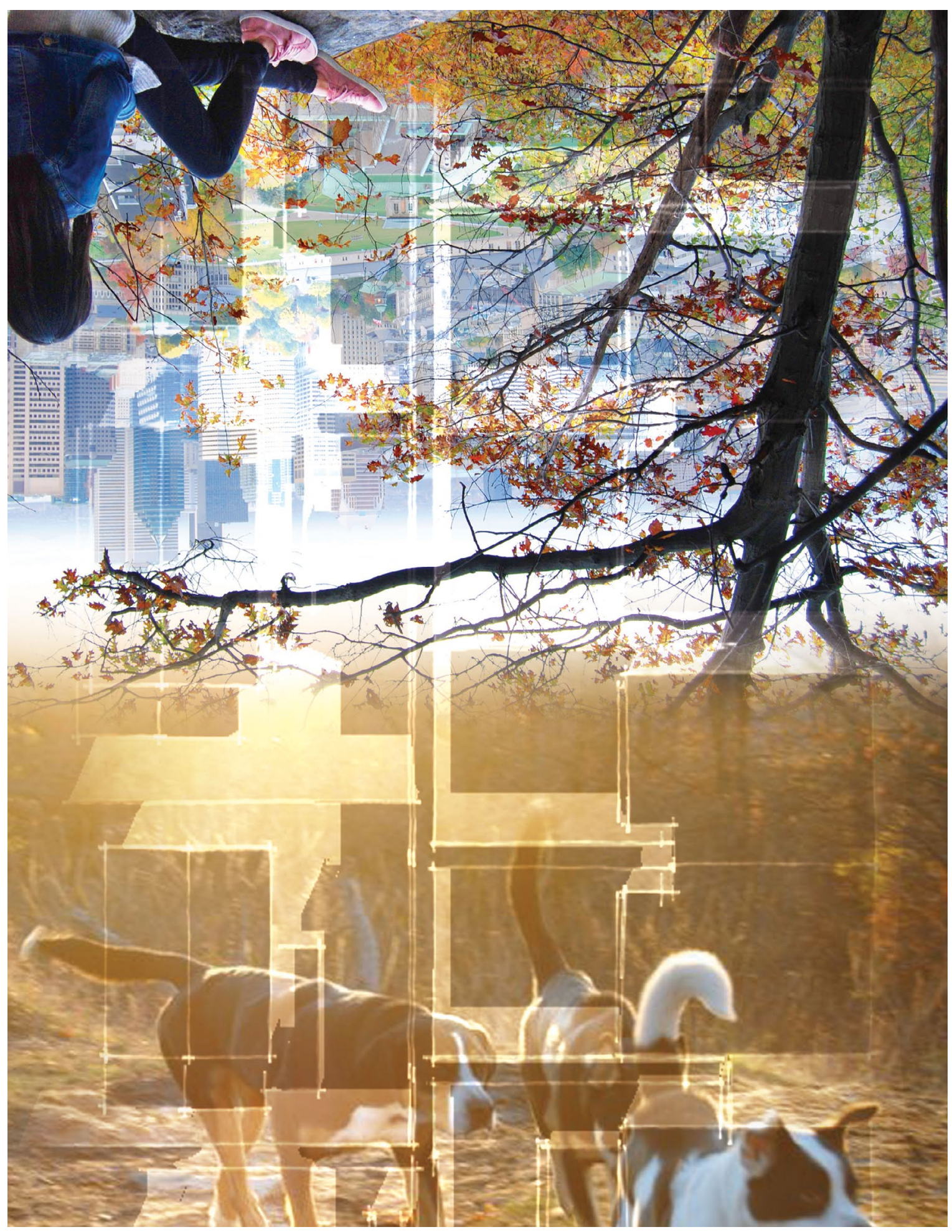

Figure 35: Exploring a connection between human and animals 


\section{Summary: Because we Care}

Despite centuries of living along side our domestic pets, understanding animals and their natural behaviour is still in its infancy. Architecture for animals is an even more new exploration in what an animal needs and feels within a space. For this reason, a guidebook was decided to be the approriate response. The guidebook is not an end product but the beginnings of an exploration to architectural solutions for animals mental welfare. It is the start of a conversation. Without a specific site in mind, the book can be applicable to multiple situations such as animal shelters, rescue homes, veterinary office, etc. The idea of the book is to guide the reader through a series of architectural details that are essential to the mental welfare of the animal. However, the goal is not to simply provide a checklist. The arrangement and binding of the book has a symbolic value that represents the nature of the animal. The book aims to both design space and to educate the reader on the characteristics of the animal.

There are two guidebooks: one for dogs and the other for cats. Each book begins at the coverpage, illustrating what the animal sees before entering the space. The reader is introduced to the confusion that the animal may experience when entering a new environment. As the book progresses, the reader is introduced to different details. It is not until the end of the book that the reader is revealed with the plan of the building. In the same manner, the abandoned animal is unfamiliar with the space. It only understands what is in front of him and that is his kennel. It is only through time, walking through the space that the animal later discovers the building. This focus on the kennel also allows the reader to realize how crucial is the design of that space considering that the animal locked in it for long hours. 
The second exploration between the two books is the binding. Each book unfolds according to the animal's loss of security and proceeds through the rebuilding of it. In the dog's guidebook, the book is bind by its corner. Next to this corner is an image of the previous owner before abandonment. On the next page it becomes black, representing the loss of security. In the next few pages, the window is blurred. As the reader flips through the pages, understanding more of the space, the image of a staff member is revealed. This symbolizes the restoration of trust with the staff member, or the reader, as he/she understands the design and the dog more. Each step that is taken to understanding the animal, the more the trust is rebuilt. See figure 65.

Figure 36: The unfolding of the dog guidebook

\section{First Page}

Dog's security hinging on the previous owner

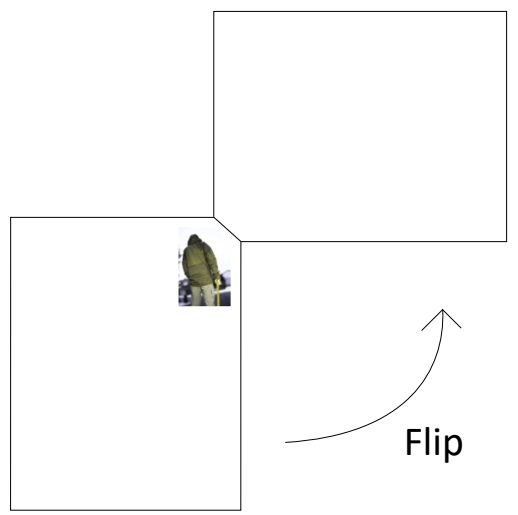

2 Second Page Loss of Security: Black

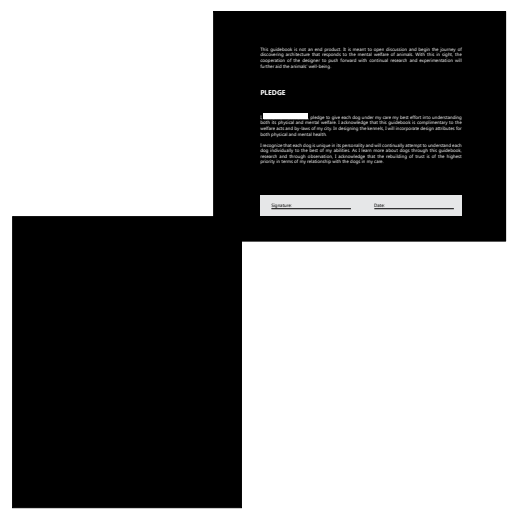

3 Consecutive pages Rebuilding of dog's trust

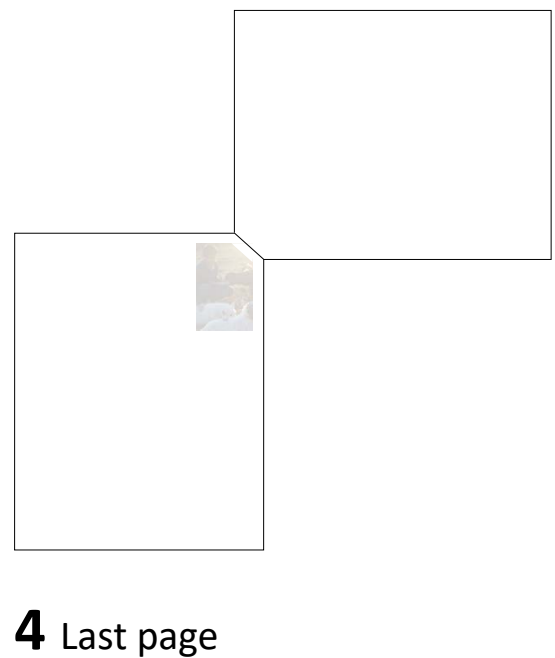

Trust is re-established and the picture of staff is revealed

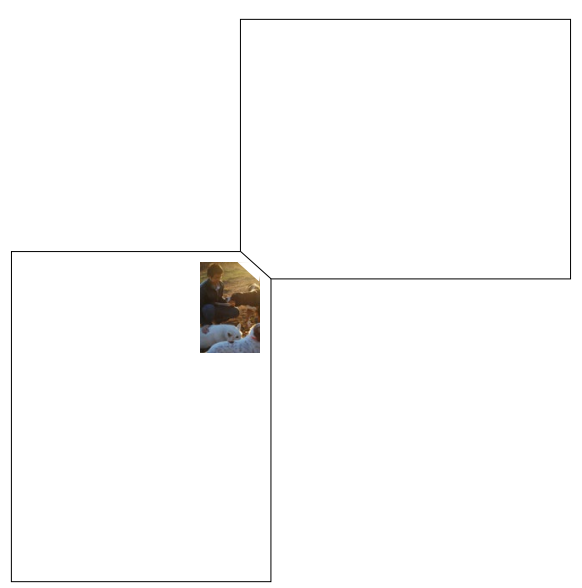


Cats on the other hand find their security in their environment. When entering a new place, cats would slowly explore the space from one safe corner to the next. The book first introduces the impression a cat may have upon entering an animal shelter, filled with foreign cat scents. Unable to predict if they are friendly, the cat may be afraid. However, cats are explorers and love to wander. As they begin to find comfort in their new home, they will claim spots within the house by depositing their own scent. For this reason, the book unfolds in different directions. In the same manner, as the reader learns more about the characteristics of cats and their sense, the book will shift directions, see figure 37.

Figure 37: The unfolding of the cat guidebook

1 First Section

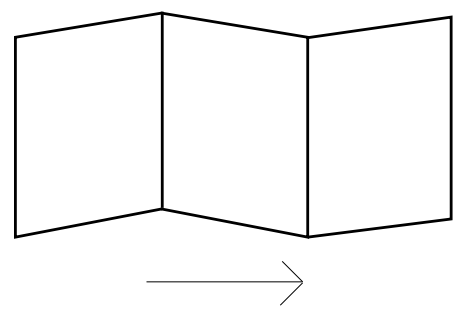

2 second section

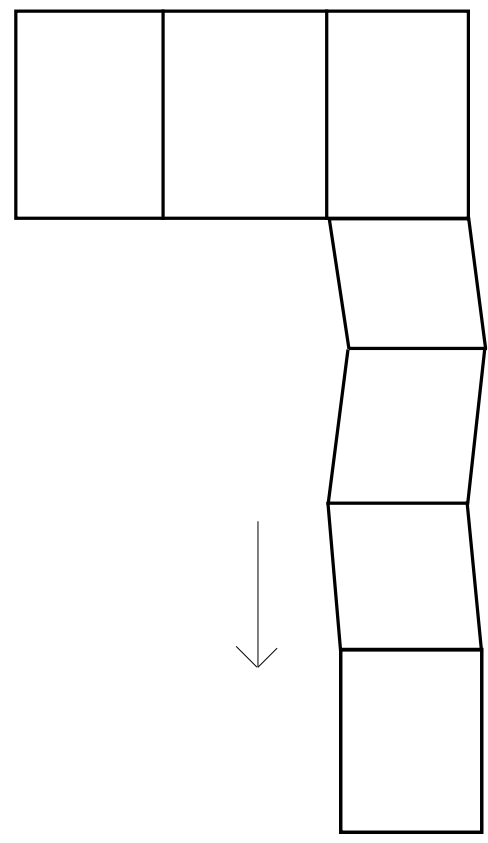

3 Third section

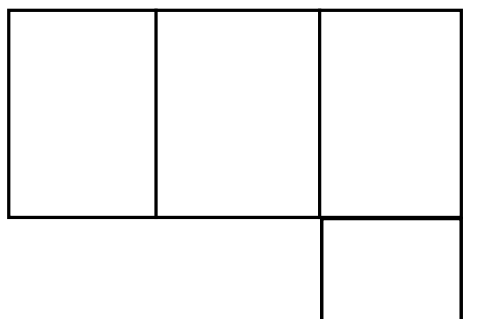

Reverse Side 


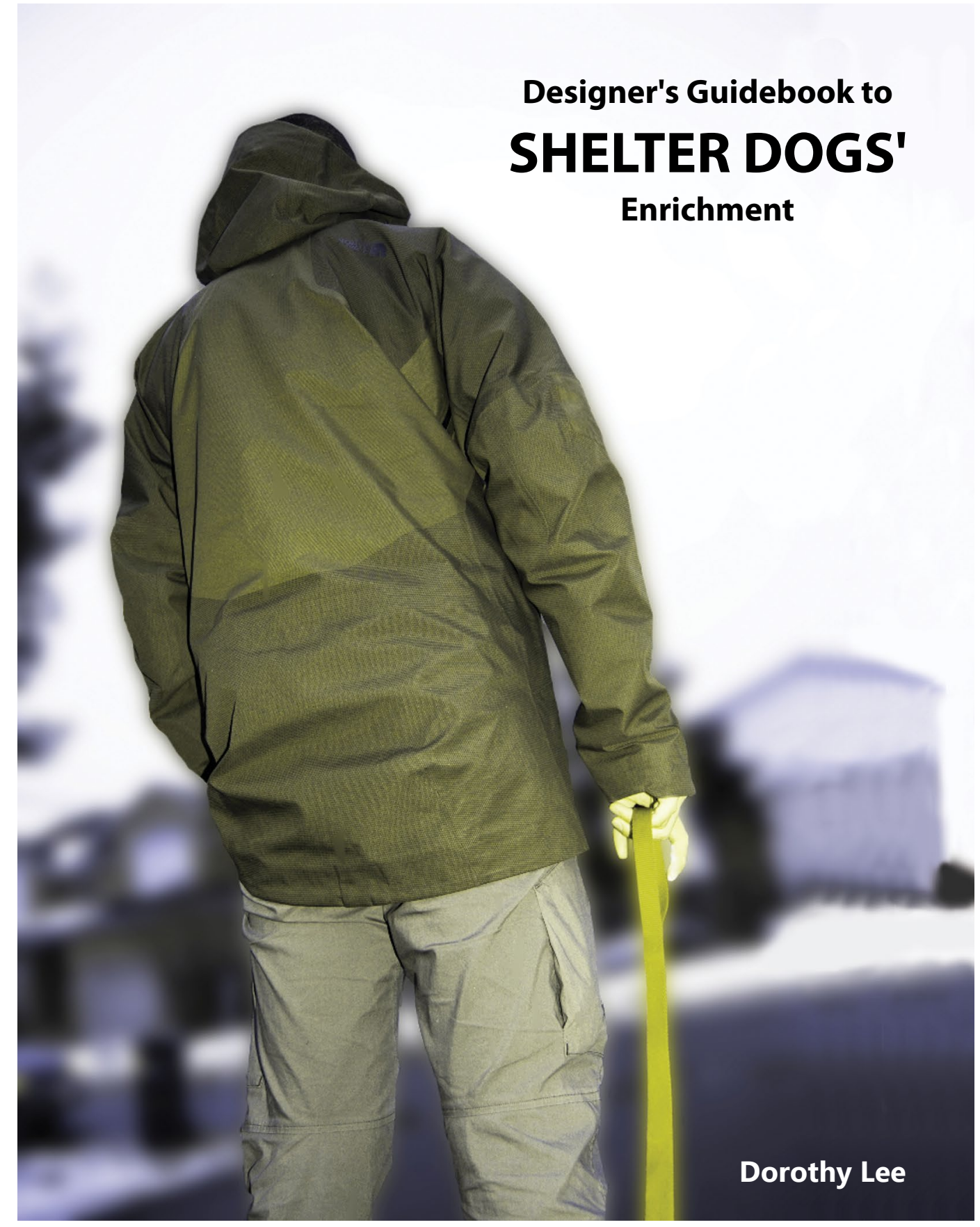




\section{A DOG'S SECURITY IS FOUND IN ITS OWNER.}

HIS MENTAL WELFARE HINGES ON YOU.
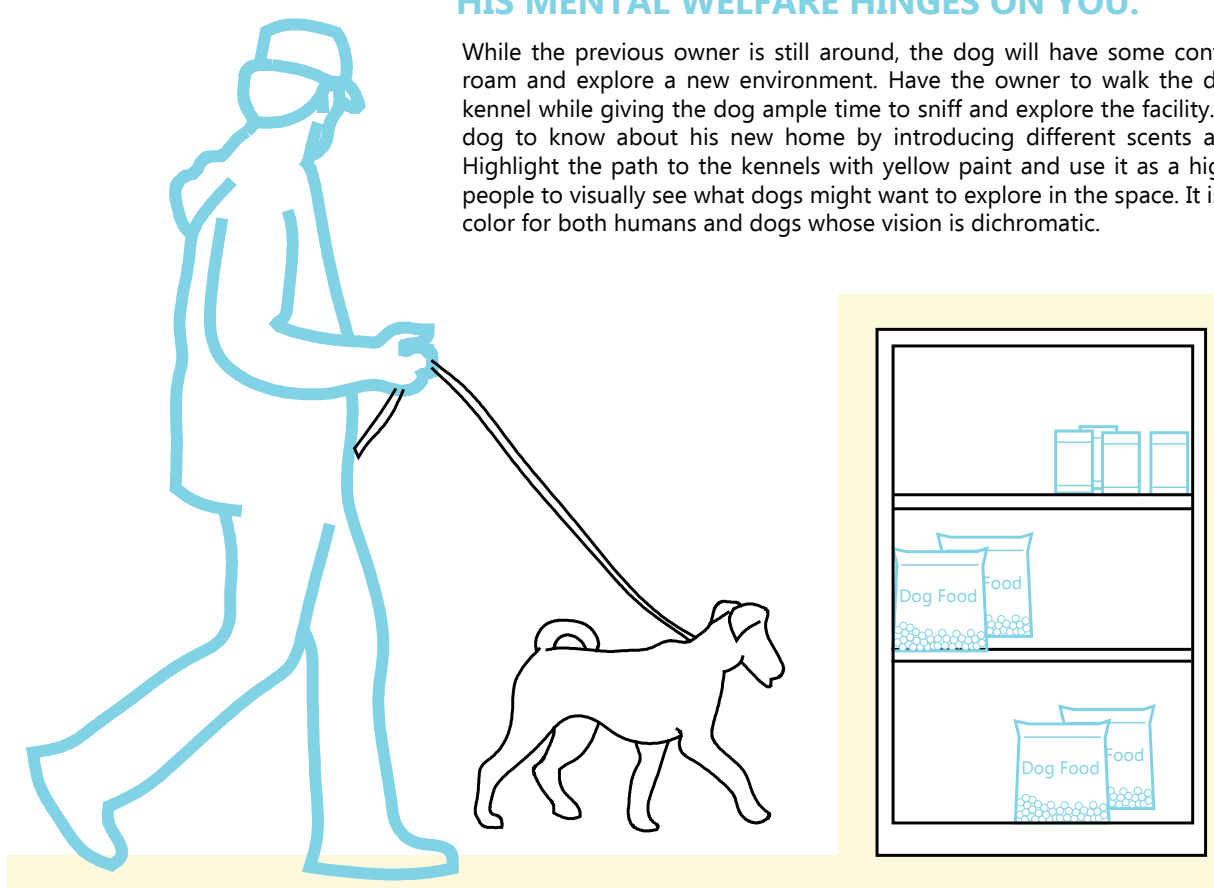


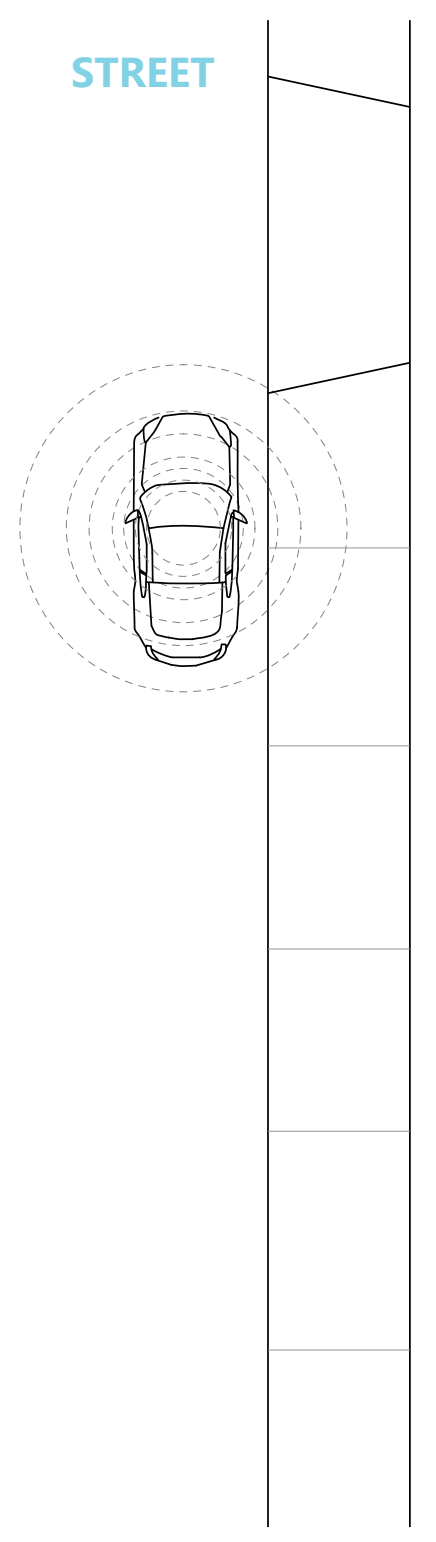

SIDE ENTRY
Move entry away
from noise of traffic
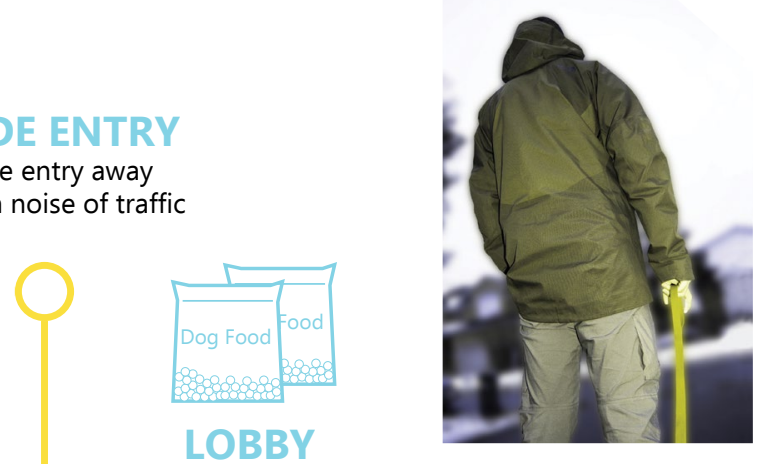

Sale dog food and treats at lobby

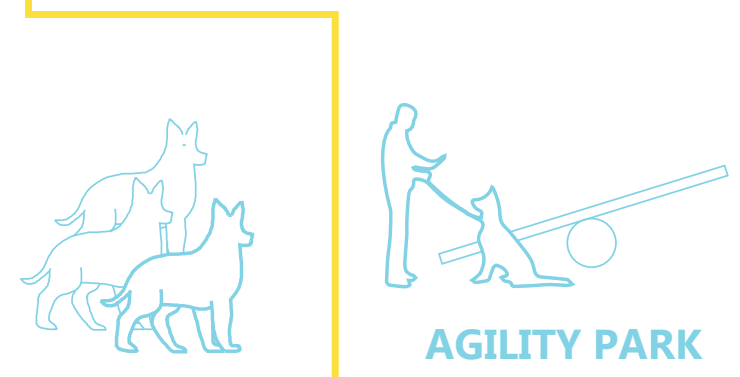

\section{OTHER}

\section{DOGS}

Allow the dog to sniff around for scents of other dogs

Allow the dog to sniff and see dogs playing at the agility park

\section{NEW DOGS KENNEL}
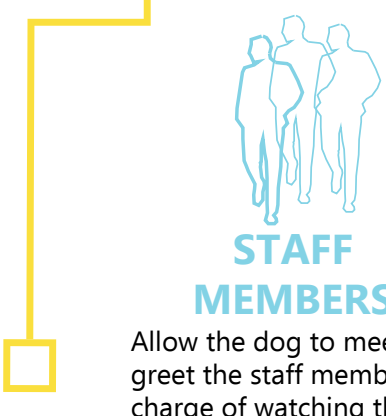

MEMBERS

Allow the dog to meet and greet the staff members in charge of watching the dog 
This guidebook is not an end product. It is meant to open discussion and begin the journey of discovering architecture that responds to the mental welfare of animals. With this in sight, the cooperation of the designer to push forward with continual research and experimentation will further aid the animals' well-being

\section{PLEDGE}

I, pledge to give each dog under my care my best effort into understanding both its physical and mental welfare. I acknowledge that this guidebook is complimentary to the welfare acts and by-laws of my city. In designing the kennels, I will incorporate design attributes for both physical and mental health.

I recognize that each dog is unique in its personality and will continually attempt to understand each dog individually to the best of my abilities. As I learn more about dogs through this guidebook research and through observation, I acknowledge that the rebuilding of trust is of the highest priority in terms of my relationship with the dogs in my care. 


\section{A DOG'S SENSE OF SECURITY AND \\ TRUST IS LOST BY THE \\ ABANDONMENT OF ITS OWNER}




\begin{tabular}{l} 
BENEFITS OF \\
STAFF PROXIMITY \\
- A dog's sense of security is on \\
its caretaker. Placing the bed \\
near the caretaker can ease \\
his tension. \\
- Minimal socialization for the \\
dog. \\
- Visual stimulation as the staff \\
moves around while working. \\
- Staffs are normally volunteers \\
who work based on their love \\
for animals. Allowing the staff \\
to be at close proximity to the \\
animals they work for \\
increases motivation, pride \\
and eases stress. \\
- Allowing for the staff to \\
interact with the dog allows \\
the staff to understand the \\
dog's personality better. This \\
will faciliate in choosing the \\
correct family for the dog. \\
\hline
\end{tabular}

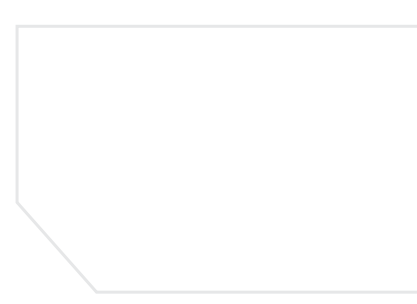

\section{KENNEL PLAN}

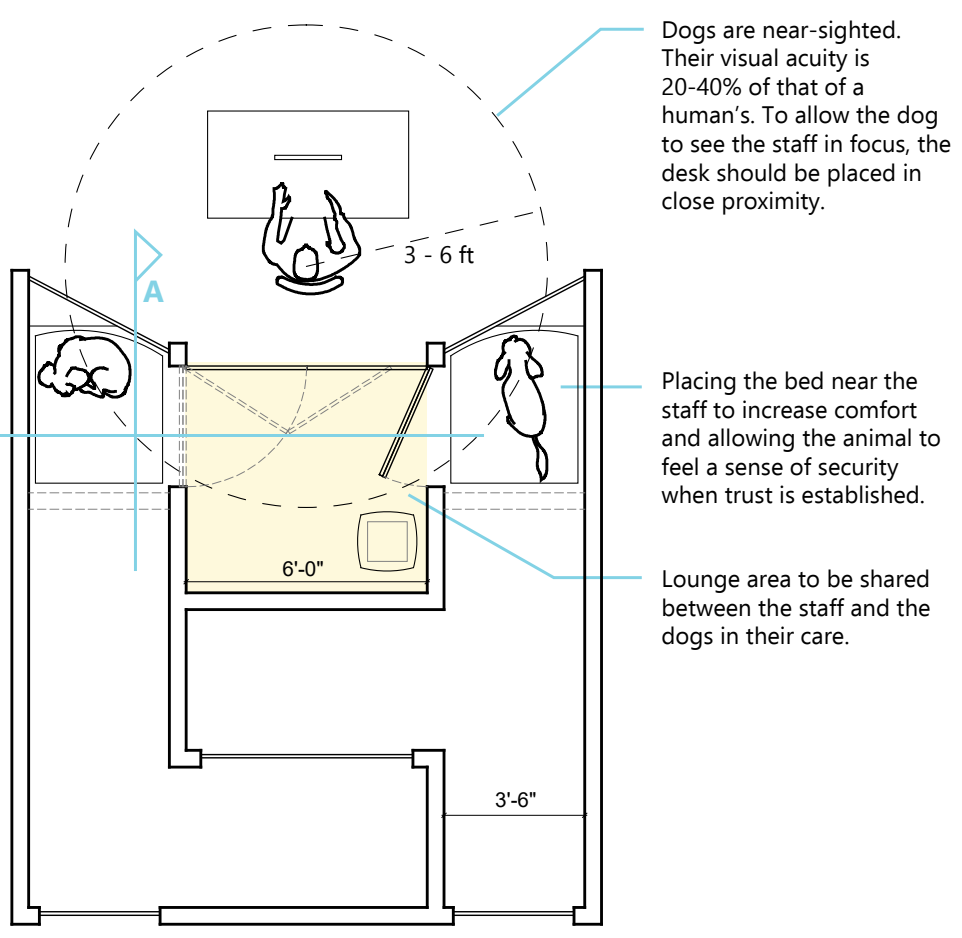

Scale: $3 / 16^{\prime \prime}=1^{\prime}-0^{\prime \prime}$ 


\section{PROXIMITY TO STAFF}
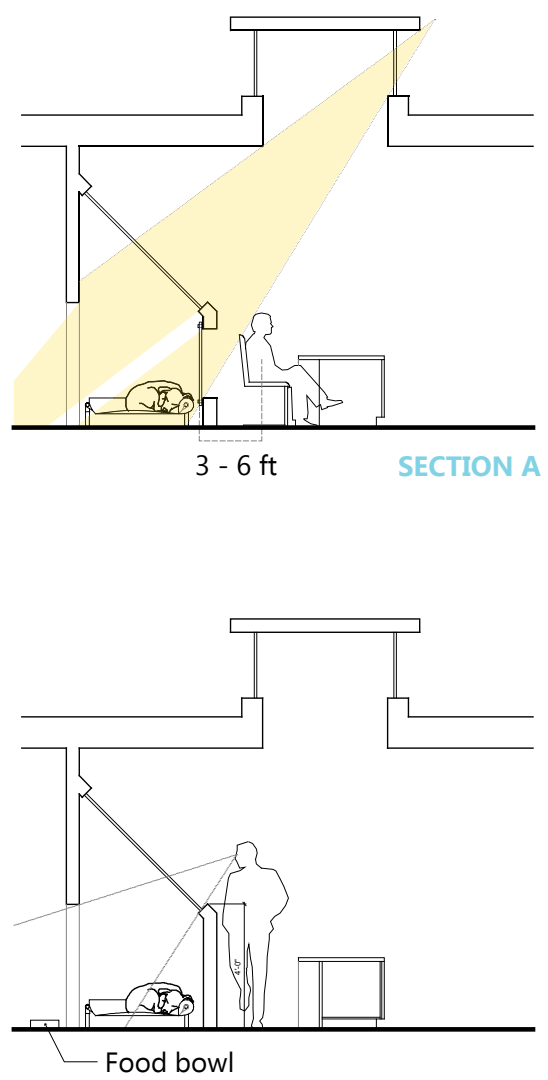

\section{STAFF-DOG SOCIALIZATION}

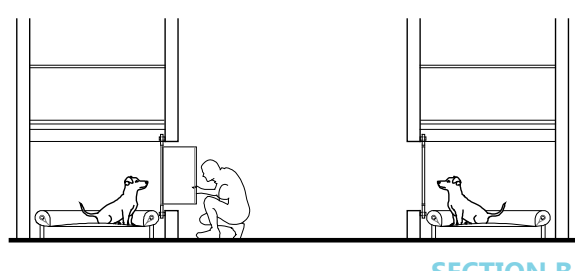

SECTION B

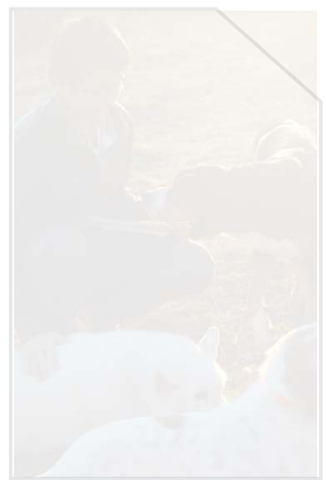

- Dog can only be seen by staff when standing up. Keeping the proximity of the staff worker can help the dog learn to trust humans again (even if only just one person) and yet allowing for the sense of privacy required by aggressive dogs by removing the bottom window.

- Place their food bowl close to the bed to allow the dog a sense of control over his environment and belongings

Scale: $1 / 8^{\prime \prime}=1^{\prime}-0^{\prime \prime}$

- Allow for a lounge space for the dog and staff to socialize

- Two friendly dogs can share this lounge space simultaneously to allow for more socialization - which is critical to a dog's welfare.

- Lower the door between the lounge and the kennel. A kneeling staff is less aggressive to the dog than a standing one. 


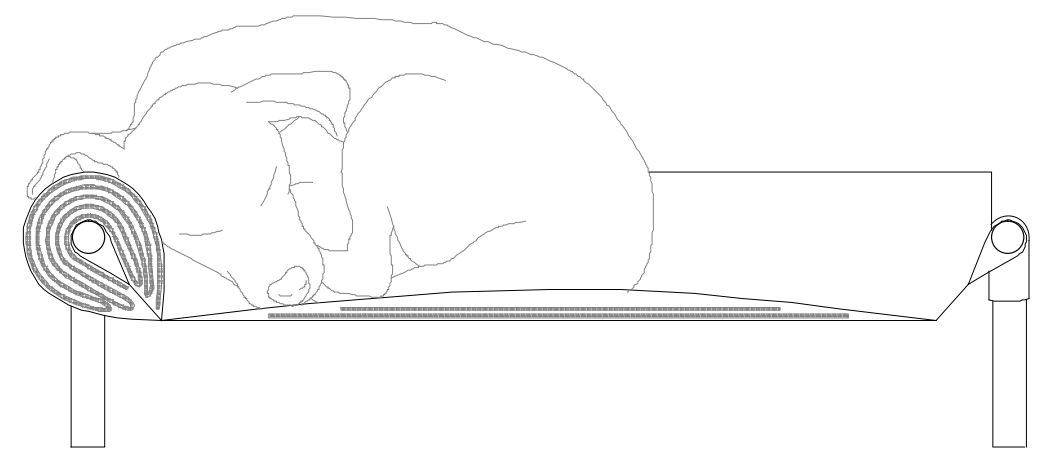

REDESIGNING THE BED FOR THE DOG'S COMFORT 

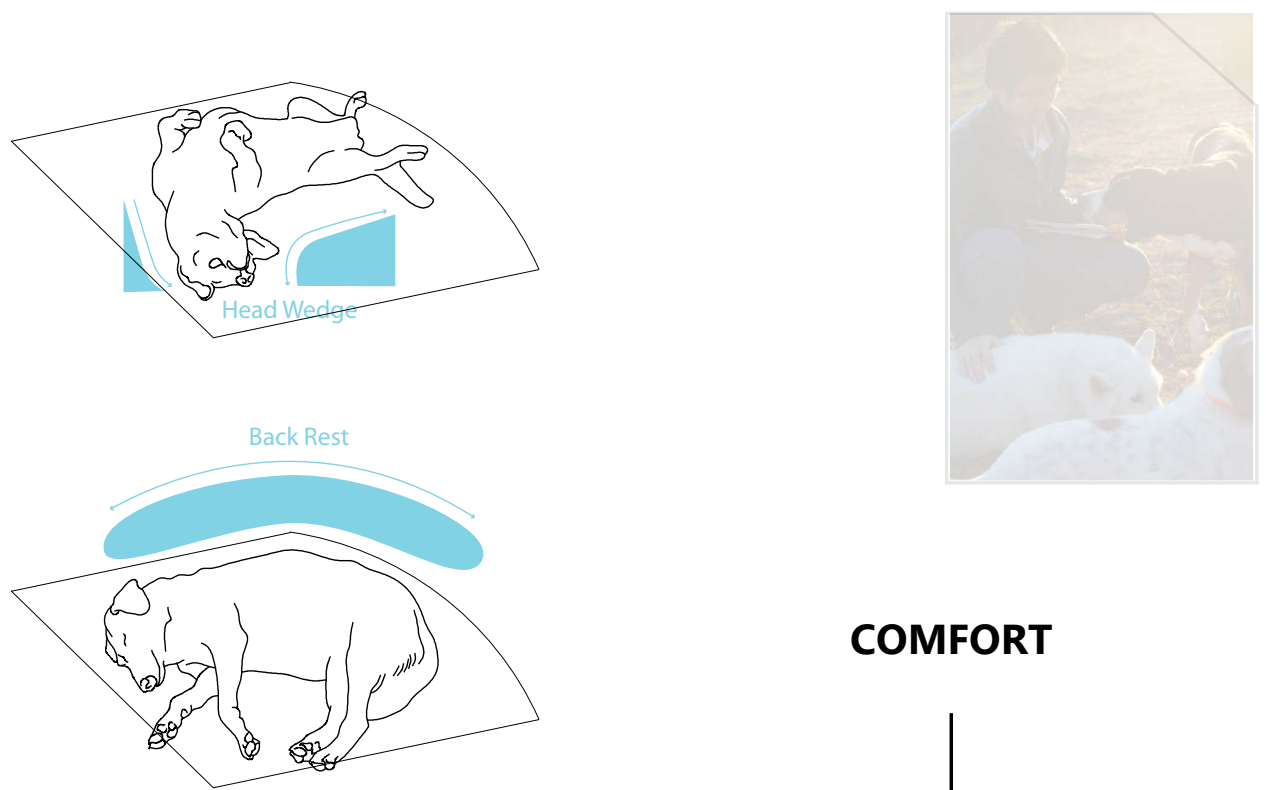

\section{COMFORT}
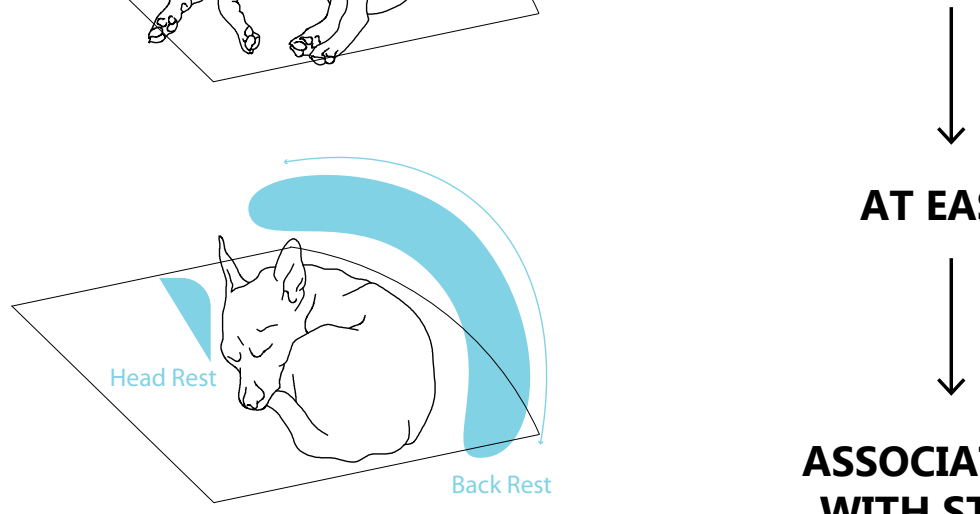

AT EASE
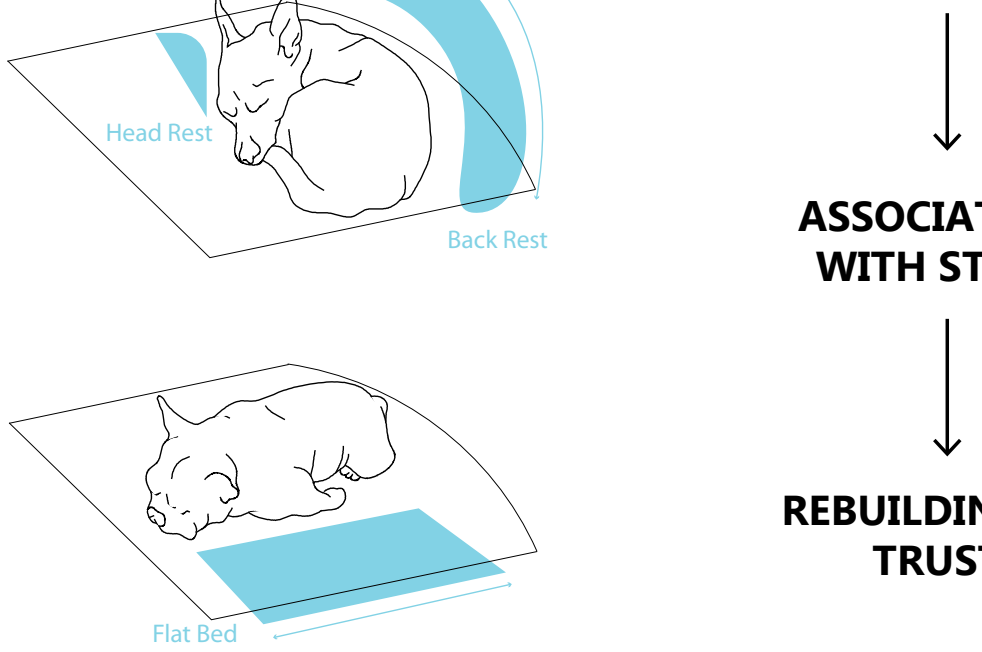

ASSOCIATION

WITH STAFF

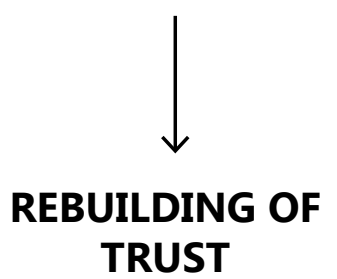


STEP 1

- Fold fabric B 1" from the edge along the

dashed line.

- Fold again 3

inches from the

last fold, along

the dashed line

and sew
STEP 2

- Fold fabric A 1"

from the edge

along the

dotted line.

- Insert fabric B

between fabric $A$

and sew along

the dotted line

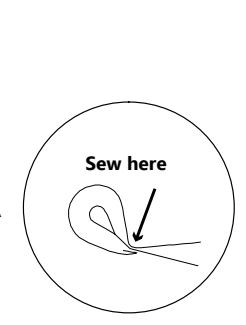

STEP 3

- Insert PVC pipes into the fabric

- Fold and slip a closed-cell yoga mat into the

fabric

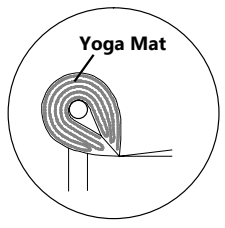




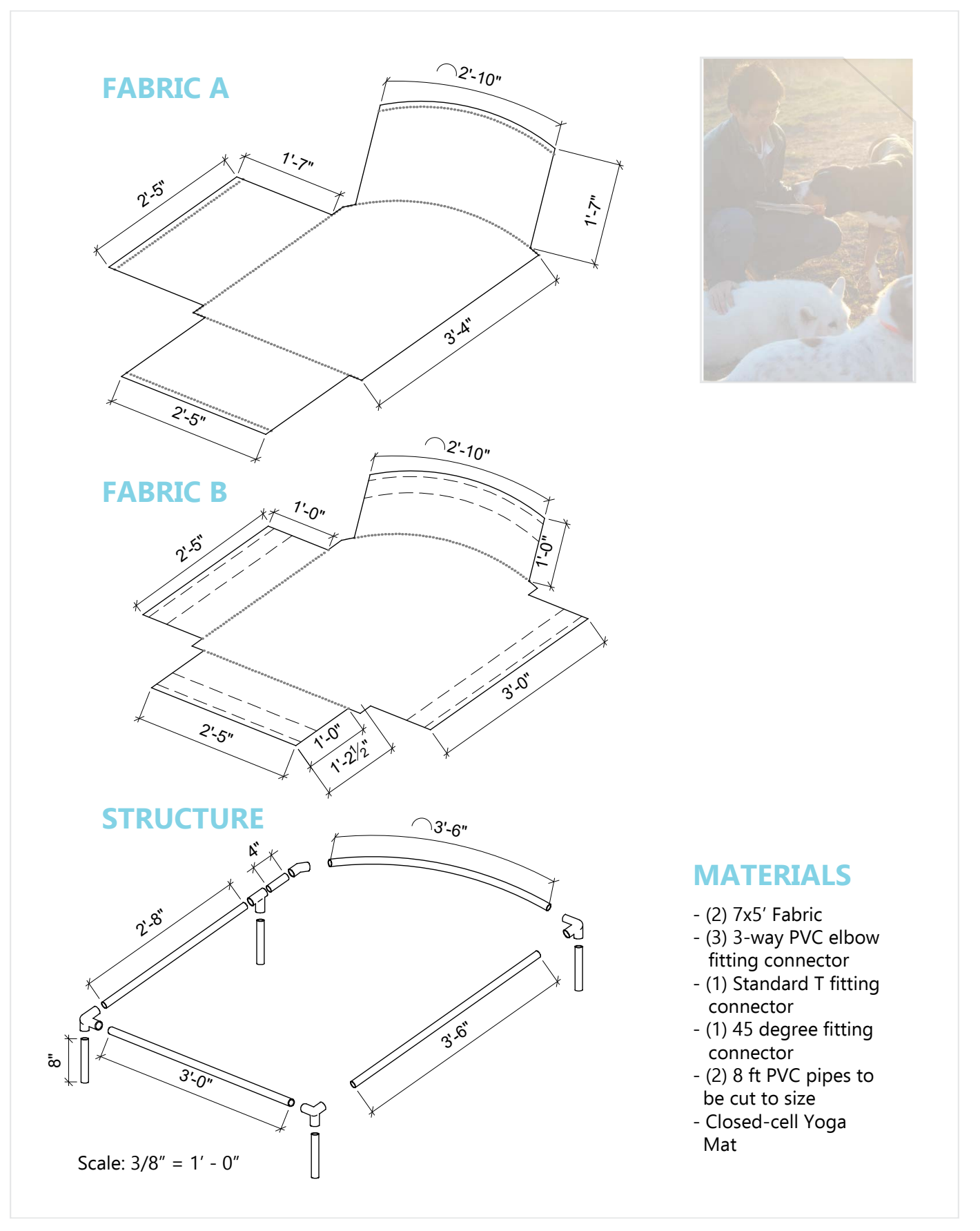




\section{BENEFITS OF A COMPANION DOG}

- Staff members are typically busy and with the

overwhelming number of shelter animals, dogs are often left alone for long hours.

Introducing a companion dog will allow for the much

needed socialization of a dog. - Dogs learn from one another. Matching a senior dog with a naughty younger dog allows for the correction of behaviour. - Removes an isolation of scent in typical kennels by allowing the dog to smell the

companion dog.

- Giving opportunity to dogs to socialize allowing for the possibility to adopt from families who have multiple animals.

\section{IMITATING THE FENCE}
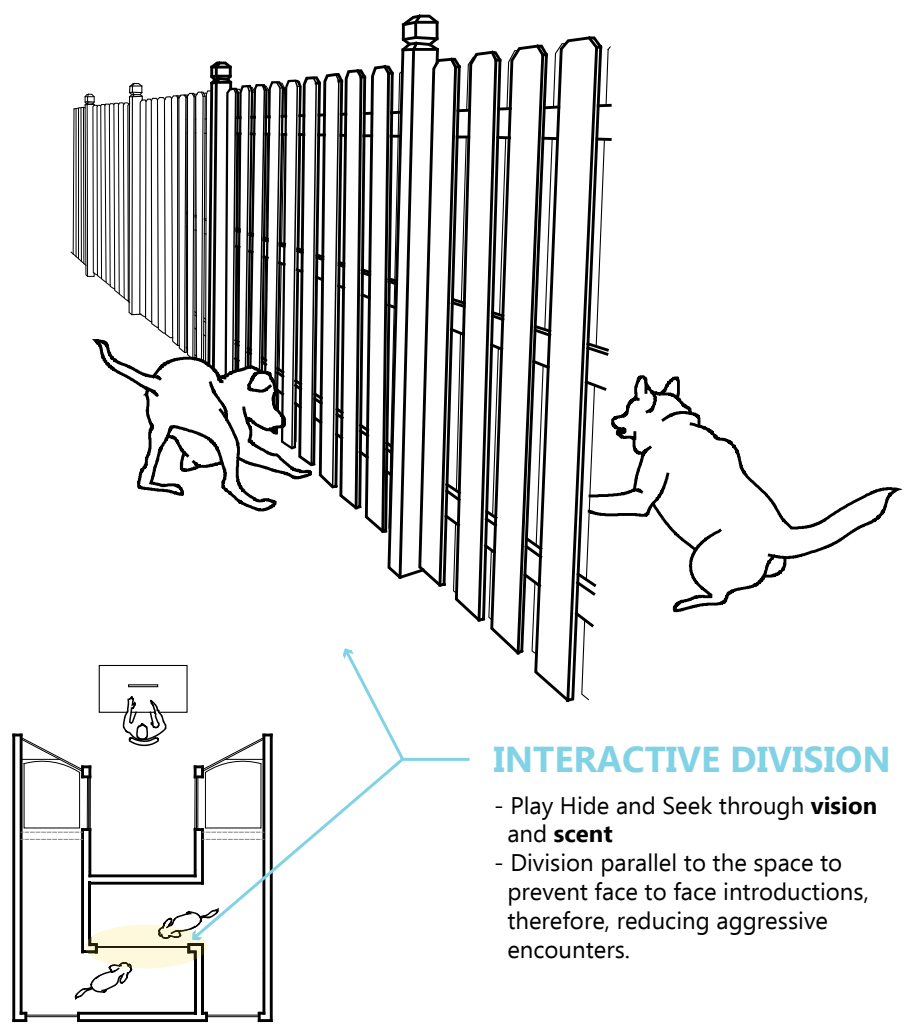

INTERACTIVE DIVISION

- Play Hide and Seek through vision and scent

- Division parallel to the space to prevent face to face introductions, therefore, reducing aggressive encounters. 


\section{HIDE AND SEEK}
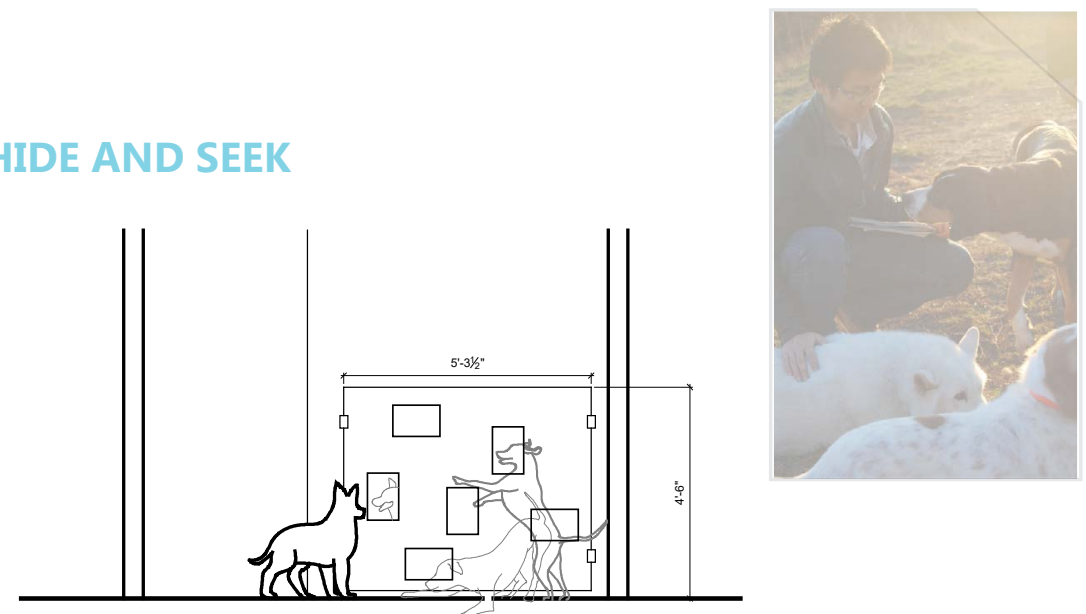

Scale: $3 / 16^{\prime \prime}=1^{\prime}-0^{\prime \prime}$

\section{PLAY OF VISION AND SCENT}

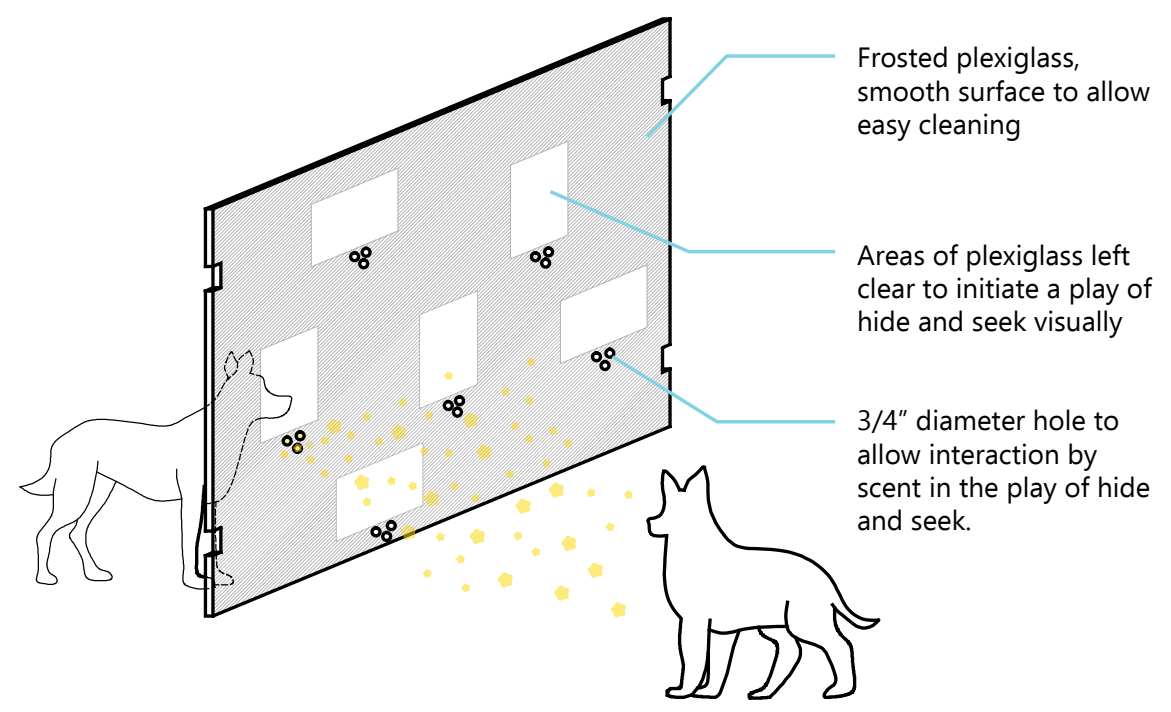




BENEFITS OF A
HUMAN-DOG
SOCIAL SPACES
- Staff members are typically
busy. Allowing visitors to
interact with the dog gives the
dog the socialization it needs
and increases the chance of
adoption.
- Visitors who does not have a
flexible schedule to commit as a
volunteers are given the
opportunity to help.
- Play, training and socialization
will increase the dog's positive
emotions and stimulate both its
physical and mental states. Just
like humans, dogs need puzzles
to solve to avoid boredom and
exercise to stay healthy.
- Allowing for more interaction,
more people would stick around,
resulting in a community that is
aware of the shelter's needs.

aware of the shelter's needs.

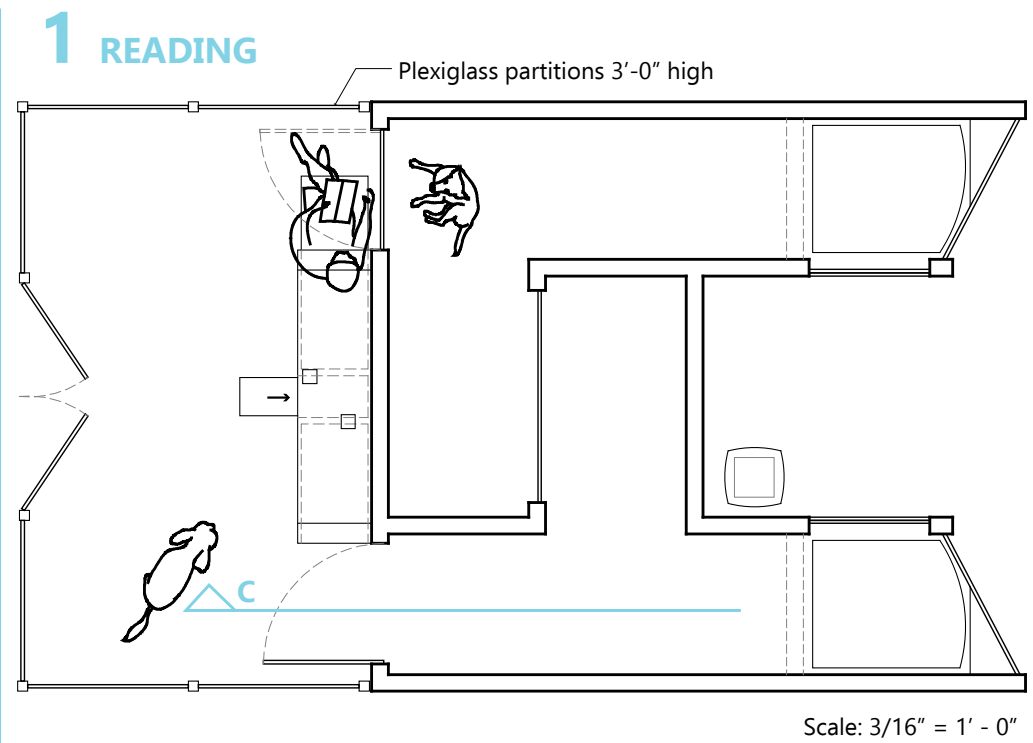

TYPES OF ACTIVITIES:

1. READING: Dogs have a preference for calm and composed individuals. Reading allows for a relaxing setting to socialize between the visitor and the dog.

2. AGILITY AND OBEDIENCE TRAINING: Dogs are smart and require both physical and mental stimulation. Training and play allows for both to be obtained.

3. SCAVENGER HUNT FOR TREATS: Dog's main sense to understanding space is scent (versus humans whose main sense is vision). Stimulating their sense of smell by hiding treats in the furniture is a fun challenge and game for the dog.

4. BALL TOSS: Ball tossing allows the visitor to interact with the dog without needing supervision from the busy volunteers. 
2 AGILITY AND OBEDIENCE TRAINING

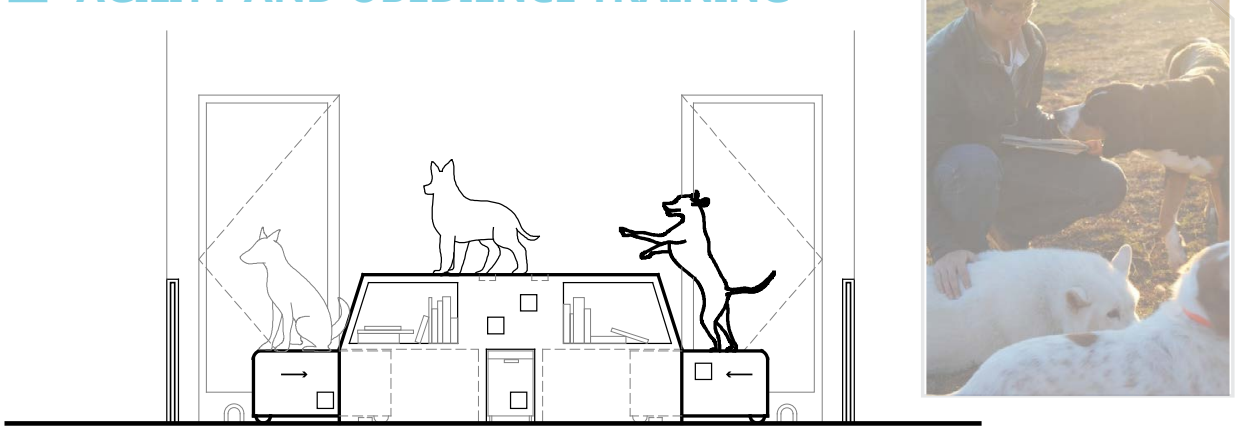

3 scavengr RuNT ror rears
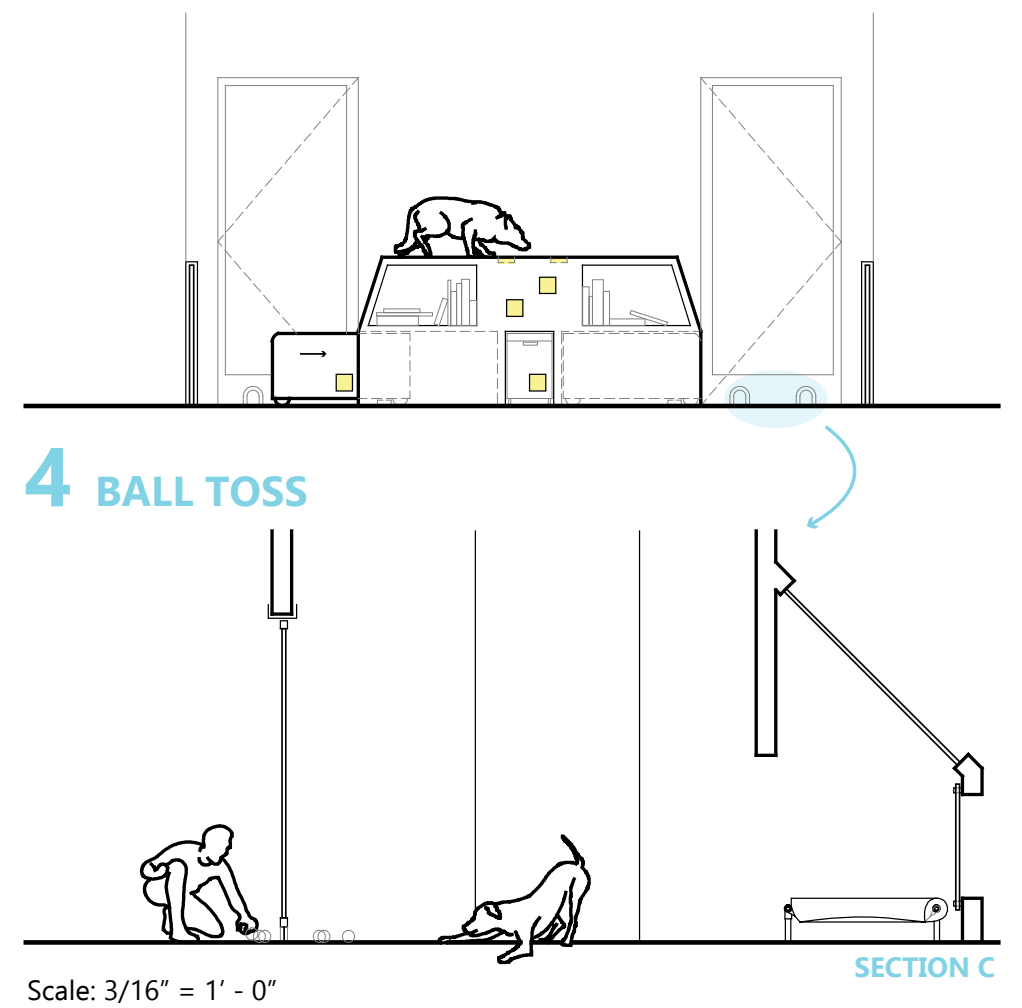
HOW DOES THE KENNEL DESIGN HELP MENTAL WELFARE?

BY INCREASING POSITIVE EMOTIONS SUCH AS COMFORT, SAFETY AND CURIOSITY. THIS IS DONE BY STIMULATING THE SENSES
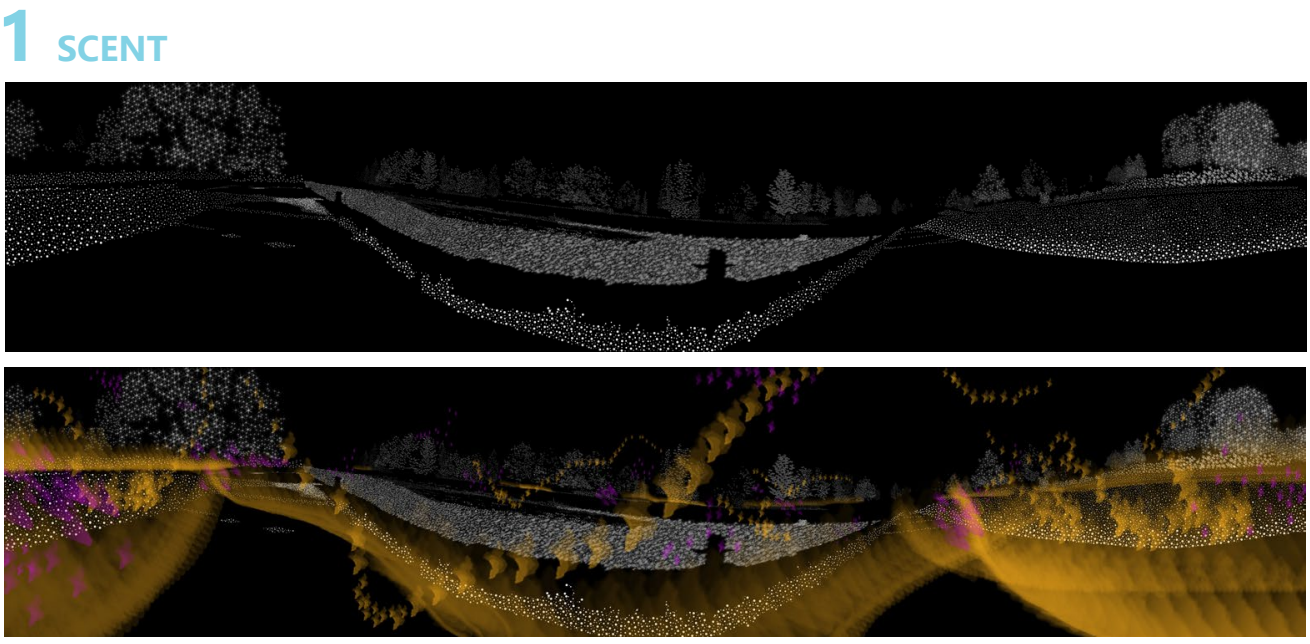

Top Image: Drawing of a dog's understanding of a space through smell. Their ability to smell is more mature than that of a human being. Each element in the drawing has a specific shape, representing the dog's capacity to differentiate and locate each object.

Bottom Image: Dogs also has the capacity to smell things that have occured in the past (represented in yellow) and things that are to come in the future (represented in pink). A dog's understanding is richer than our own. Dogs can track and predict what the wind is carrying in its direction. 

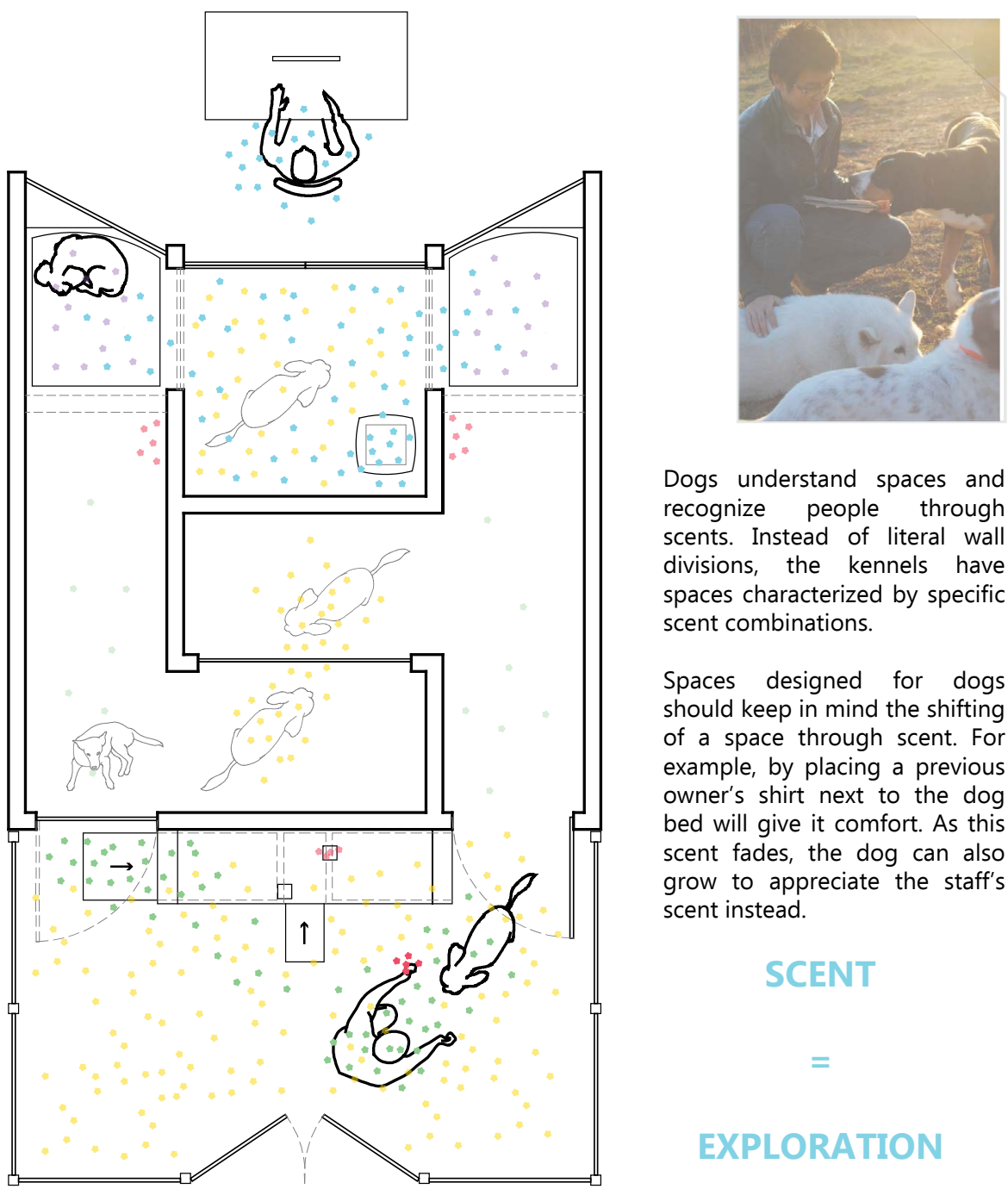

Dogs understand spaces and recognize people through scents. Instead of literal wall divisions, the kennels have spaces characterized by specific scent combinations.

Spaces designed for dogs should keep in mind the shifting of a space through scent. For example, by placing a previous owner's shirt next to the dog bed will give it comfort. As this scent fades, the dog can also grow to appreciate the staff's scent instead.

\section{SCENT}

$=$

\section{EXPLORATION}

PREVIOUS OWNER: STAFF MEMBER: COMPANION DOG:

FOOD:

VISITOR:

VISITOR FROM BALL:
Item from previous owner enhancing the feeling of safety Scent to replace the pervious owner's scent as it fades away Presence of a consistant companion in all social areas Enticing and exciting scent New scent

New scent entering kennel, allowing the dog to learn how to be friendly with people without being invasive 


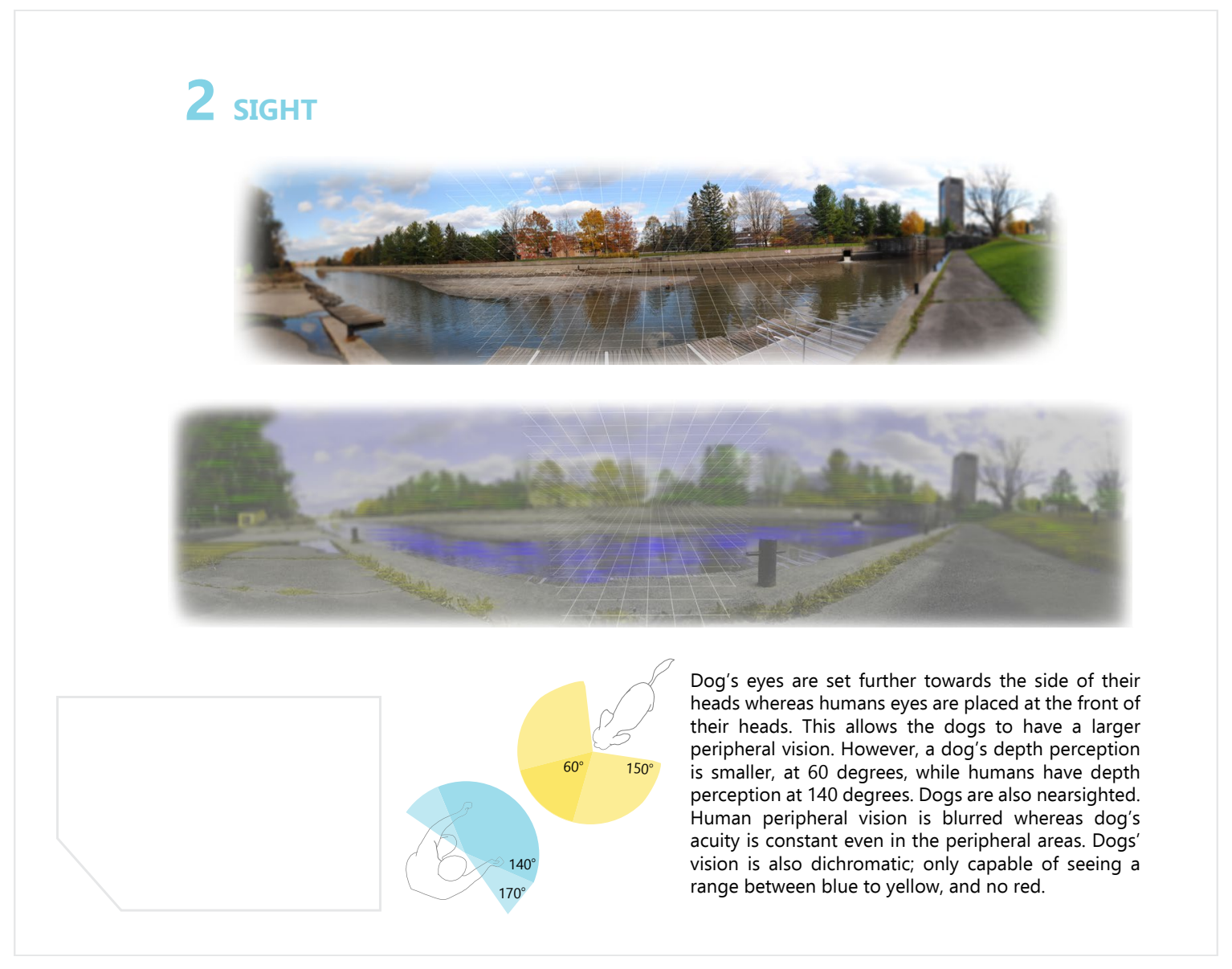



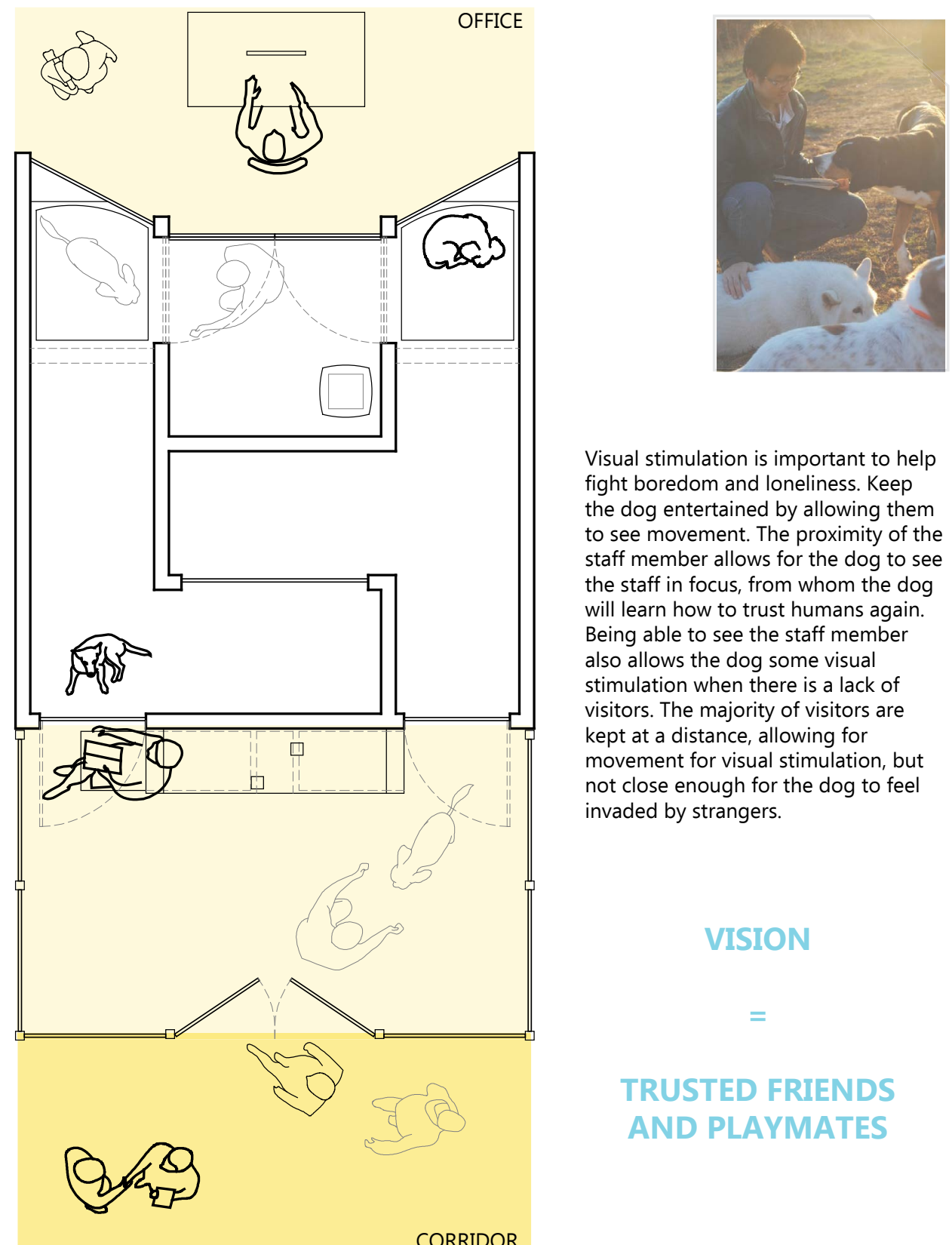

Visual stimulation is important to help fight boredom and loneliness. Keep the dog entertained by allowing them to see movement. The proximity of the staff member allows for the dog to see the staff in focus, from whom the dog will learn how to trust humans again. Being able to see the staff member also allows the dog some visual stimulation when there is a lack of visitors. The majority of visitors are kept at a distance, allowing for movement for visual stimulation, but not close enough for the dog to feel invaded by strangers.

\section{VISION}

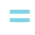

TRUSTED FRIENDS AND PLAYMATES 

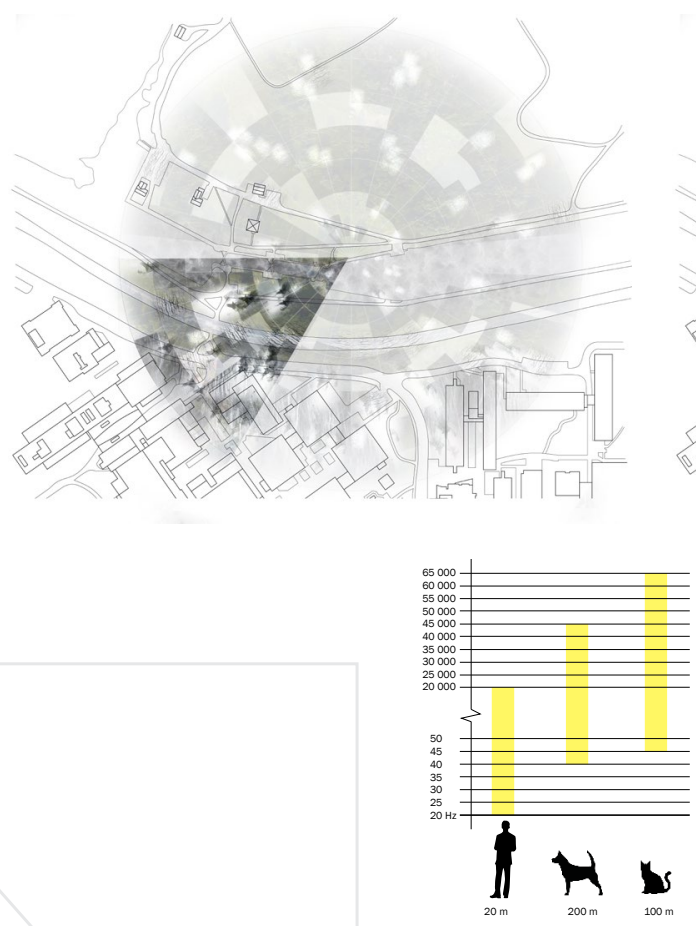

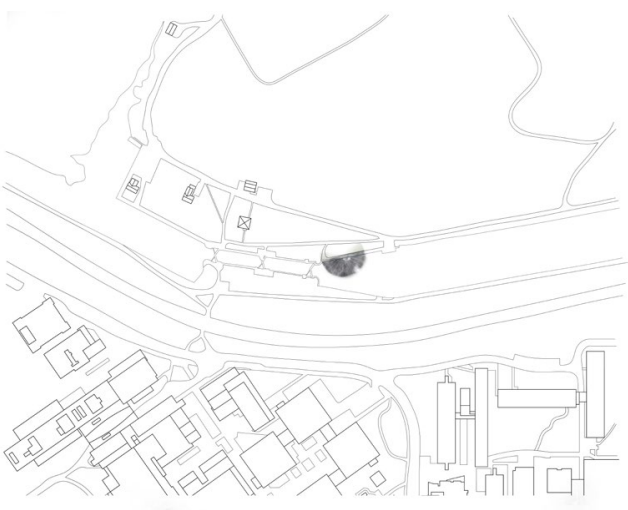

A dog's hearing is more sensitive than that of humans. Not only are they capable of hearing higher frequency by $20000 \mathrm{~Hz}$ compared to that of human hearing, but they can also hear from a farther distance. On average, humans can have a hearing range of $20 \mathrm{~m}$. Dogs can hear $200 \mathrm{~m}$ away. In addition to their extensive ear muscles, dogs can turn their ears to pin point and amplify the sound without turning their heads.

In designing a kennel for dogs, it is important to design peaceful rooms in which dogs are not overloaded with noise pollution. This does not mean dead quiet rooms but a much more hushed environment. 

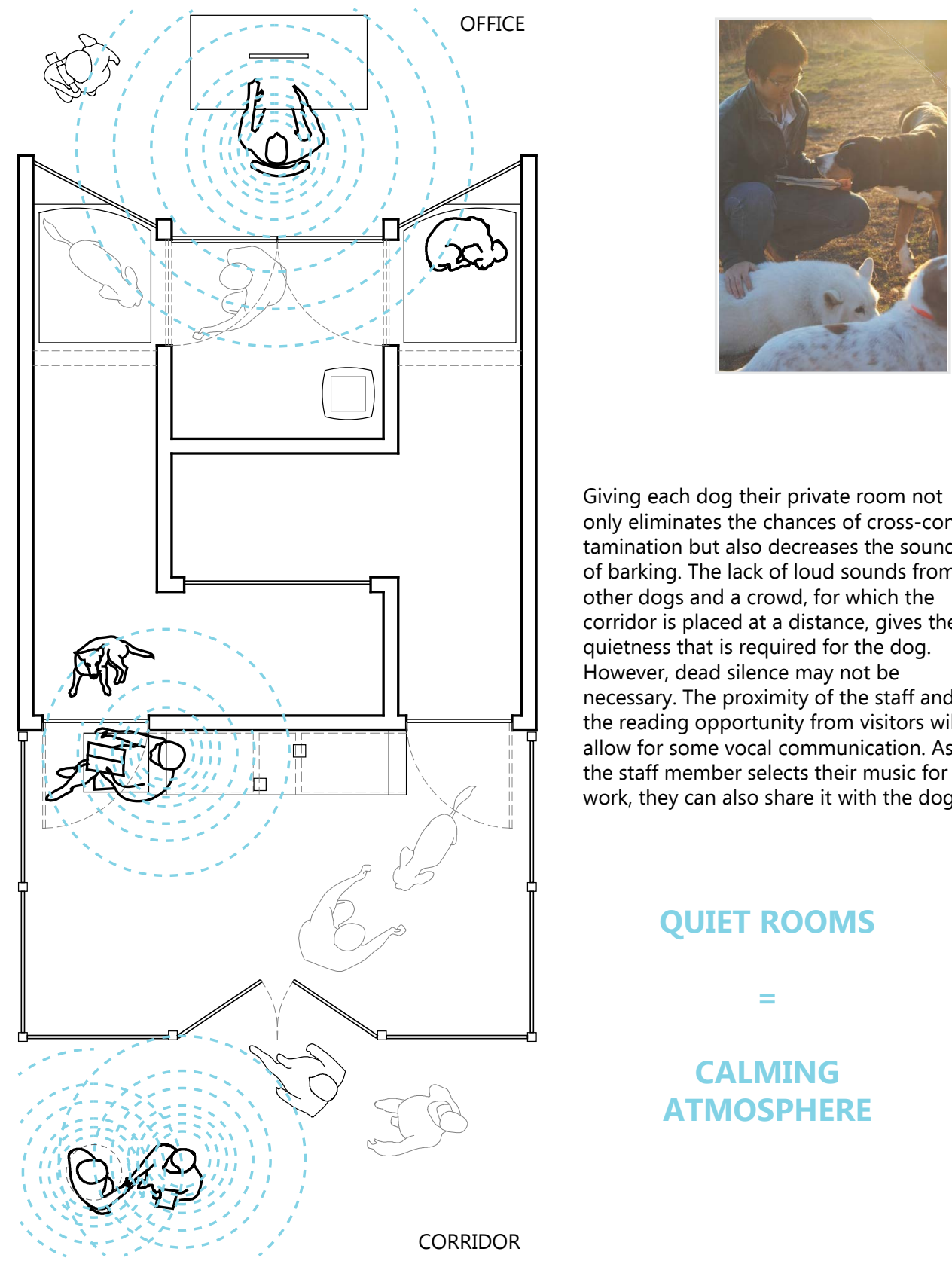

Giving each dog their private room not only eliminates the chances of cross-contamination but also decreases the sounds of barking. The lack of loud sounds from other dogs and a crowd, for which the corridor is placed at a distance, gives the quietness that is required for the dog. However, dead silence may not be necessary. The proximity of the staff and the reading opportunity from visitors will allow for some vocal communication. As the staff member selects their music for work, they can also share it with the dog.

QUIET ROOMS $=$

CALMING ATMOSPHERE 


\section{EXAMPLE CIRCULATION}

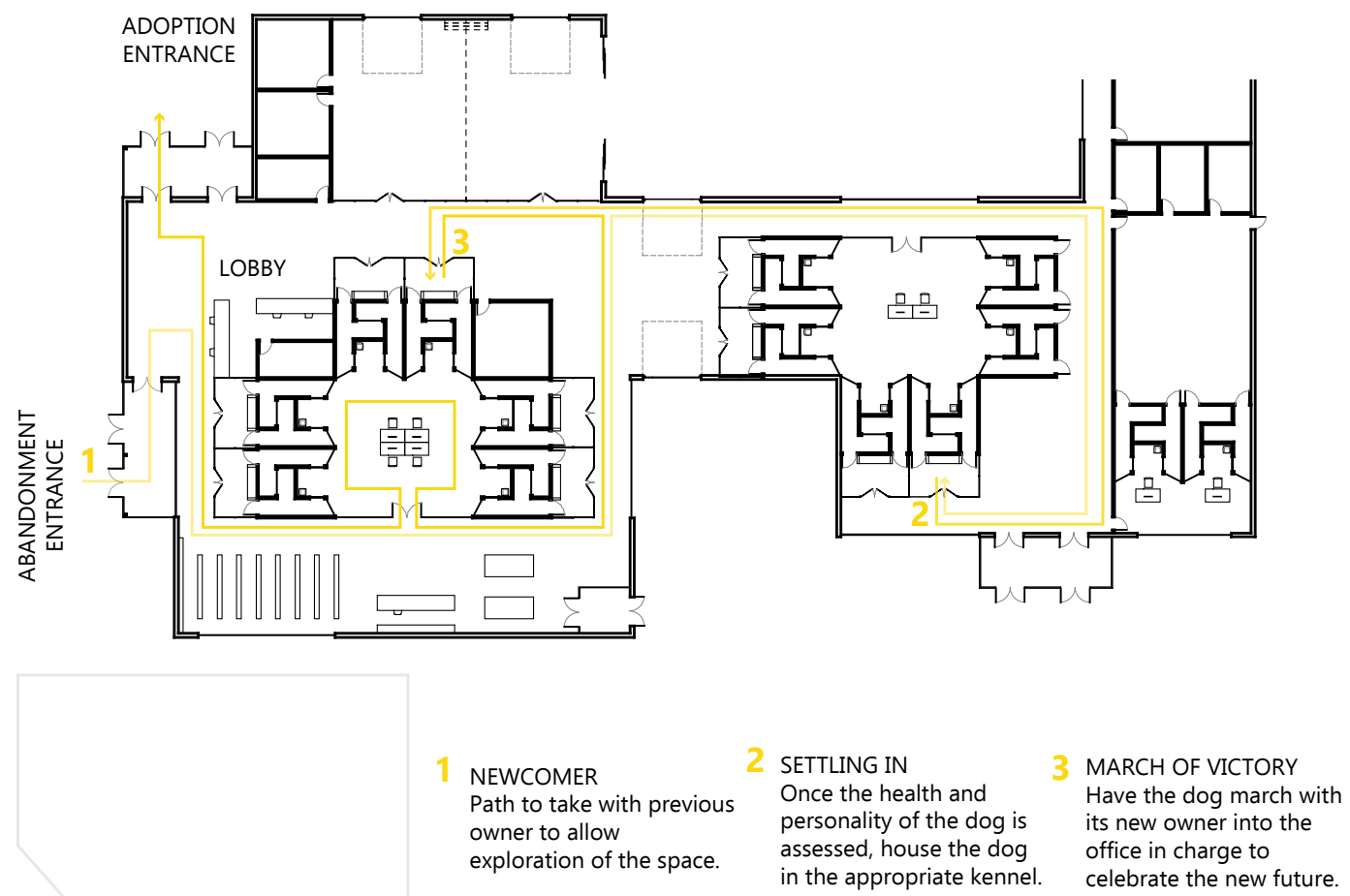




\section{EXAMPLE LAYOUT: TYPES OF DOGS}

A FRIENDLY DOGS

These dogs love to socialize. Place them in the front to welcome new visitors.

B ACTIVE DOGS Active dogs need space to run around often. Placing them near the indoor agility playground gives them ample room to play and train all year round. Can be replaced by friendly dogs.

C AGGRESSIVE DOGS These dogs need isolation to feel safe. Place them furthest away from the commotion of the entrance. New dogs should be placed here too so that staff members can get to know the dog's behaviours before any socialization.

SICK DOGS

Sick dogs need isolation and constant supervision. Keep them separate from the rest of the dogs and in quiet areas. Place the surgery rooms between the mech. room and the kennels to keep the

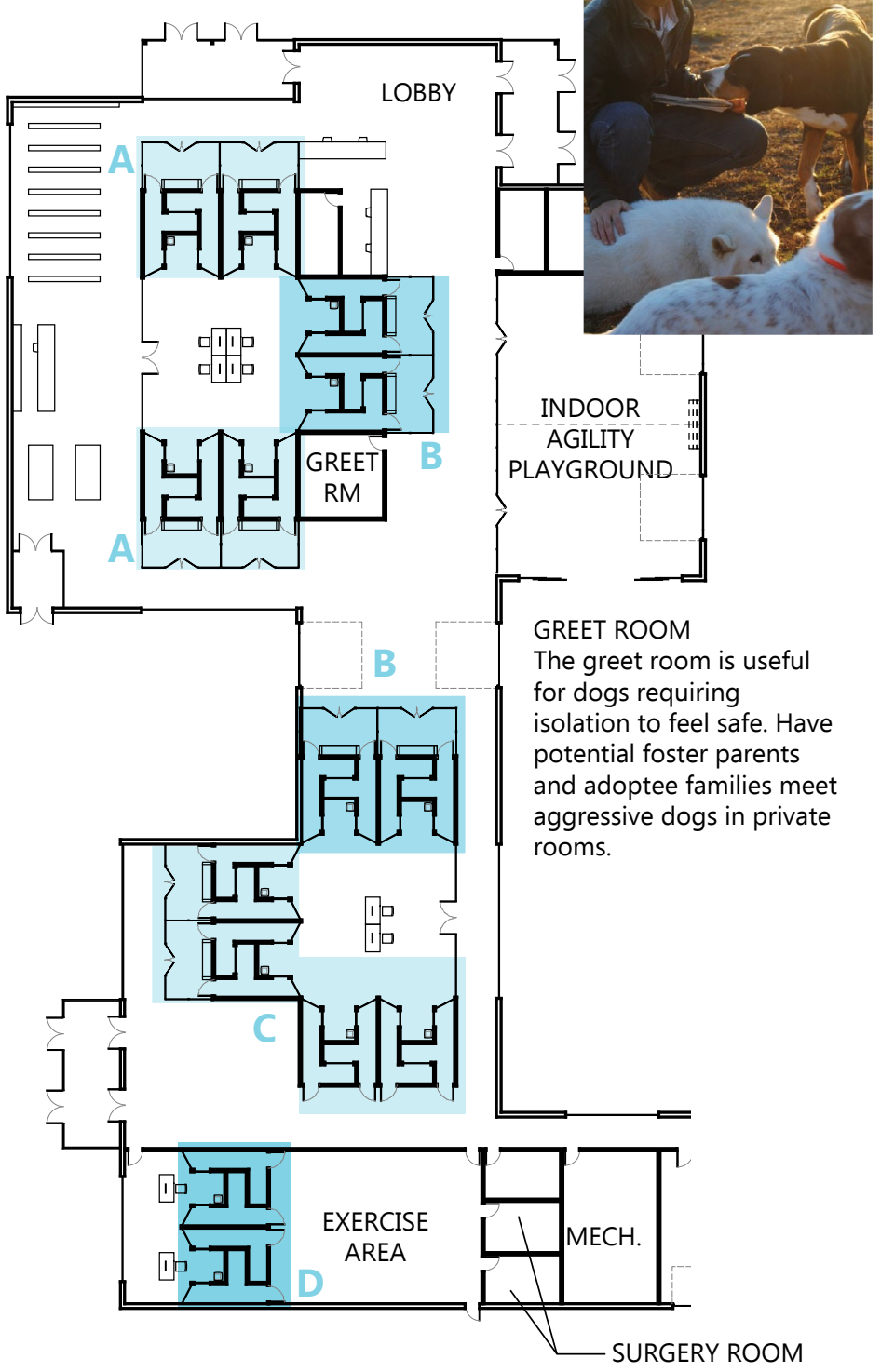
noise level down. 


\section{PUBLIC AWARENESS}

Dogs require socialization and with the staff occupied with running the facility, this need is often left unfulfilled. By combining the facility with public programs, dogs are able to socialize with visitors and simulateneously the public becomes aware of the facility's needs. In addition to the human-dog interaction furniture at each kennel, additional programs will draw public into the facility and allow them to linger.

DOG AGILITY PARK

The agility park is critical for the shelter dogs to exercise but some of these agility park can be open to public. This allows current dog owners to visit the facility without leaving their own dogs at home.

Having multiple agility parks also allows the shelter dogs to have novelty and excitement. Dogs love to explore and try new equipement.

MARKET + STORE

Shopping center are excellent ways of drawing the public to the facility. It is also a good opportunity to educate owners of appropriate toys, equipements and food for their pets.

GREET ROOM

The greet room is often used for potential adopters but the room can also be used as an animal therapy session

CHILDREN'S PARK

A park allows parents to bring their children and linger around the facility. Often the facility is used only when families want to adopt but by creating a park, families that cannot afford to buy a pet can also aid in socializing with the animals.

MULTIPURPOSE ROOM

Look around the site. Often pairing the facility with another complementary program is both beneficial to the animals and people. Optional programs can be:

1. Nail trimming services

2. Indoor agility park for shelter animals and for obedience training for existing owners

3. Birthday party / event venue

EDUCATION CENTER

Allowing for school field trips and other educational events

Looking around the facility's site can give ideas to programs that are complimentary. Benefits can be reaped not only for the animals but for people as well, such as fighting loneliness for elderly and de-stressing among students. Here are some ideas:

1. Schools:

2. Elderly Homes:

3. Public Parks:

4. Disabilities School:

5. Veterinary Clinic:

6. Restaurant landscape

7. Homeless with Pets:
Café, therapy, de-stressing event during exams, volunteering, animal yoga, education center Café, reading to the animals

Dog park, education center, fundraiser, café, animal care services, obedience class

Therapy, education center, reading to the animals

Education center, animal services, bring your own dog café, dog park, obedience class

Café + Desserts, dog park

Homeless Shelter, Soup kitchen for people and pets 


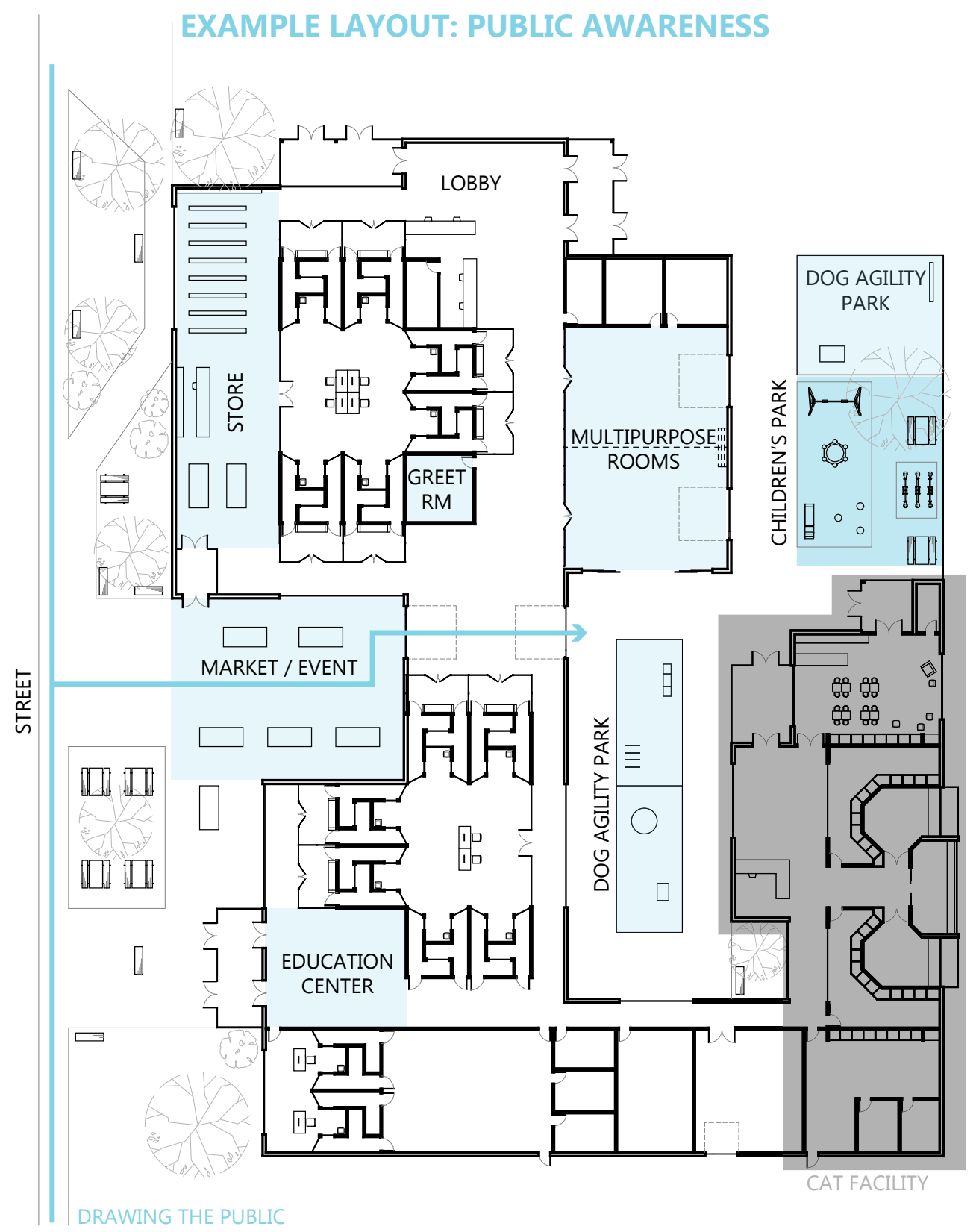




\section{DESIGN ALTERNATIVES}

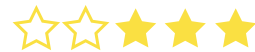

PREFERABLE MEDIUM KENNEL (M):

$\square$ Non-porous material

Drain in each kennel

Large windows for visitors to see and interact with the dog

Hiding spot with bed for aggressive dogs

$\square$ Each dog has their own seperate rooms that muffles barks and other unwanted sounds

Platform or a turn in the kennel to allow exploration of spaces through smell

Dog companion window division

Back window for visual stimulation

\section{$\hat{y} \hat{N} \hat{N} \hat{N}$}

IDEAL LARGE KENNEL (L):

Non-porous material

Drain in each kennel

Hiding spot with bed for aggressive dogs

Each dog has their own seperate rooms that muffles barks and other unwanted sounds

Platform or a turn in the kennel to allow exploration of spaces through smell

Dog companion window division

Interactive door and furniture for play between dog and visitors

Windows on both ends of the kennel

Front: towards visitors and

social areas for visual

stimulation

Back: Towards staff for

rebuilding of trust

\section{CAUTION}

It is important to note that although a smaller cage is possible, a small kennel requires more time for the animal to roam outside its cage. This means longer runs at the agility park or longer walks. Spread out the walks and exercises throughtout the day so that the animal is not enclose for more than 6 hours. 


\section{KENNEL DESIGN ALTERNATIVE (M)}

Min. dimensions: $4^{\prime} \times 8^{\prime} \times 6^{\prime}$

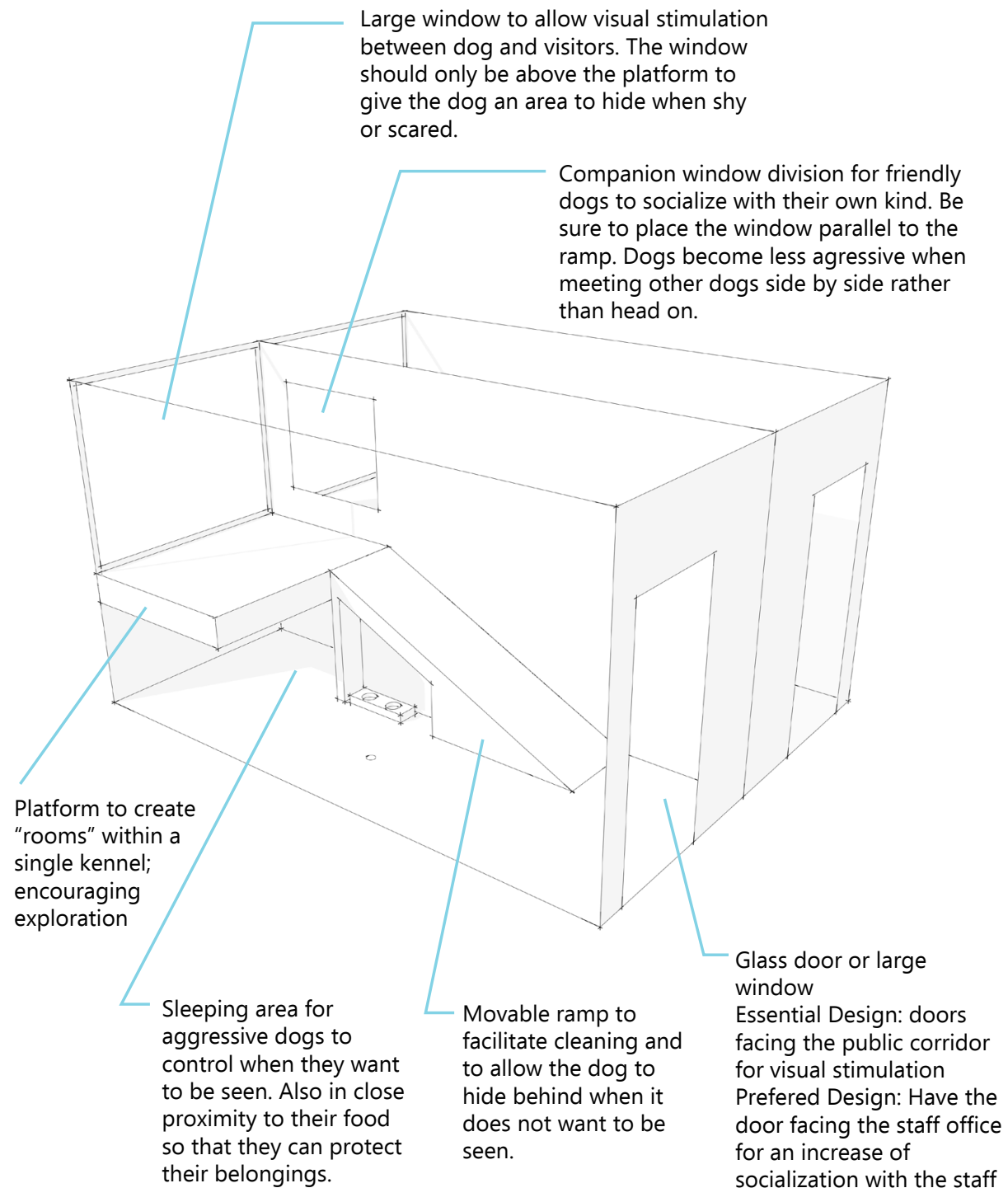


DESIGN ALTERNATIVES

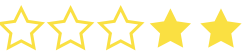

\section{ESSENTIAL SMALL KENNEL (S):}

Non-porous material

Drain in each kennel

Large windows for visitors to see and interact with the dog

Hiding spot with bed for aggressive dogs

Each dog has their own seperate rooms that muffles barks and other unwanted sounds

Platform or a turn in the kennel to allow exploration of spaces through smell

\section{tht tht tht}

IDEAL LARGE KENNEL (L):

Non-porous material

Drain in each kennel

$\square$ Hiding spot with bed for aggressive dogs

$\square$ Each dog has their own seperate rooms that muffles barks and other unwanted sounds

Platform or a turn in the kennel to allow exploration of spaces through smell

$\square$ Dog companion window division

Interactive door and furniture for play between dog and visitors

Windows on both ends of the kennel

Front: towards visitors and social areas for visual stimulation

Back: Towards staff for rebuilding of trust

\section{CAUTION}

It is important to note that although a smaller cage is possible, a small kennel requires more time for the animal to roam outside its cage. This means longer runs at the agility park or longer walks. Spread out the walks and exercises throughtout the day so that the animal is not enclose for more than 6 hours. 


\section{KENNEL DESIGN ALTERNATIVE (S)}

Min. dimensions: $4^{\prime} \times 5^{\prime} \times 4^{\prime}$

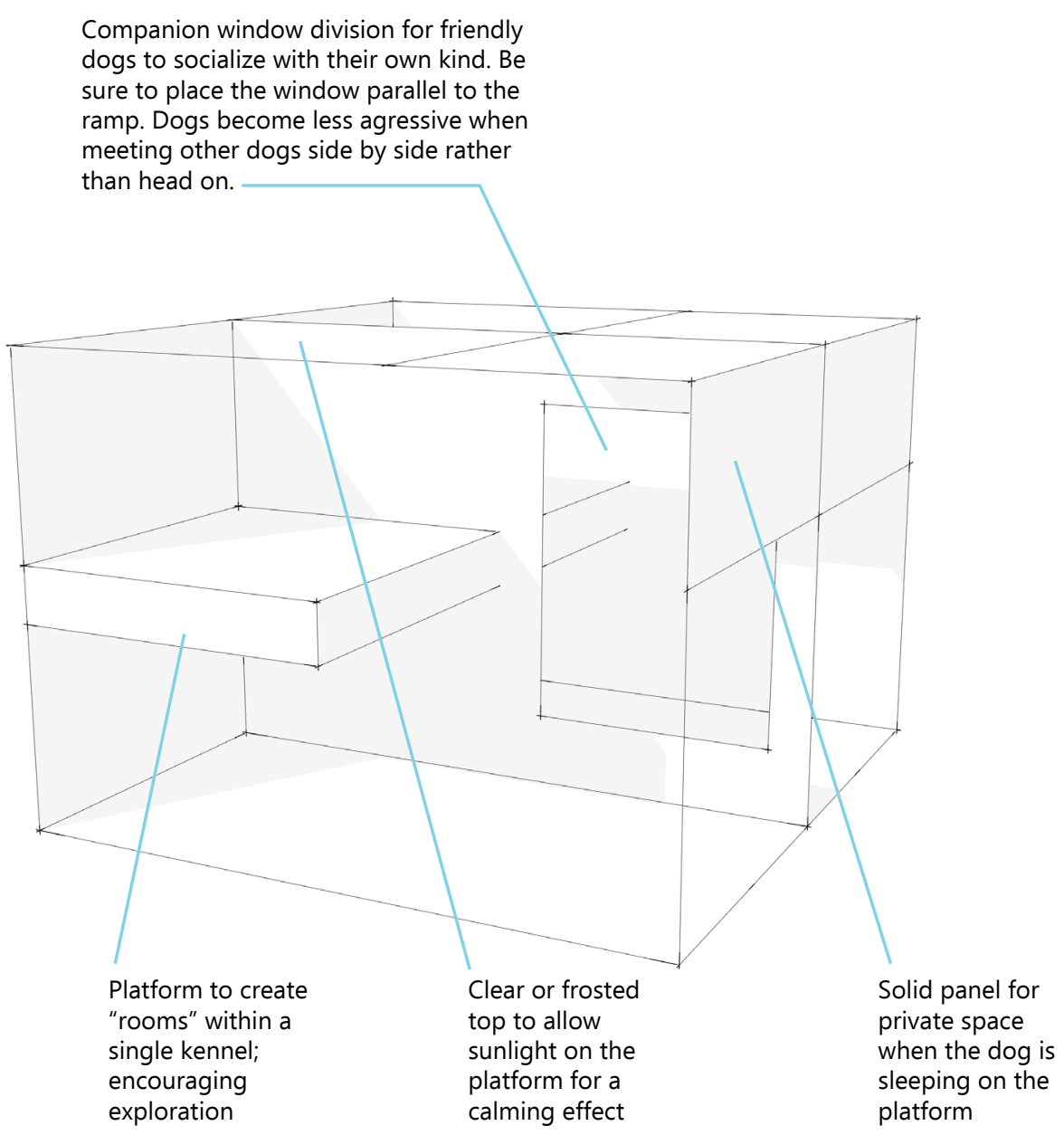




\section{Designer's Guidebook to \\ SHELTER CATS'}

Enrichment

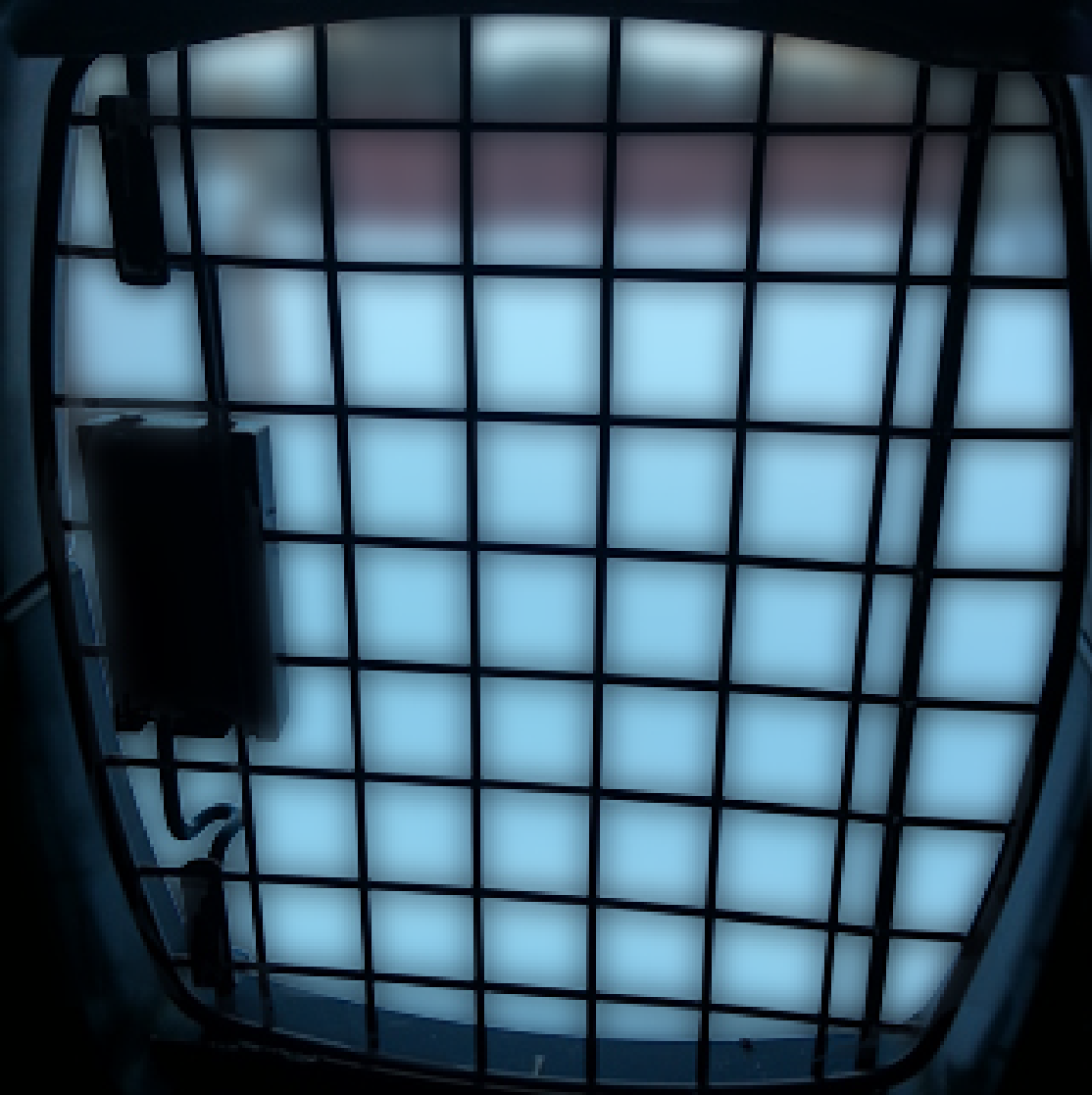

Dorothy Lee 


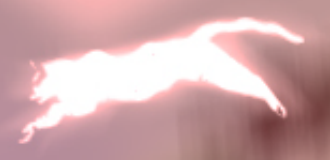

A new environment can look friendly to us but to a cat, the space can be threatening

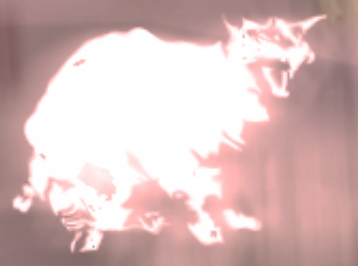




\section{A CAT'S SECURITY IS NOT FOUND IN THE OWNER BUT IN THE ENVIRONMENT}

\section{Reason for fear:}

1. Unaware of where the owner is taking them and having no control of the movement

2. A cat's ability to smell is stronger than those of humans. It is temporal and a cat can smell what has passed by the space as well as what is to come in the future.

Image below depicts the canal through the sense of smell:

White for all objects presently existing in the space,

Yellow for animals that passed by before and,

Pink for future passer-by
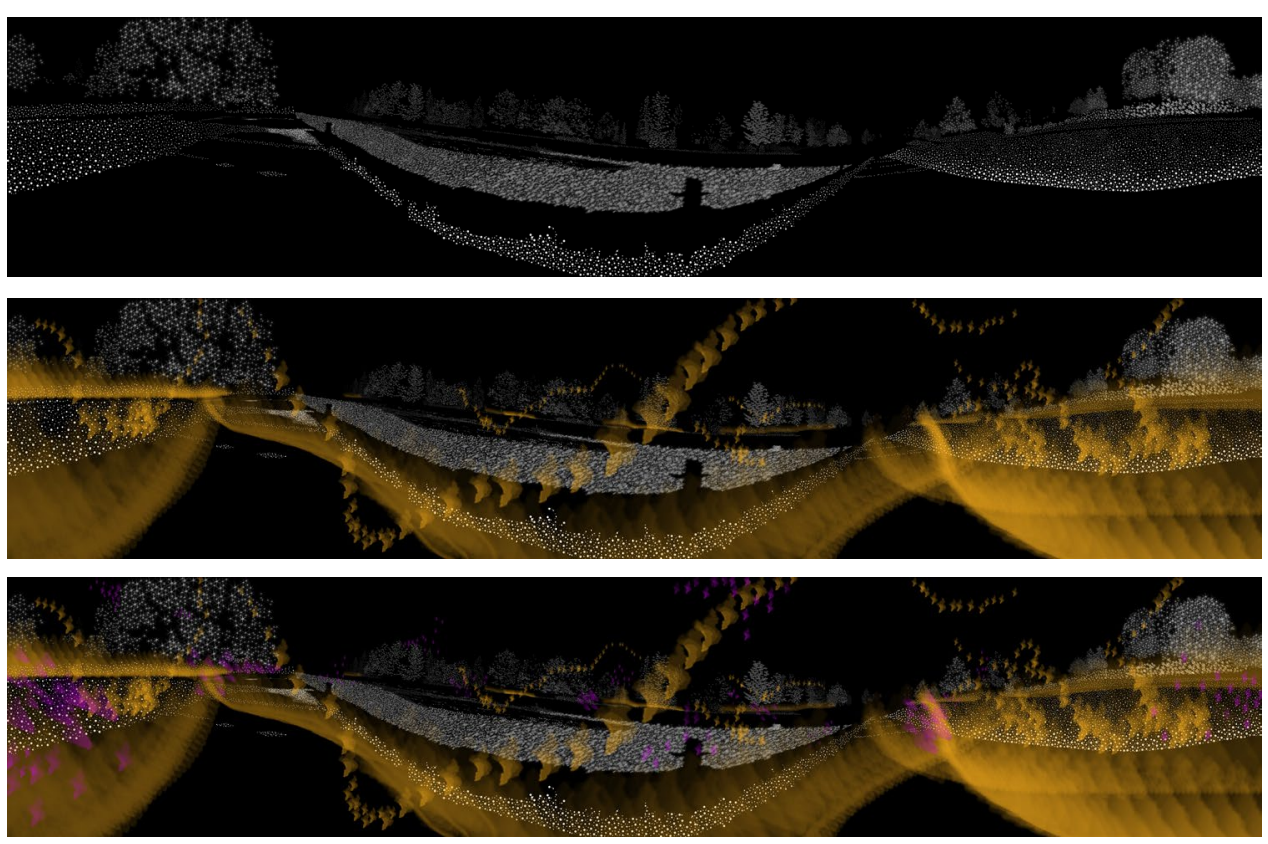

3. New cats means new personalities. Cats can smell the scent left behind by other cats and without knowing their behavior, those cats can be seen as threats.

4. Unaquanted cats tolerate one another and with time, a dominant cat is established. Without that structure, fights can eascalate easily. 
This guidebook is not an end product. It is meant to open discussion and begin the journey of discovering architecture that responds to the mental welfare of animals. With this in sight, the cooperation of the designer to push forward with continual research and experimentation will further aid the animals' well-being.

\section{PLEDGE}

I, pledge to give each cat under my care my best effort into understanding both its physical and mental welfare. I acknowledge that this guidebook is complimentary to the welfare acts and by-laws of my city. In designing the kennels, I will incorporate design attributes for both physical and mental health.

I recognize that each cat is unique in its personality and will continually attempt to understand each cat individually to the best of my abilities. As I learn more about cats through this guidebook, research and through observation, I acknowledge that the rebuilding of a cat's new habitat to ease their fear is of highest priority. 


\section{PERSONAL KENNELS}

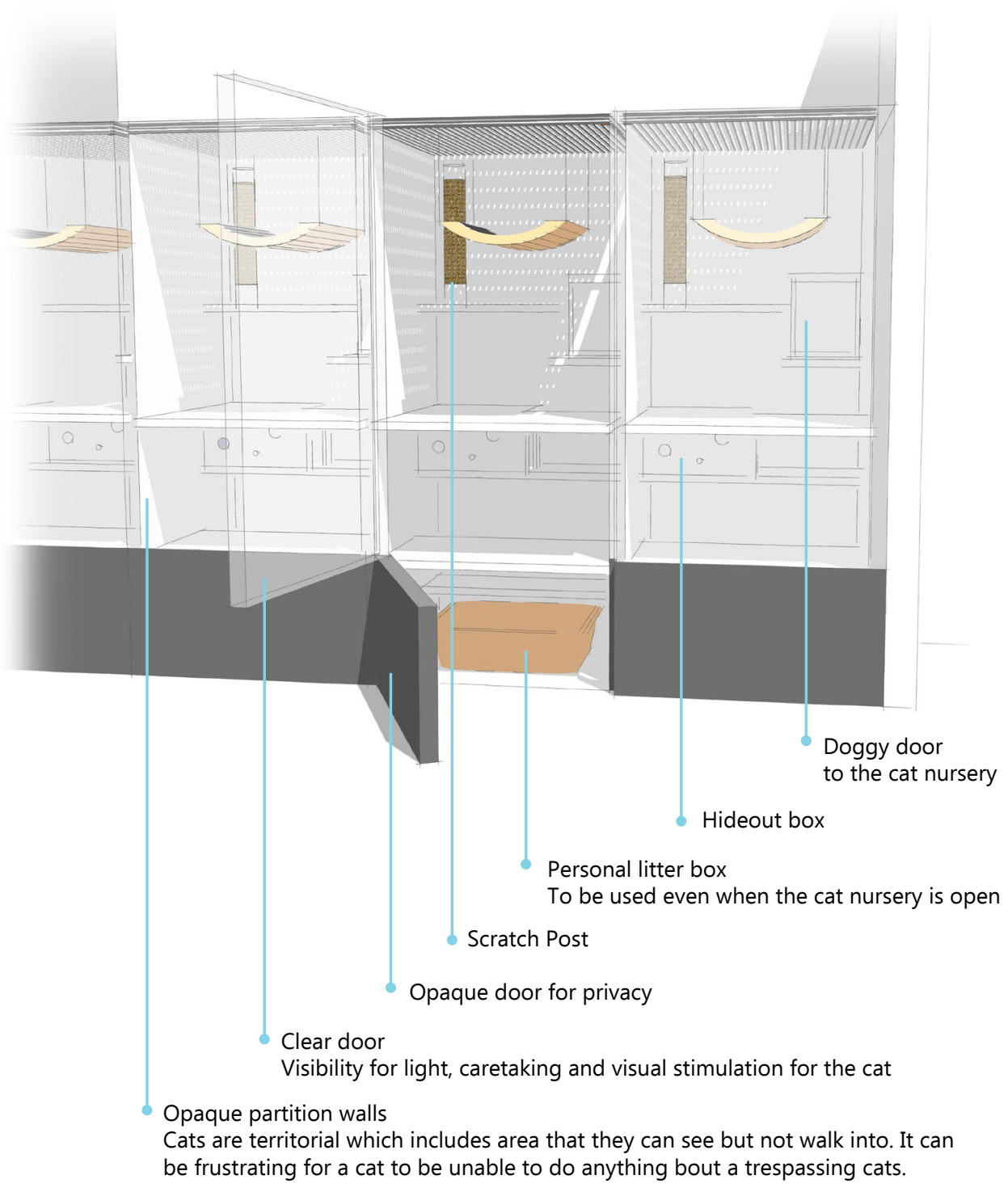




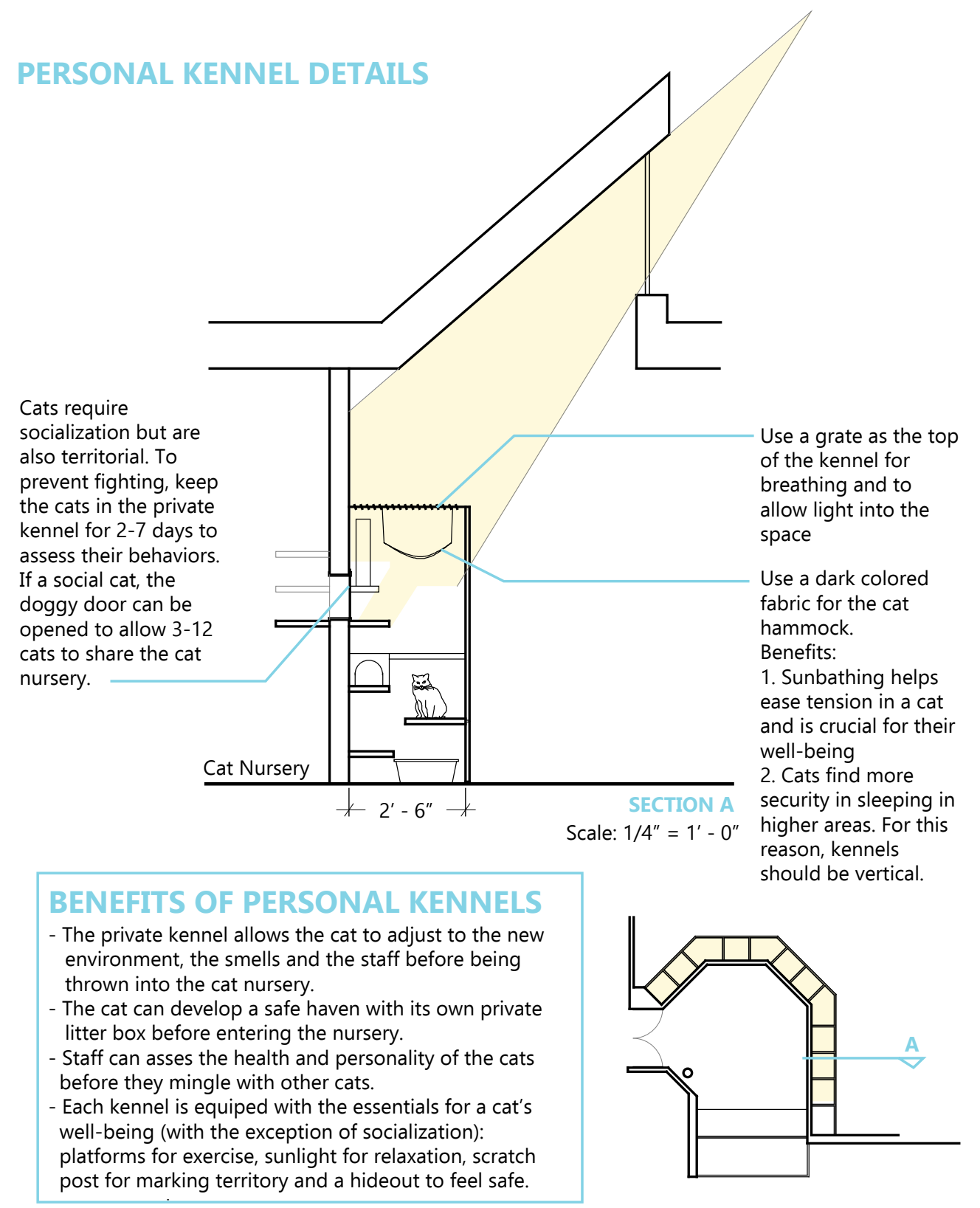




\section{CAT ROOM DESIGN ALTERNATIVE}

Min. dimensions: $2^{\prime}-6^{\prime \prime} \times 2^{\prime}-6^{\prime \prime} \times 6^{\prime}$
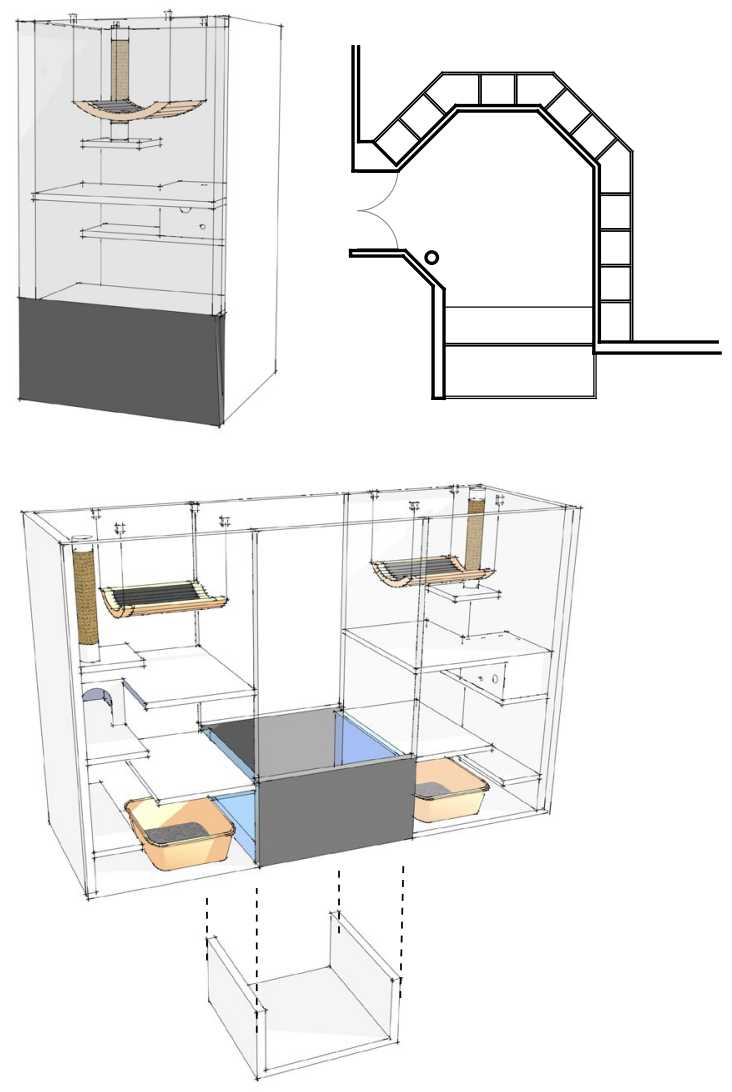

TWO CAGE CONFIGURATION

SIX CAGE CONFIGURATION

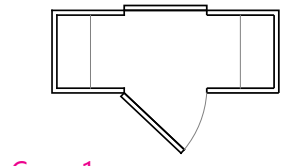

Cage 1

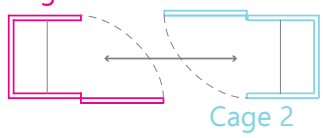

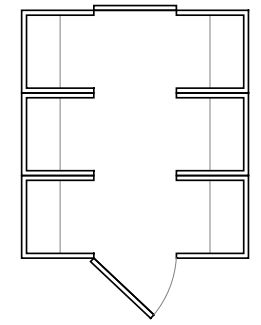

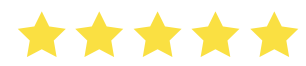

LARGE DESIGN ATERNATIVE:

The personal kennels are desi! run adjacent to a cat nursery $t$ holds up to 12 cats. This allow ample room to exercise, social and a cat-human interaction $r$

Personal Kennel Min. dimen $2^{\prime}-6^{\prime \prime} \times 2^{\prime}-6^{\prime \prime} \times 6^{\prime}$

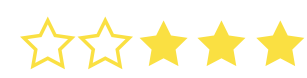

SMALL DESIGN ATERNATIVE: If the existing site cannot accomodate for such a large $r$ the personal kennels can be reconfigured according to hor cats are in need of sheltering I opening the kennel doors. Eac can still have its own litter box hideout box, scratching post a bed. Cage configurations shor hold more than 12 cats.

\section{CAUTION}

It is important to note that although a smaller cage is possible, a small kennel requi more time for the animal to $r$ outside its cage. This means 1 cat requires space to explore outside. It can take in the forı an outdoor exercise pen or $w$ Spread out the walks through the day so that the animal is enclose for more than 6 hour 

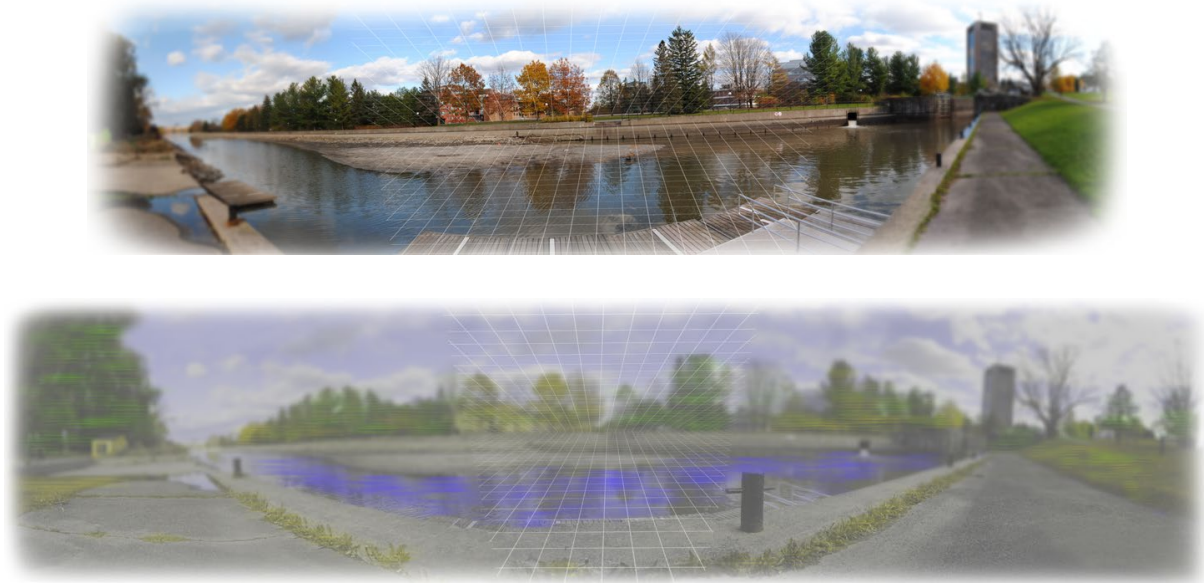

Cat's eyes are set further towards the side of their heads whereas humans eyes are placed at the front of their heads. This allows the dogs to have a larger peripheral vision. However, a cat's depth perception is smaller, at 60 degrees, while humans have depth perception at 140 degrees. Cats are also nearsighted. Human peripheral vision is blurred whereas cat's acuity is constant even in its peripheral. Cats vision's can be unfocused but they have a strong ability to perceive motion. Their vision narrows onto the moving object, which makes them the perfect predator.

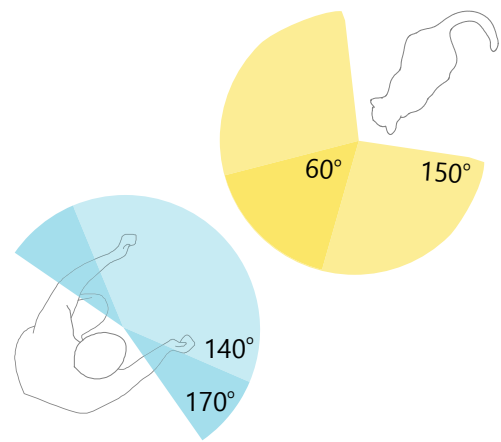




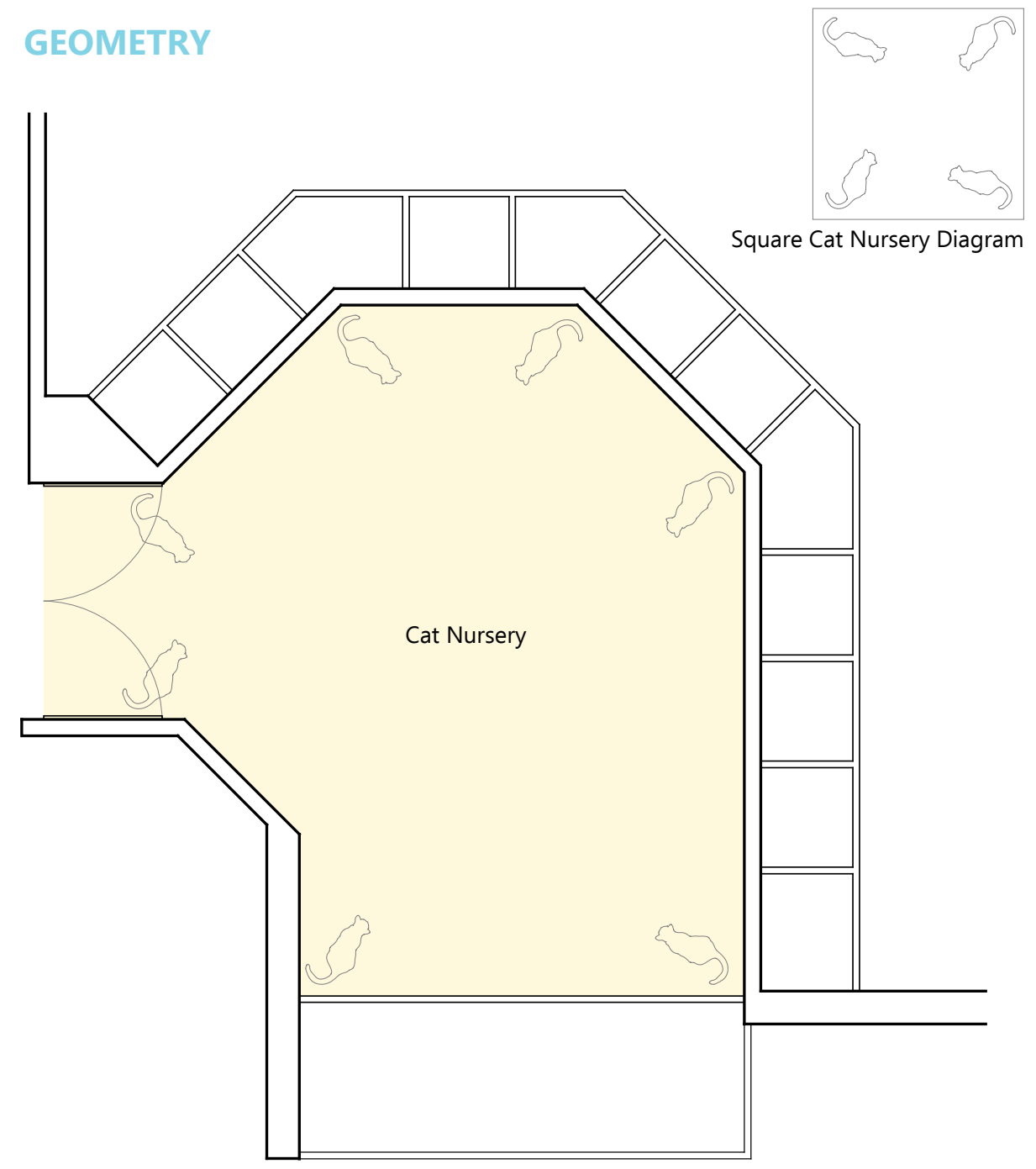

Upon entering a foreign room, the cat must explore the room to understand if there lies any threats. Cats tend to hide in a corner to start as it is the safest area of the room versus the center. Unable to rely on their vision for far distance, cats need to explore the space through scent or approaching the area. The shape of the cat nursery is designed to create more corners for cats to hide in when first entering the space. A square would not be enough hiding spots for a cat nursery that houses up to 12 cats. 


\section{BENEFITS OF A CAT NURSERY}

- Cats have kept their natural instincts and have not been completely domesticated. For this reason, they do not rely on people as much as dogs. Cats without human interaction can be just as healthy as those who do interact with people.

- Cats learn better by observing other cats and immitating them. Unwanted behaviors can be removed with cat-to-cat socialization.

- A cat nursery allows multiple cats to play with one another. Play is more than emotional stability or sensory stimulation. Play allows the cat to exercise and is crucial for their physical health. Forms of play can be practice hunting, chasing, stalking and pouncing.

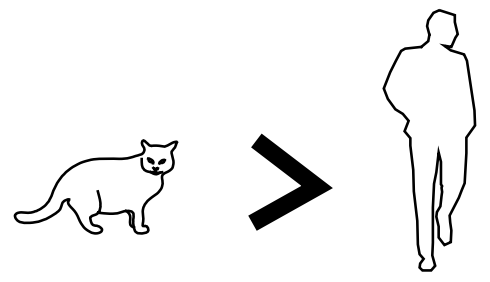

\section{FOUR ESSENTIAL BEHAVIOURS FOR WELL-BEING}
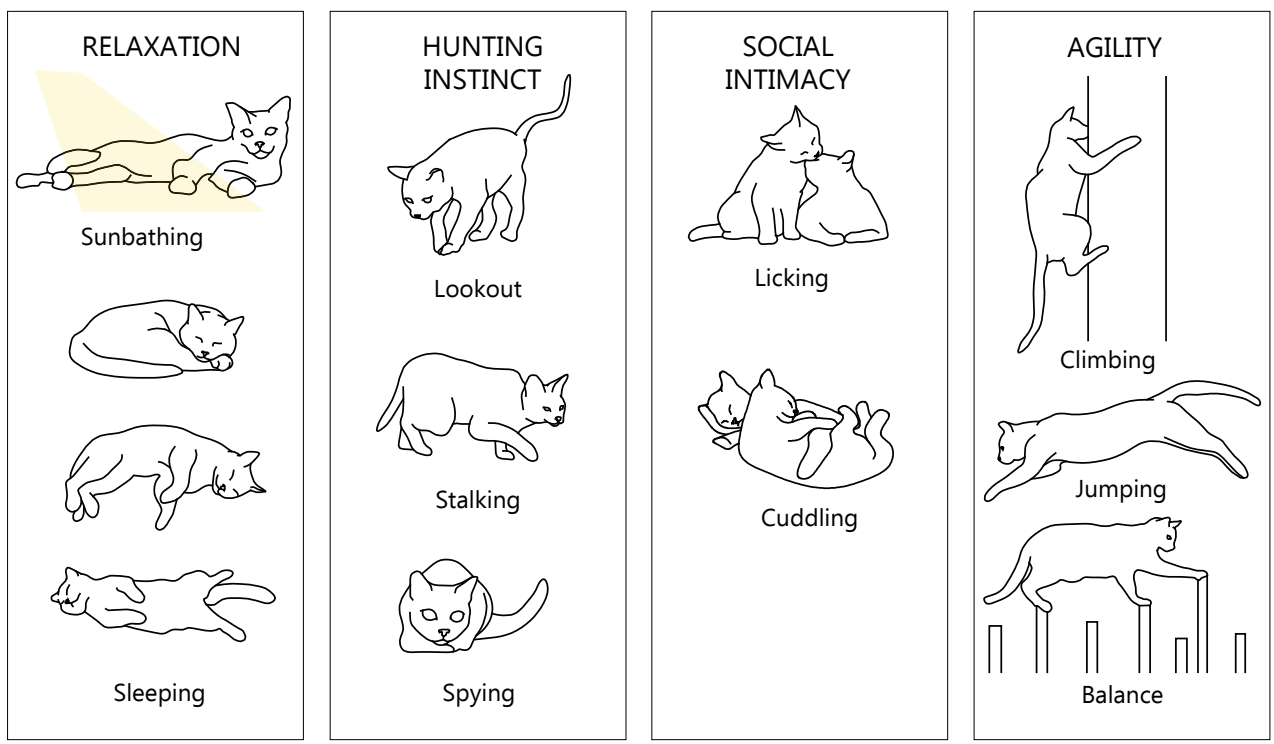


\section{DESIGN FOR HUNTING INSTINCTS AND AGILITY}

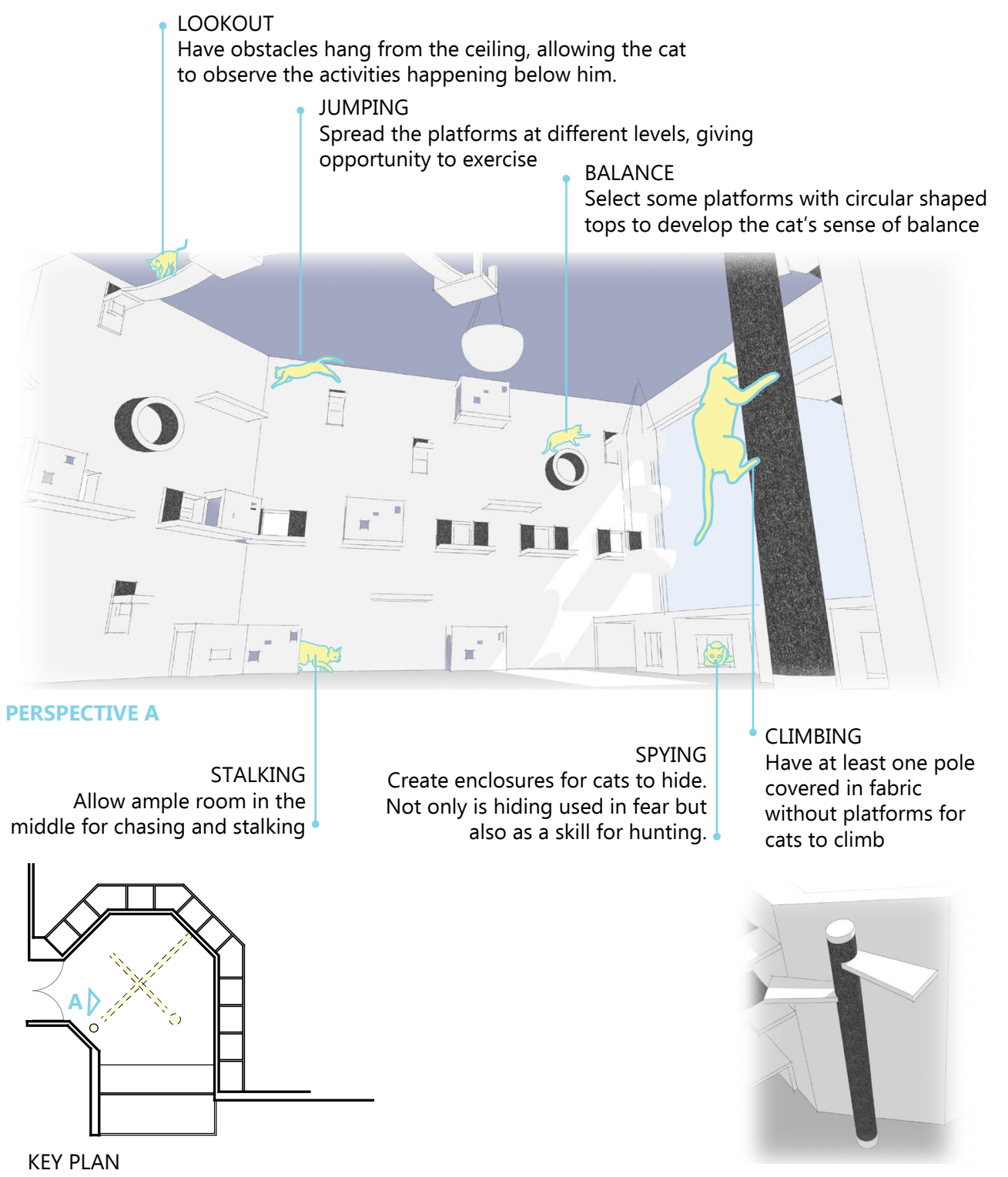




\section{DESIGN FOR RELAXATION AND SOIAL INTIMACY}

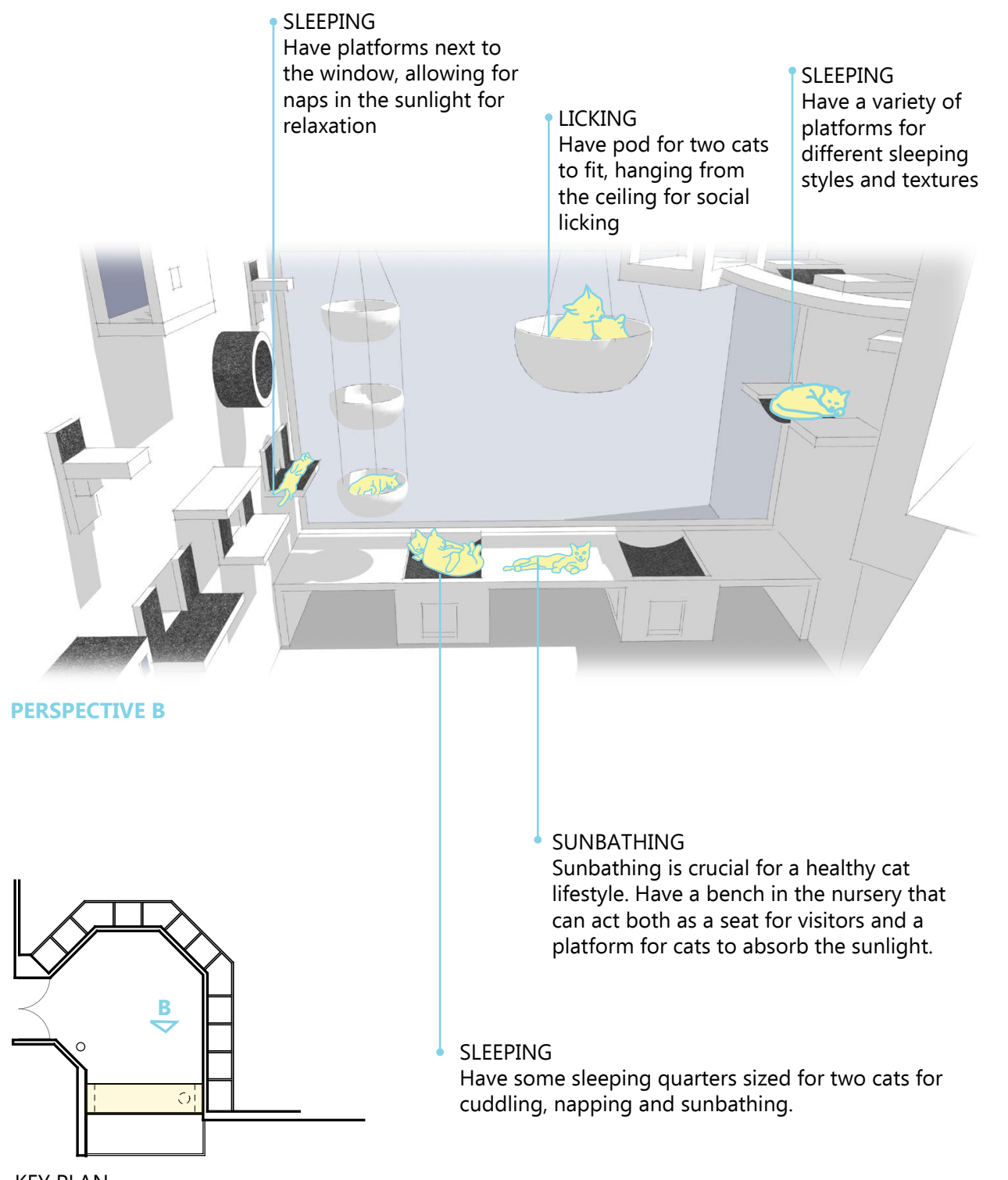




\section{BENEFITS OF BEHAVIOUR BASED OBSTACLE COURSE DESIGN}

- Cats require socialization for a healthy mental state and exercise for physical health. The nursery equipped with obstacle courses allows for cats to play which combines socialization and exercise.

- Behaviour based designes allows cats to more easy act out their natural instincts. Animals tend to development abnormal behaviours when their expression is limited.

For example, a gerbil that doesnt live underground would develop a digging dissorder in which it'll dig for hours to no gain. Giving the gerbil an underground home would alleviate the need to dig.

$\begin{array}{cccc}\text { FREEDOM OF EXPRESSION } & \text { PHYSICAL } & \text { DECREASE IN } & \text { HEALTHY } \\ \text { OF NATURAL BEHAVIOR } & \text { EXERCISE } & \text { ANXIETY } & \text { MENTAL AND } \\ & & & \text { PHYSICAL STATES }\end{array}$

\section{SCENTS SENSORS}

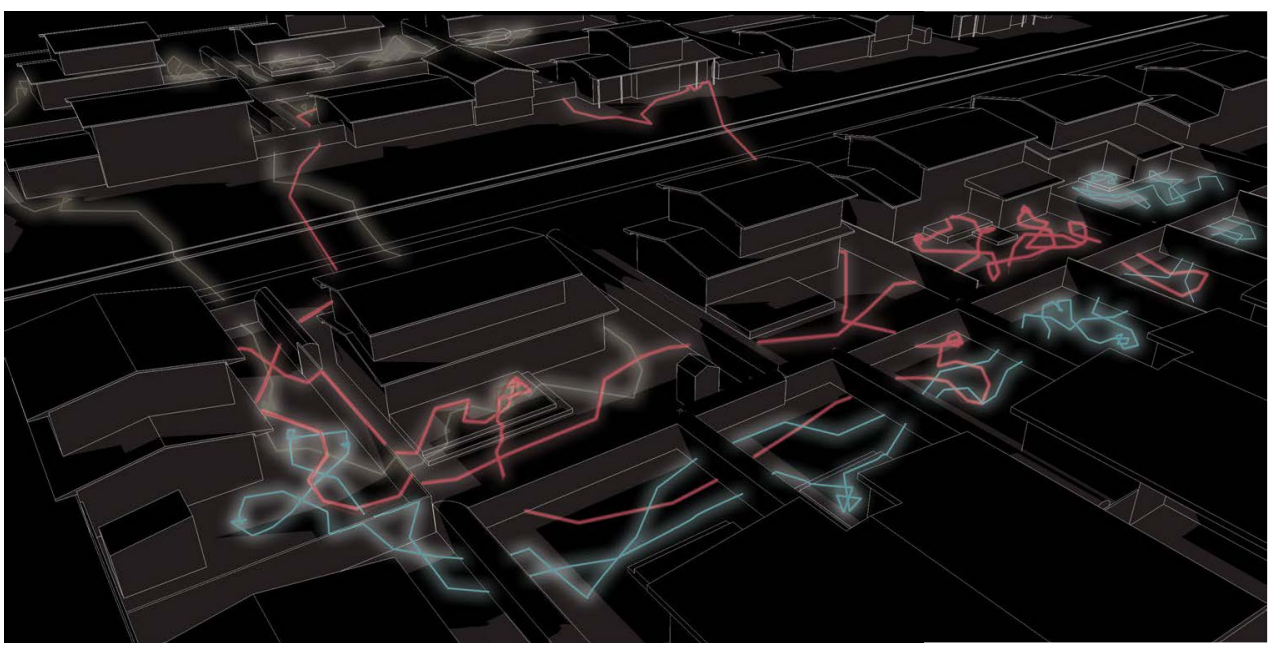

Cats are wanderers and with the presence of multiple cats in a community, cats would rub their scent on objects to communicate between them. These scents are not possible for humans to smell. In addition, each scent deposit is different to communicate different ideas. Reasons for markings:
1. Marking territory.
2. Looking for a mate
3. Showing respect
4. Showing intimacy or care
5. Selt soothe
6. Announcing its presence, etc.

Scratching is another way of communcation. 


\section{SCRATCH PAD OPTION 1}

Cats scratch to file their nails down and to mark their territory as a communication tool with other cats. Utilizing cardboard strips compacted into a frame is an economical design to achieve a

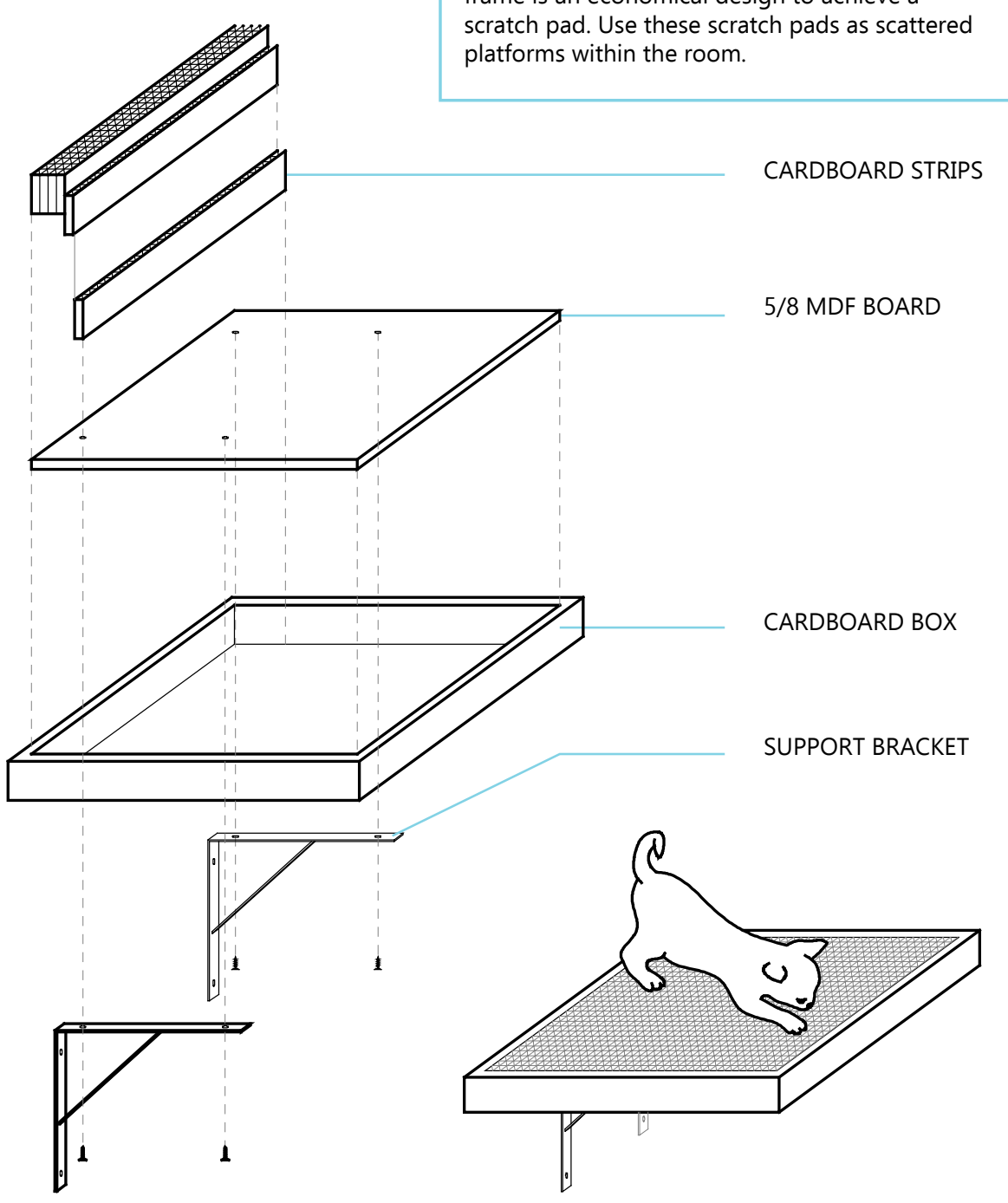




\section{SCRATCH PAD OPTION 2}

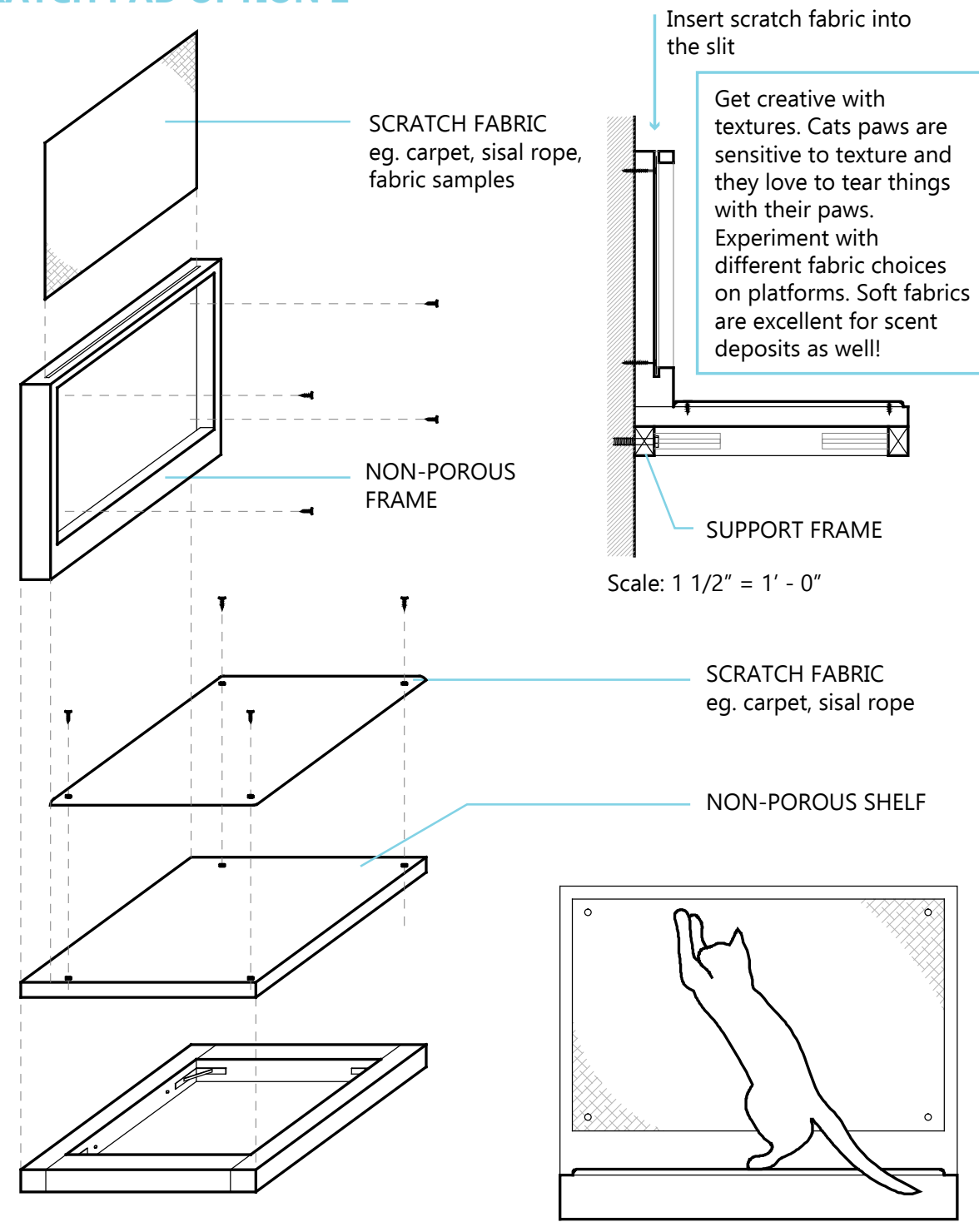




\section{VISUALIZING SCENT DEPOSITS}

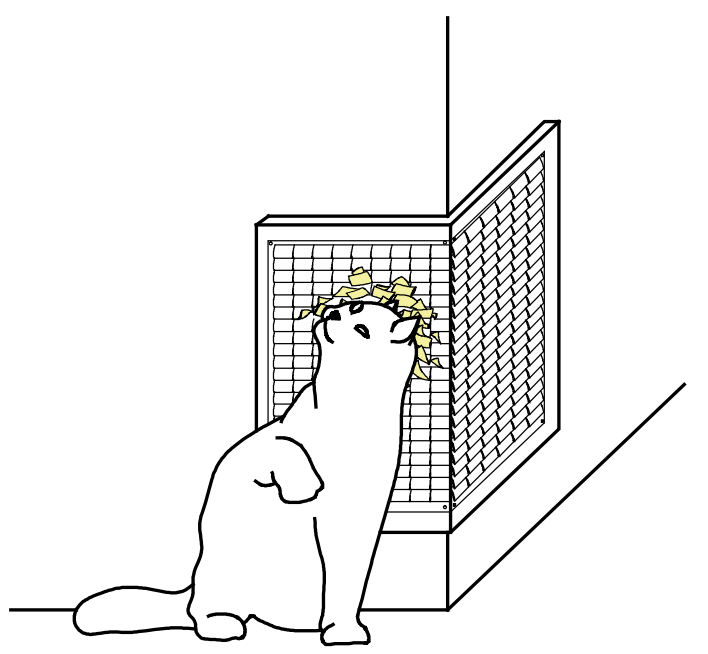

Cats communicate by depositing scent and without their

Jacobson's organ, we are unable to smell these deposits. Using dual colored felt panels can help staff members to virtually see these scent deposits visually. As the panels flip, the felt fabrics will stick together and reveal the color underneath.

Possible locations cats would deposit their scents:

- Corner of furniture

- Entry to their private kennel

- Sleeping areas

- Highest platform

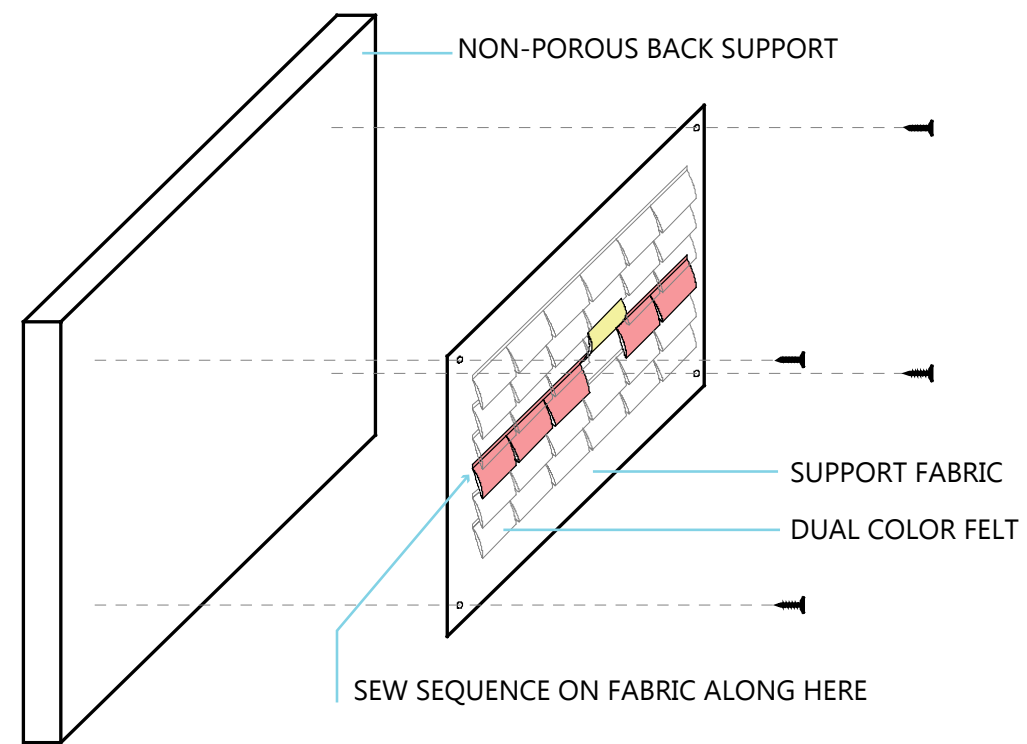




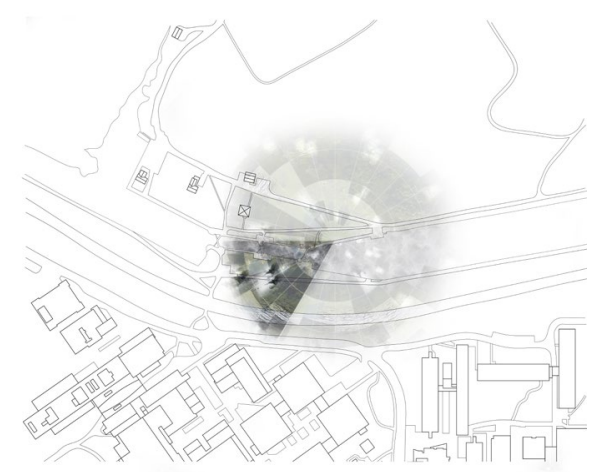

RANGE OF HEARING FOR CATS

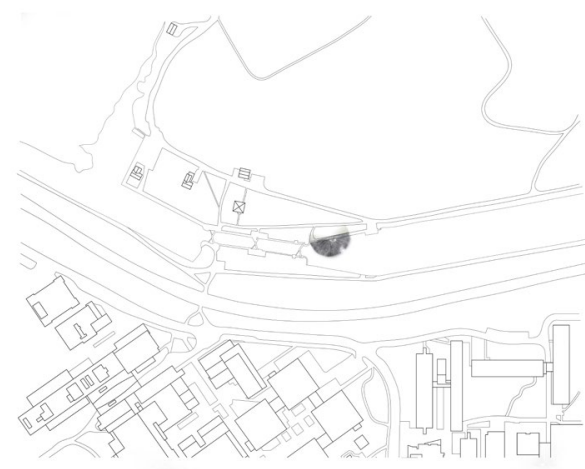

RANGE OF HEARING FOR HUMANS

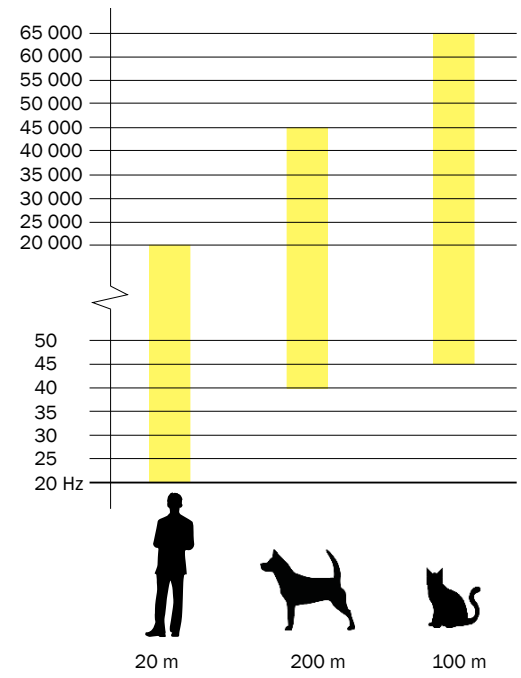

Cats can hear $5 x$ farther than a human and $45000 \mathrm{~Hz}$ higher. For this reason, their hearing is much more sensitive and more easily annoyed.

Unlike humans who are more sensitive to sounds facing in front of them, cats can adjust their ears to pin point and locate different sounds from all 360 degrees of their heads.

It is ideal to keep the cat nurseries and kennels farthest from the traffic of the street and the mechanical units. 


\section{COMPLIMENTARY CAT PROGRAMS}

A CAT CAFE

Cats who lived without other cats often get stressed in a nursery. However, they still need socialization. Pairing up a human-cat interactive space allows visitors to grow fond of potential cats to adopt as well as provide for that socialization lacking in the cat kennels

B LOBBY AND SMALL ADMINISTRATION

C CAT NURSERY

Cats strive by socializing with other cats. Provide a cat nursery for a small colony of 3-12 cats. This space can also have a dual purpose for human-cat interactive class. Example: Cat training class, cat yoga, etc

D EXTERIOR NURSERY

Have a doggy door under the bench to allow cats to lounge outside during certain hours of the day.

E PRIVATE ROOM

Private room for potential owners to meet cats one on one. Also an opportunity to provide services such as nail trimming.

F VOLUNTEER ROOMS

Direct access for volunteers to clean litter boxes from each kennel.

G SICK CATS ROOM

Have enough space for quick consultation and exercise area for sick cats.

H SURGICAL ROOMS

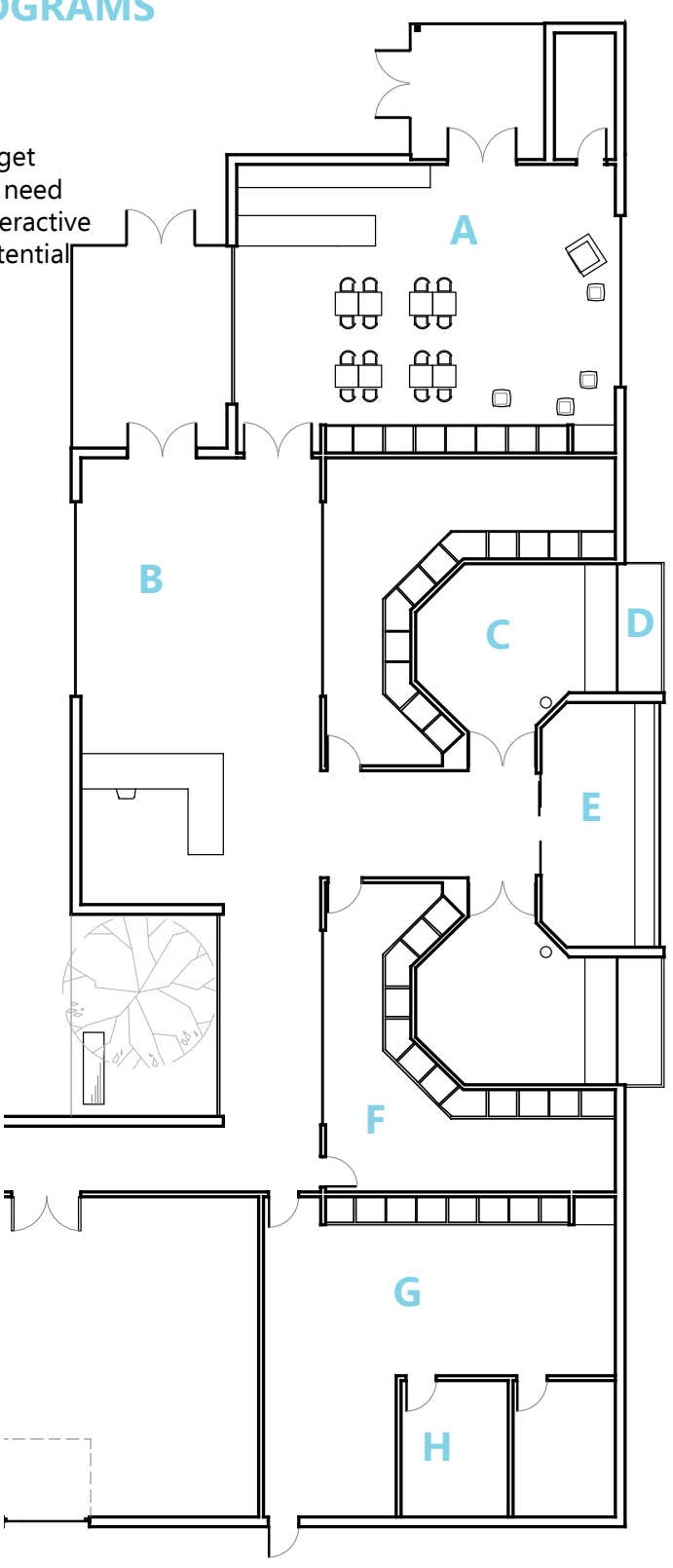




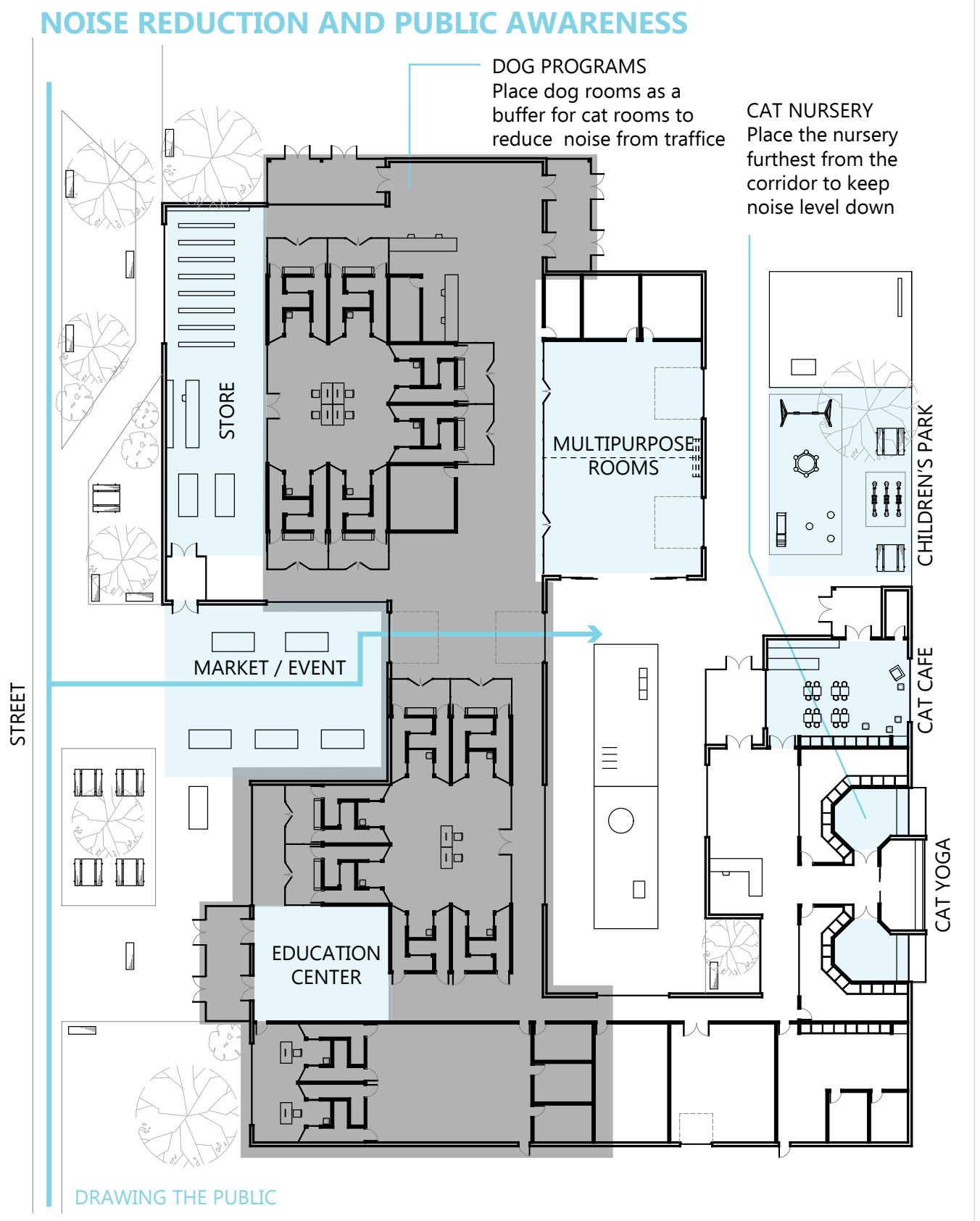




\section{PUBLIC AWARENESS}

Cats require socialization and with the staff occupied with running the facility, this need is often left unfulfilled. By combining the facility with public programs, cats are able to socialize with visitors and simulateneously the public becomes aware of the facility's needs. In addition to the human-cat rooms, additional programs will draw public into the facility and allow them to linger.

MARKET + STORE

Shopping center are excellent ways of drawing the public to the facility. It is also a good opportunity to educate owners of appropriate toys, equipements and food for their pets.

\section{CHILDREN'S PARK}

A park allows parents to bring their children and linger around the facility. Often the facility is used only when families want to adopt but by creating a park, families that cannot afford to buy a pet can also aid in socializing with the animals.

\section{EDUCATION CENTER}

Allowing for school field trips and other educational events

\section{MULTIPURPOSE ROOM}

Look around the site. Often pairing the facility with another complementary program is both beneficial to the animals and people. Optional programs can be:

1. Nail trimming services

2. Indoor agility park for shelter animals and for cat training for existing owners 3. Birthday party / event venue

Looking around the facility's site can give ideas to programs that are complimentary. Benefits can be reaped not only for the animals but for people as well, such as fighting loneliness for elderly and de-stressing among students. Here are some ideas:

1. Schools:

2. Elderly Homes:

3. Public Parks:

4. Disabilities School:

5. Veterinary Clinic:

6. Restaurant landscape:

7. Homeless with Pets:
Café, therapy, de-stressing event during exams, volunteering, animal yoga, education center

Café, reading to the animals

Dog park, education center, fundraiser, café, animal care services, obedience class, cat training

Therapy, education center, reading to the animals

Education center, animal services, bring your own dog café, dog park, obedience class

Café + Desserts, dog park

Homeless Shelter, Soup kitchen for people and pets 


\section{Conclusion}

The thesis began with a concern for the sheltered animals' mental welfare. The design for the physical and medical welfare in each kennel is critical and predominant as seen in the precedents. However, the thesis aims to incorporate designs details that can help remove some of the mental diseases that plague these animals and simultaneously compliment the existing designs for physical welfare.

To begin design, a study on the emotional state of the animal and an understanding of an animal's experience of space is imparative. Each animal that enters the space is under anxiety due to their loss of their sense of security such as their owner or their habitat. The priority in design then became comfort, novelty and mental stimulation to help alleviate negative emotions and replace it with the seeking emotion. Meanwhile, the exploration of the animal's senses aided in understanding what forms of space is required for each type of animal and its location within the complex.

The final product of the thesis became two guidebooks: one for cats and one for dogs (Figure 38). Each book not only introduces the reader with example details to incorporate in their design but also educates the reader on the animal - symbolically and literally. The three details explored in the dog guidebook is the dog's sleeping quarters (Figure 39), a companion dog wall division and a dog-human interaction bench. Since the dog finds his security in their owners, the details focuses on re-establishing trust and socialization. The cat, on the other hand, finds its security in its habitat and therefore the details explored in the cat guidebook is the gradual growth of the cat's rooms: from a personal kennel to a cat nursery. An often neglected aspect of cats in design is their ability to communicate through smell. The details aim to allow cats to use porous materials to deposit scents and be removeal for sanitizing. 
Despite centuries of living with these domestic pets, our understanding of these animals is just beginning. For example, cats communication through scent is difficult to understand when humans do not possess the organ to process those scents. In the hopes of continual studies of domestic animals, the cat guidebook introduces a furniture detail to visual the cat's scent through the change of fabric color (Figure 40). The guidebooks are in no way the complete guide to designing for animals but an introductory step in a positive direction. Just as there are millions of characteristics and personalities in humans, animals too have multiple personalities for us to understand and explore.

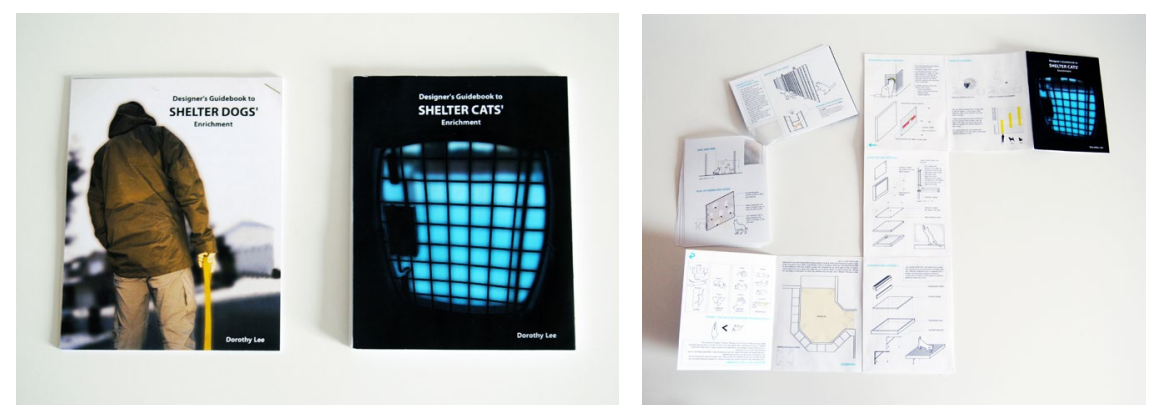

Figure 38: Photos of the dog and cat guidebooks

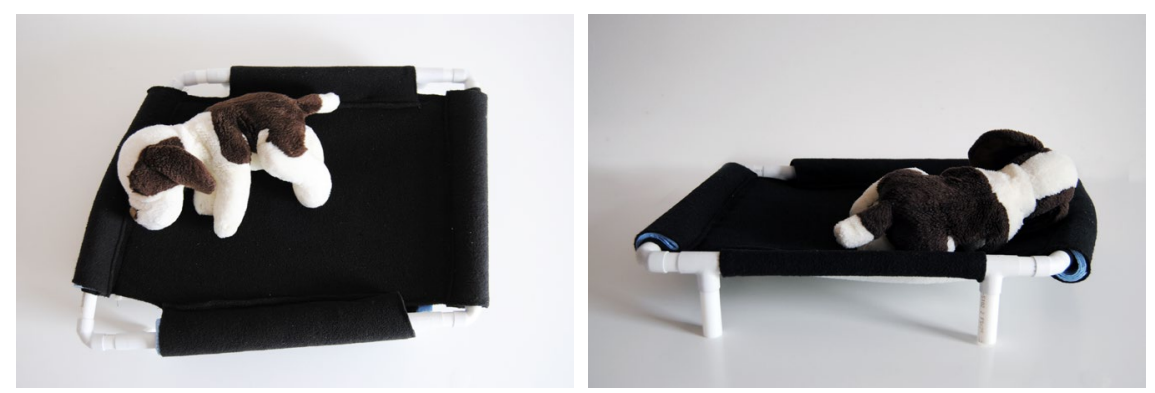

Figure 39: Photos of the dog bed design from the "Designer's Guidebooks for Shelter Dogs' Enrichment."
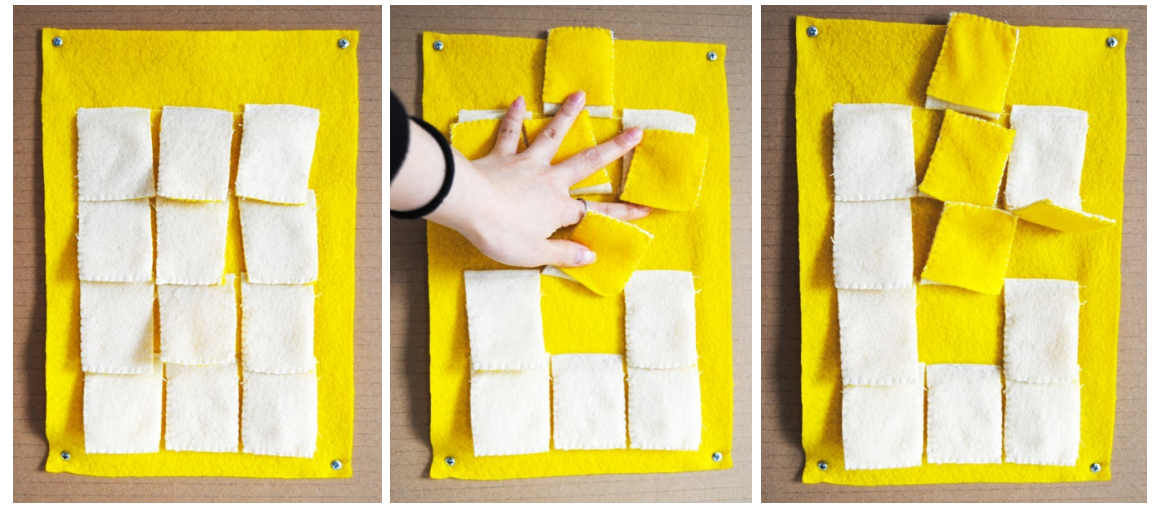

Figure 40: Photos of the cat rubbing furniture detail from the "Designer's Guidebooks for Shelter Cats' Enrichment." 


\section{Bibliography}

"2013 Canadian Animal Protection Laws Rankings." Animal Legal Defense Fund, 28 July 2013. http://aldf.org/press-room/press-releases/201-canadiananimal-protection-laws-rankings. Accessed 16 Oct. 2017.

Andrews, Kristin. The Animal Mind: An Introduction to the Philosophy of Animal Cognition. Routledge, 2015.

B-3.1 - Animal Welfare and Safety Act. Publications Québec.Éditeur officiel du Québec, 1 June 2017.

"Cat Watch 2014: The New Horizon Experiment." BBC TWO, 14 Oct. 2014. http:// www.bbc.co.uk programmes/b04lbyp8. Accessed 7 Dec. 2017.

Chandler, Cynthia K., et al. "Matching Animal-Assisted Therapy Techniques and Intentions with Counseling Guiding Theories." Journal of Mental Health Counseling, vol. 32, no. 4, Oct. 2010, pp. 354-374.

"De-stress with puppies at the Schulich and HSSL Libraries!" McGill Library. 2015. https://www.mcgill.ca/library/channels/event/de-stress-puppies-schulich-andhssl-libraries-256890. Accessed 23 March 2018.

"Dog Vision: What Colors Can Dogs See and Can They See in the Dark?" Improve Eyesight HQ. 2012. http://www.improveeyesighthq.com/dog-vision.html. Accessed 31 Dec. 2017.

Divorsky, George. "Prominent Scientists sign declaration that animals have conscious awareness, just like us." Gizmodo, 23 Aug. 2012. https://io9.gizmodo. com/5937356/prominent-scientists-sign-declaration-that-animals-haveconscious-awareness-just-like-us. Accessed 19 Oct. 2017.

"ESP Therapy Dog." Carleton.ca. https://carleton.ca/health/therapydog. Accessed 23 March 2018.

Flagg, Gaye. "About Hearing Cats." The Cat Site, 1 Nov. 2011. https://thecatsite. com/ams/about-hearing-in-cats.22409. Accessed 1 Jan. 2018.

Flynn, Clifton P. Social Creatures: A Human and Animal Studies Reader. Lantern Books, 2008.

Fraser, Andrew F. Feline Behaviour and Welfare. CABI, 2012.

Fraser, Marie-Ève. "A Devastating Combination for Pet Abandonment: Moving Season Coupled with Breed Specific Legislation." Society for the Prevention of Cruelty to Animals, 28 June 2017. https://www.spca.com/?p=14471\&lang =en. Accessed 16 Oct. 2017.

Gilbert, Ben. "Dogs see the world very differently from human beings - here's how it works." Business Insider, 19 Apr. 2017. http://www.businessinsider.com/ how-dogs-see-the-world-through-scent-2017-4/\#its-really-hard-to-getoutside-our-perspective-1. Accessed 4 Nov. 2017. 
Grandin, Temple, and Catherine Johnson. Animals Make Us Human: Creating the Best Life for Animals. First Mariner Books, 2010.

Horowitz, Alexandra. "How do dogs "see" with their noses?" TEDEd. https://ed.ted. com/lessons/how-do-dogs-see-with-theirnoses-alexandra-horowitz.

Accessed 4 Nov. 2017

“How Does a Dog... Hear?" YouTube, unloaded by EukanubaEurope, 5 Apr. 2014. https://www.youtube.com/watch?v=uRUu2ba8CaA. Accessed 7 Dec. 2017.

P-42, r 10.1 - Regulation Respecting the Safety and Welfare of Cats and Dogs. Publications Québec. Éditeur officiel du Québec, 1 Aug. 2017.

Rohdin, Linda. "Some MUST READ Statistics on Canada's Pet Overpopulation Problem." The Toronto Pet Daily, 11 Feb. 2016. http://www.torontopetdaily. com/2014/05/some-must-read-statistics-on-canadas.html. Accessed 16 Oct. 2017.

Spector, Dina. "How Cats See The World Compared To Humans." Business Insider, 16 Oct. 2013. http://www.businessinsider.com/pictures-of-how-cats-seethe-world-2013-10. Accessed 4 Nov. 2017.

Stafford, Kevin. The Welfare of Dogs. Springer, 2007. "The Montreal SPCA's Investigations and Inspections Department." Society for the Prevention of Cruelty to Animals, 2014. https://www.spca.com/?page_id=595\&lang=en. Accessed 17 Oct. 2017.

"The Montreal SPCA's Investigations and Inspections Department." Society for the Prevention of Cruelty to Animals, 2014. https://www.spca.com/?page_ id=595\&lang=en. Accessed 17 Oct. 2017.

“What Do Dogs and Cats See?" Veterinary Vision, Inc. http://veterinaryvision.com/ resources/what-do-dogs-and-cats-see. Accessed 4 Nov. 2017.

Wise, Steven M. "Thats One Small Step for a Judge, One Giant Leap for the Nonhuman Rights Project." Nonhuman Rights Project Blog, 4 Aug. 2015. https://www.nonhumanrights.org/blog/thats-one-small-step-for-a-judge -one-giant-leap-for-the-nonhuman-rights-project. Accessed 5 Jan 2018. 


\section{Lexicon}

Animal

Domestic dogs and cats that are the focus of this thesis

Animal Shelter

Privately owned charity that organizes and cares for abandonned or rescued domestic animals

Cat Nursery

Room designed for 4-12 cats to use simultaneously

Consciousness

Ability to experience and reflect the quality of life similar to humans

Creature

Including all animals in the animal kingdom in general including human beings

Human

Human beings or homo sapiens

Mental Welfare

Phychological welfare including depression, loneliness, and stress.

Physical Welfare Health welfare including sickness, pain and injury

Rescued Animal An animal that is abandoned to fend for themself or an animal that is confiscated from an owner due to animal abuse

Well-being

Includes both mental and physical welfare 